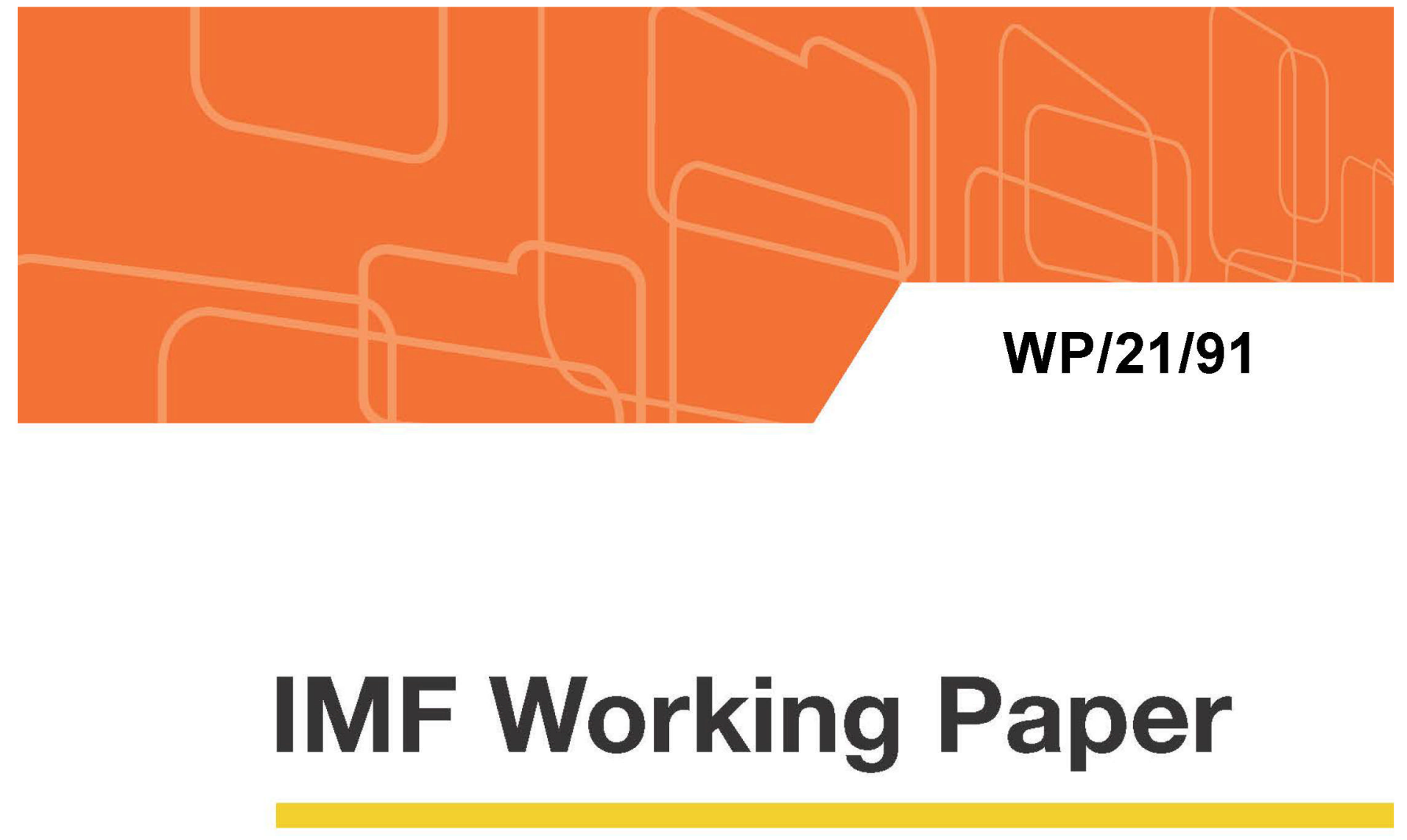

\title{
Search Externalities in Firm-to-Firm Trade
}

by John Spray

IMF Working Papers describe research in progress by the author(s) and are published to elicit comments and to encourage debate. The views expressed in IMF Working Papers are those of the author(s) and do not necessarily represent the views of the IMF, its Executive Board, or IMF management. 


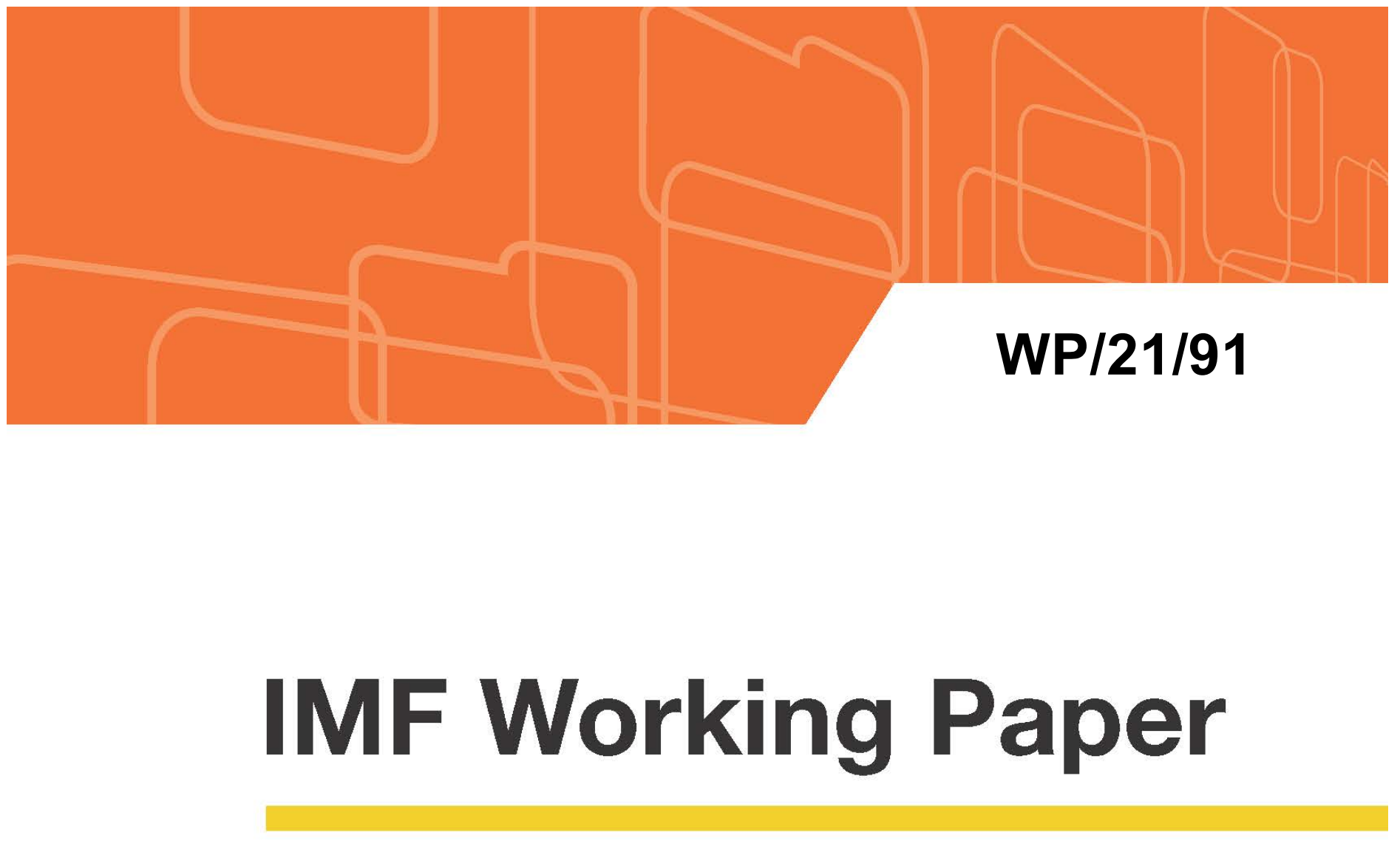

\section{Search Externalities in Firm-to-Firm Trade}

by John Spray

IMF Working Papers describe research in progress by the author(s) and are published to elicit comments and to encourage debate. The views expressed in IMF Working Papers are those of the author(s) and do not necessarily represent the views of the IMF, its Executive Board, or IMF management.

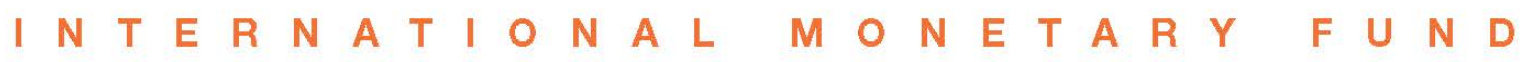




\title{
IMF Working Paper
}

Research Department

Search Externalities in Firm-to-Firm Trade *

Prepared by John Spray

Authorized for distribution by Chris Papageorgiou

March 2021

\begin{abstract}
IMF Working Papers describe research in progress by the author(s) and are published to elicit comments and to encourage debate. The views expressed in IMF Working Papers are those of the author(s) and do not necessarily represent the views of the IMF, its Executive Board, or IMF management.
\end{abstract}

\begin{abstract}
I develop a model of firm-to-firm search and matching to show that the impact of falling trade costs on firm sourcing decisions and consumer welfare depends on the relative size of search externalities in domestic and international markets. These externalities can be positive if firms share information about po-tential matches, or negative if the market is congested. Using unique firm-to-firm transaction-level data from Uganda, I document empirical evidence consistent with positive externalities in international markets and negative externalities in domestic markets. I then build a dynamic quantitative version fo the model and show that, in Uganda, a $25 \%$ reduction in trade costs led to a $3.7 \%$ increase in consumer welfare, $12 \%$ of which was due to search externalities.
\end{abstract}

JEL Classification Numbers: F14, F15, O19

Keywords: Firm-to-Firm Trade, VAT Data, Search-and-Matching, Importing

Author's E-Mail Address: jspray@imf.org

\footnotetext{
* I would like to express my gratitude to Vasco Carvalho, Meredith Crowley, Dave Donaldson, Matt Elliott and Pramila Krishnan for advice throughout th is project. I would also like to thank Andrew Bernard, Jing Cai, Simon Quinn, Gabriella Santangelo, and Daniel Xu for helpful advice. Finally thanks to Jakob Berndt, Zeina Ha sna, Richard Newfarmer, Gustavo Nicolas Paez, Ja kob Rauschendorfer, Ritwika Sen, Lida Smitkova, Dan Wa les, Alan Walsh for many helpful conversations. Financial support from the European Research Council under the grant EMBED \#757229 is gra tefully a cknowledged. Finally, I would like to thank the Uganda Revenue Authority who made this research possible.
} 


\section{Contents}

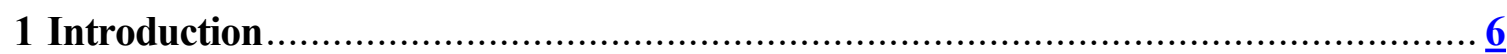

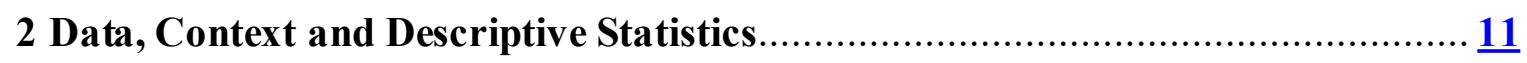

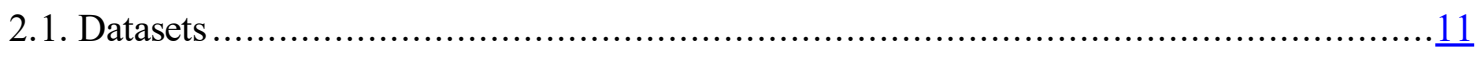

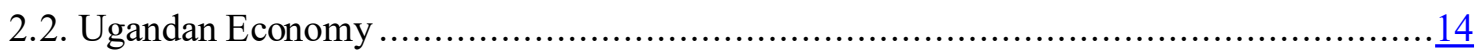

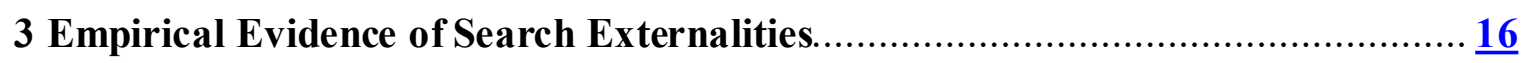

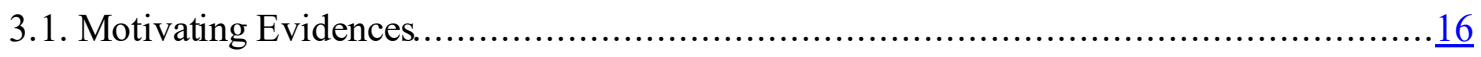

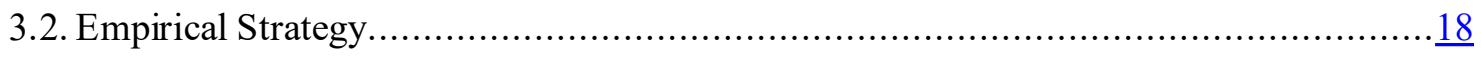

3.3. Main Specification ………………

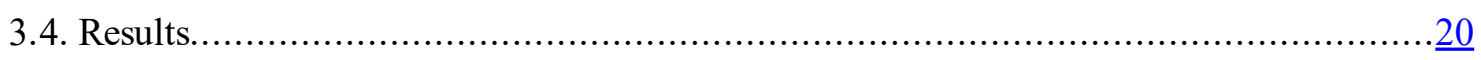

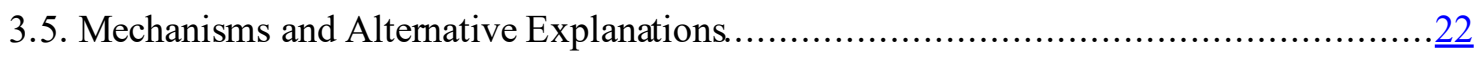

4 A Simple Model of Firm-to-Firm Search in Two Markets ................................... $\underline{23}$

4.1. Buyers, Suppliers, and Consumers ................................................................

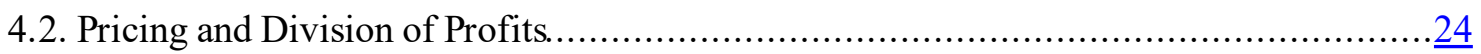

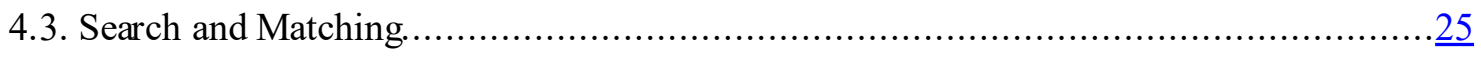

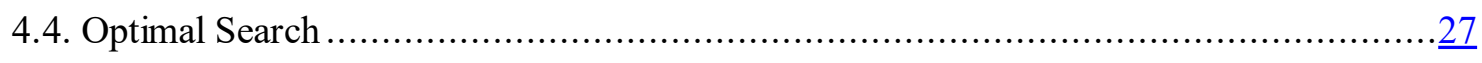

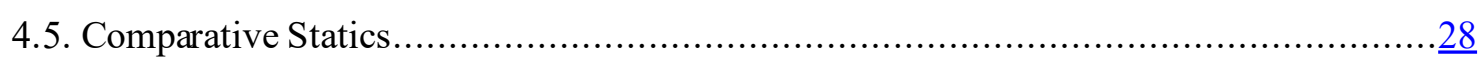

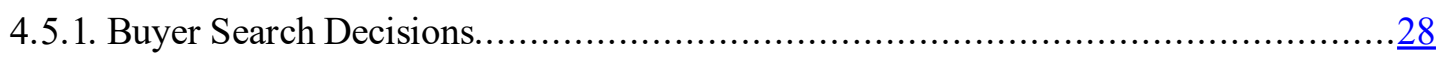

4.5.2. Consumer Welfare and Matching Efficiency.....................................................29

5 A Quantitative Model of Buyer-Supplier Search in Two Markets........................ $\underline{30}$

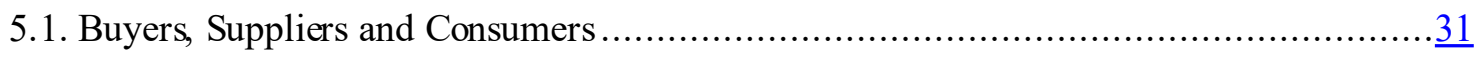

5.2. Pricing and Division of Profits..................................................................

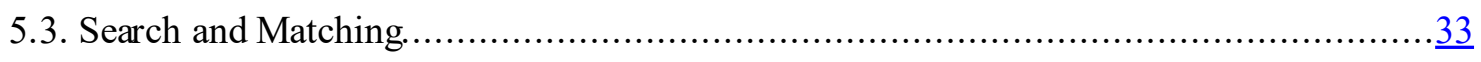

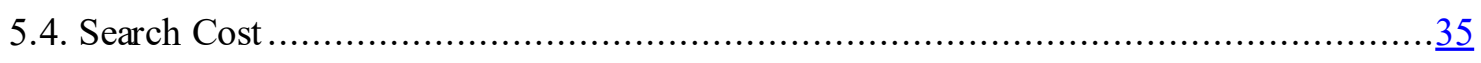

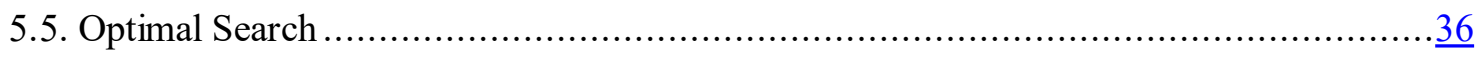

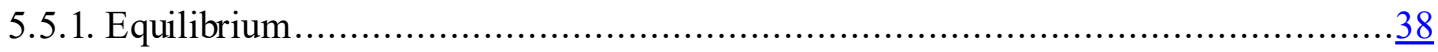

6 Estimation

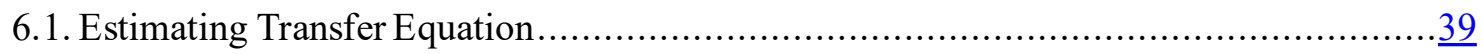

6.2. Externally Calibrated Parameters ..............................................................

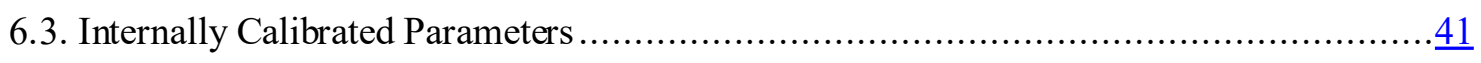

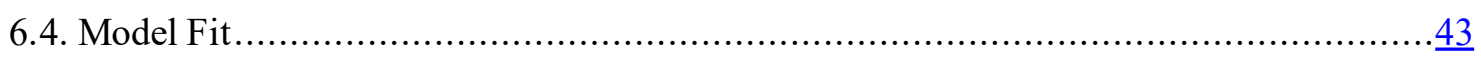

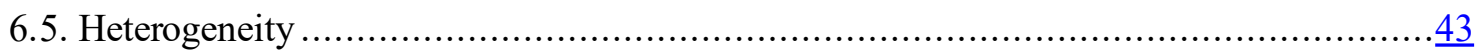


7.1. Experiment 1: Transport Cost Reduction Under Structurally Estimated Parameters.

7.2. Experiment 2: Transport Cost Reduction Under Constant Returns to Scale Matching Function. .$\underline{48}$

7.3. Experiment 3: Transport Cost Reduction

8 Concluding Remarks

References

A.1. Map of Trade Corridor........................................................................................

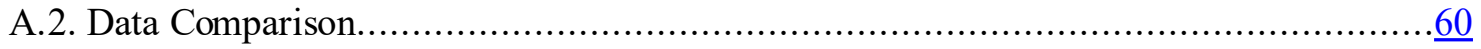

B A Quantitative Model of Buyer-Supplier Search in Two Markets..................... $\underline{62}$

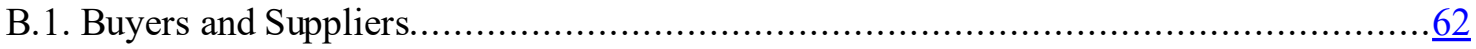

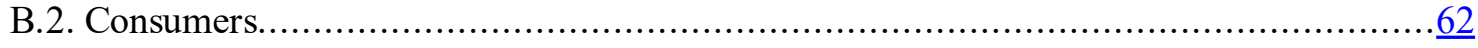

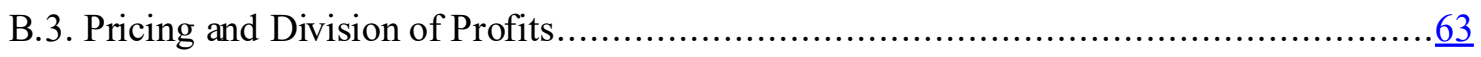

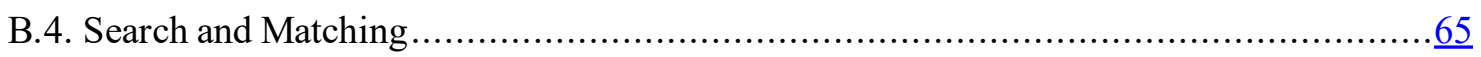

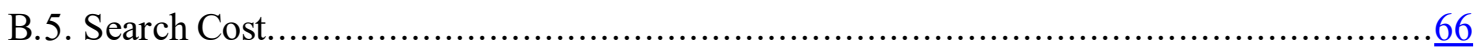

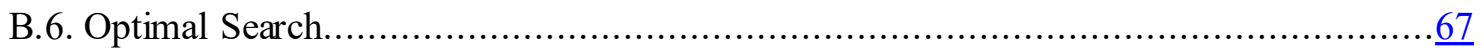

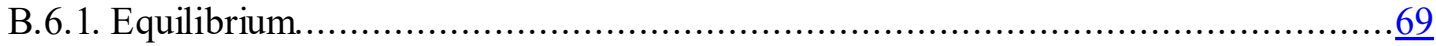

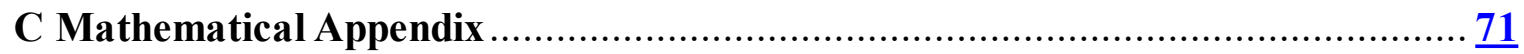

C.1. Comparative Statics in the Two-Period Model.............................................

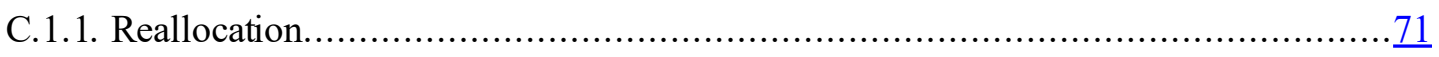

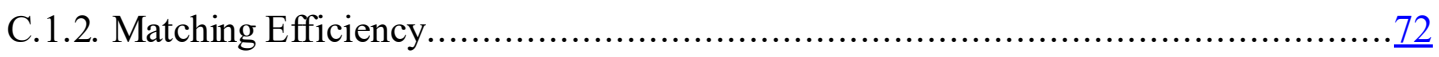

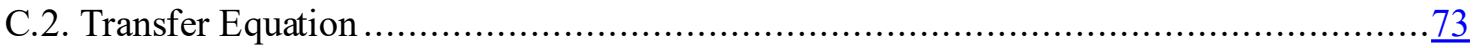

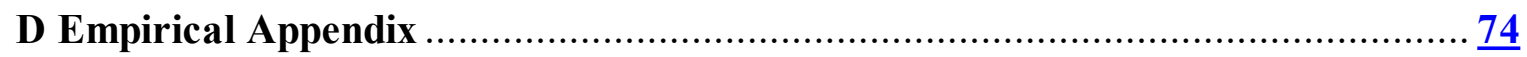

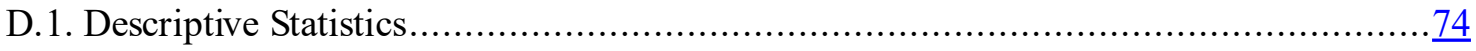

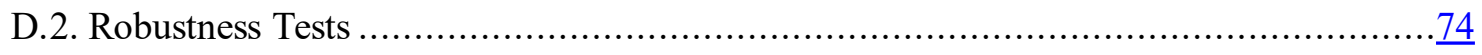

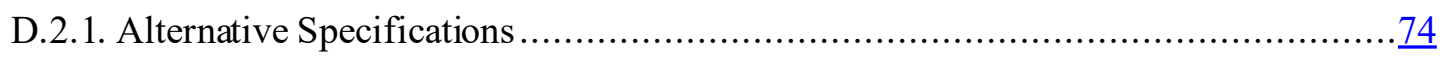

D.2.2. Very Local Shocks Drive Results.......................................................... 77

D.2.3. Spillover Exists But is Not Search Related.............................................. 77 


\section{List of Tables}

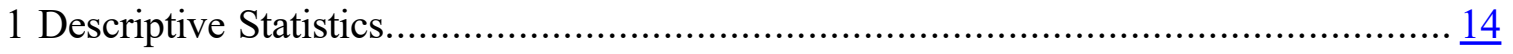

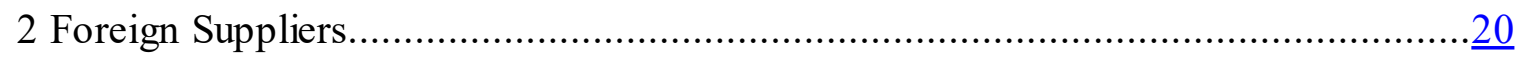

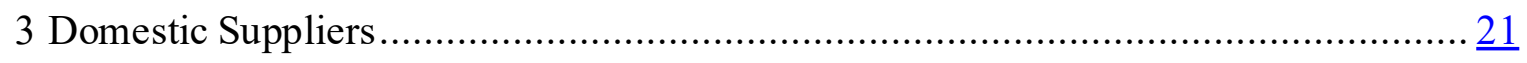

4 Estimating the Transfer Equation.............................................................. 40

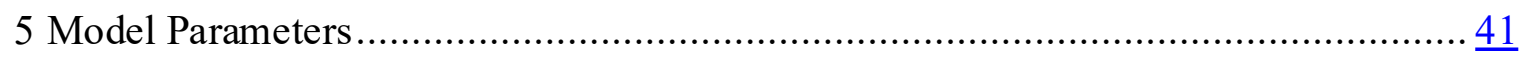

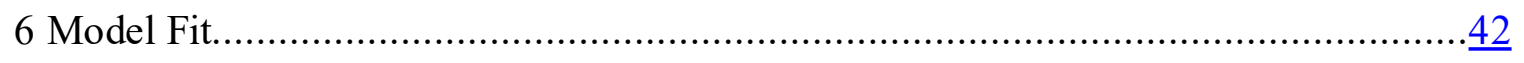

7 Outcomes from 25\% Transport Cost Reduction................................................ 46

8 Outcomes from 25\% Transport Cost Reduction Under Different Matching Functions. 49

9 Outcomes from 25\% Search Cost Reduction .................................................. 50

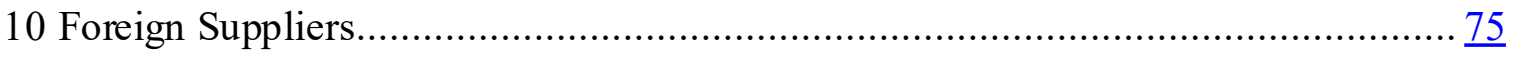

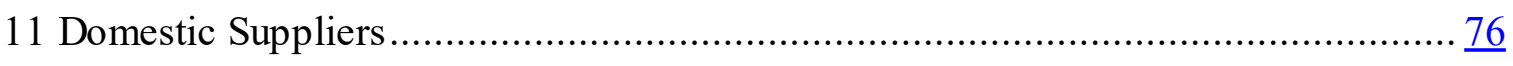

12 Same and Next-Door Balance Table …….................................................. 77

13 Imports Suppliers from East African Community ........................................... 78

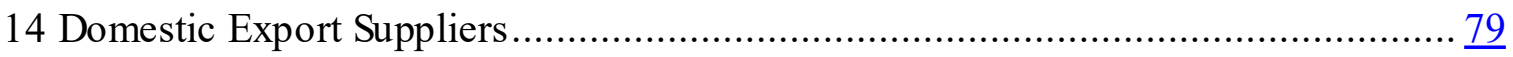

\section{List of Figures}

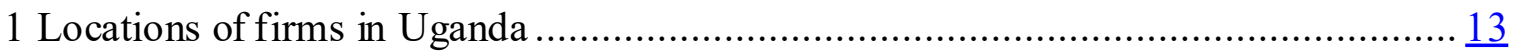

2 Transport Costs and Imports................................................................... 16

3 Percentage of suppliers' matches which have an existing buyer in location ............... 17

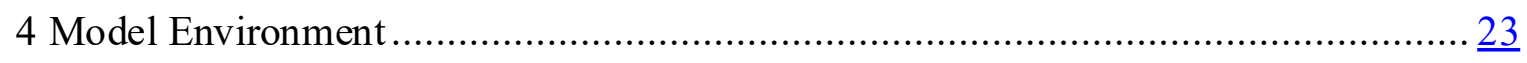

5 Model fit: buyer and supplier out-degree................................................... 44

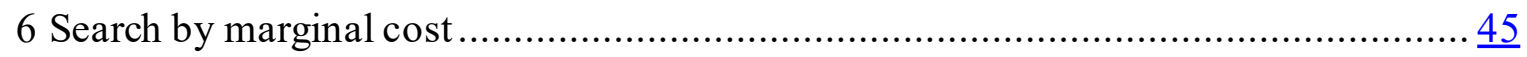

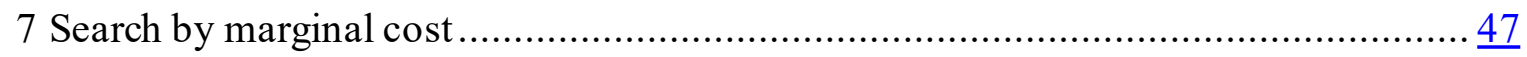

8 Mass of firms with $S_{I}$ international suppliers........................................... $\underline{48}$

9 Mass of firms with $S_{D}$ domestic suppliers....................................................

10 Average number of international and domestic suppliers for different reductions in trade costs when search externalities are shut down (CRS) compared to structurally

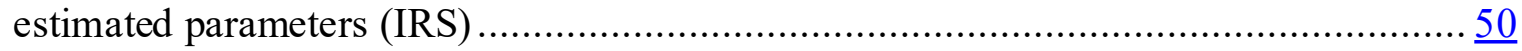

11 Consumer welfare gains from trade when search externalities are shut down (CRS) compared to structurally estimated parameters (IRS) ......................................... 51

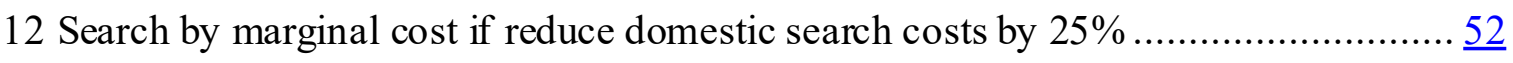

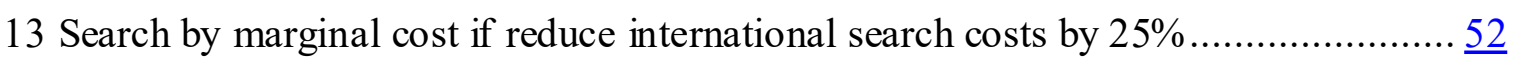

14 Map of trade corridor, Osawa, WCO........................................................... 60

15 Exports data comparison ........................................................................ 61 
16 GDP and total output..

61

17 Transport Costs and Imports.. 


\section{INTRODUCTION}

In a developing country, finding and maintaining an efficient and reliable supplier can be a costly and a time consuming process (Allen, 2014; Macchiavello and Morjaria, 2015; Startz, 2016). One factor which can make this process more difficult, is if many other firms are simultaneously searching for a supplier (Arnosti et al., 2018). This congestion externality will occur when trading frictions mean supply cannot instantaneously meet demand from multiple buyers. This is plausibly a large concern in developing countries where contracting frictions cause high adjustment costs (Macchiavello and Morjaria, 2019), and a lack of access to credit can cause firm supply-constraints (Manova, 2012). One policy response is to open to international trade, giving firms access to a large pool of suppliers which are less inhibited by these trading frictions. ${ }^{1}$

In this paper, I demonstrate that reducing international trade costs will lead to a greater number of matches in the international market, alongside an important and novel secondary benefit - the alleviation of the consequences of congestion in the domestic supplier market. I formalise this new mechanism for a domestic market consumer welfare gain from trade and consider its effects in Uganda. I document empirical evidence consistent with the Ugandan supplier market suffering from greater congestion than the international supplier market. I then demonstrate through model simulations that, for the case of Uganda, the impact of this channel on consumer welfare is quantitatively significant; a $25 \%$ reduction in international trade costs in 2011 led to a $3.7 \%$ increase in consumer welfare, $12 \%$ of which is accrued to the difference in congestion between the two markets. Finally, model simulations lend support to policy interventions to reduce search costs, especially when targeted at sectors less inhibited by congestion.

This analysis requires a unique combination of data on firm-to-firm domestic and international transactions. I use Ugandan administrative tax data that includes inform-

\footnotetext{
${ }^{1}$ These firms are likely to be less inhibited given international exporters tend to be larger (Bernard and Jensen, 2004) and with better access to credit (Manova, 2012). Indeed this channel should exist in any two markets, where one is more congested due to firms being supply-constrained.
} 
ation from Value-Added Tax (VAT) receipts and Customs receipts. These two datasets record all domestic and international firm-to-firm transactions among registered firm, which amounts to a dynamic transaction-level firm-to-firm input-output matrix. Using the firm's unique ID, allows the transaction data to be linked with other tax administration datasets: firm balance-sheet data, firm employment information and detailed firm geographic location. Together, this constitutes a dynamic picture of the entire Ugandan formal economy from 2010 to 2016. To the best of my knowledge, this is the first paper to combine this breadth of administrative firm-level transaction-data in a developing country.

I begin by documenting empirical evidence of search frictions and search externalities by observing firm sourcing behaviour. I show that firms located in the same building sequentially adopt the same foreign suppliers. ${ }^{2}$ I then show that this effect is substantially larger for firms located in the same building compared to firms located in a next-door building. This is consistent with information diffusing among firms about potential suppliers. When looking at domestic suppliers, however, this effect is not significantly different from zero. By contrast, in the domestic market, a buyer adding a specific new supplier actually reduces the probability of buyers in a different region of the country matching with that supplier. This is consistent with geographically distant firms not benefiting from the information externality, but still subject to the congestion externality.

Motivated by the empirical evidence, I develop a simple model of optimal search in two markets with different search externalities. The model serves to highlight the key mechanism proposed in this paper - after a trade cost reduction, firms increase search in international markets as these goods become relatively lower-cost to source. This is mitigated by two forces. First, as firms move into the import market, this increases aggregate import market-tightness, thus decreasing the probability of an import match. Second, as firms move out of the domestic-market, domestic market-tightness decreases, therefore increasing the probability of a domestic match. The scale of these congestion

\footnotetext{
${ }^{2}$ This is consistent with previous literature, see for instance Bisztray et al. (2018) and Kamal and Sundaram (2016)
} 
effects depends on the relative size of positive and negative search externalities in each market. These parameters also determine the welfare consequences of a reduction in international trade costs. If there is a greater positive externality to search in international markets compared to domestic markets, then a reallocation of search towards international markets not only leads to more matches in the international market, but also alleviates congestion in the domestic market. This will lead to a greater number of overall matches which benefits consumers with taste-for-variety. ${ }^{3}$

In order to quantify the impact of a search channel on consumer welfare, I build and estimate a dynamic quantitative version of the model where both buyers and suppliers choose optimal search intensity and the proportion of search in each market. The model builds on existing work by Eaton, Jinkins, Tybout and Xu (2016), adding both a domestic and an international search decision and market-specific matching functions, as well as adding firm heterogeneity and additional structure to search costs.

The most important structural parameters are those which govern the returns to scale in the matching function. I find that there are decreasing returns to scale to searching in domestic markets and increasing returns to scale to searching in international markets, as is consistent with the reduced-form results.

To test the external validity of the model, I simulate a $25 \%$ reduction in transport costs which mimics a set of transport infrastructure improvements implemented by the East African Community (EAC) in 2010-2011. ${ }^{4}$ The proportion of firms that import increases from $21 \%$ to $25 \%$, the average number of foreign suppliers increases by $13 \%$ and the average number of domestic suppliers decreases by $4.2 \%$. The change observed in the data is the same direction and of a similar magnitude to that seen in the simulation.

Finally, I run two counterfactual experiments. In the first experiment, I consider how

\footnotetext{
${ }^{3}$ An alternative way of thinking about the model is through a lens of trading frictions. In this sense, buyers may be aware of the existence of suppliers, however, there is no centralized market where buyers and suppliers meet and trade at a single price (Rogerson et al., 2005). In order to form a partnership they must undertake costly investments which involve externalities.

${ }^{4}$ The reforms are discussed in detail in Section 2. Given the reforms were exclusively conducted outside Uganda or on the border crossing, I assume they had no impact on domestic trade costs.
} 
much the increase in consumer welfare is due to differences in search externalities between markets. I again simulate the reduction in trade costs, but assume both markets have the same constant returns to scale matching function. The average number of foreign suppliers increases by a smaller amount (9\% vs. 13\%), as there is a larger increase in import market tightness. There is also a larger decrease in the average number of domestic suppliers (-6.1\% vs. $-4.2 \%)$, this is because the reduction in search domestically does not have the mitigating effect of reducing congestion in the domestic market. This results in an increase in consumer welfare which is $12 \%$ smaller than when I allow there to be differences in externalities between markets, demonstrating that allowing for search externalities has a quantitatively important impact on welfare.

In the second experiment, I simulate the government of Uganda's goal of a " $25 \%$ reduction in search costs for suppliers" as one of its four goals in trade (Government of Uganda, 2019). ${ }^{5}$ I show that this leads to a $2-4 \%$ increase in consumer welfare, depending on where the reduction is targeted. If the government reduces international search costs, then this will significantly increase the number of matches in the same manner as the trade cost reduction. If, however, the government reduces domestic search costs then the impact, albeit still positive, is dampened by the increase in domestic congestion caused by a greater number of searching firms.

This paper relates to three main strands of the literature. This paper contributes to the literature on firm-to-firm search. The literature has shown that the competitive equilibrium does not necessary result in the socially optimal level of search (Krolikowski and McCallum, 2017), that search frictions explain firm's export market decisions (Chaney, 2014), and that search influences predictions on gains from trade (Antras and Costinot, 2011). I build on work by Eaton, Jinkins, Tybout and Xu (2016), who write a dynamic quantitative model of optimal two-sided buyer-supplier search which is rich enough to take

\footnotetext{
${ }^{5}$ The specific sub targets are i) establishing a internet platform support programme (e.g. organize quarterly trainings on the use of Ali Baba), ii) encourage firms peer-to-peer learning (e.g. organize quarterly peer groups with Uganda business groups), iii) target key firms in supplier development programmes (e.g. establish anchor firm support unit and annual public-supplier meetings).
} 
to the data. ${ }^{6}$ This paper's contribution is to separately model search in domestic and international markets and incorporating different matching technologies in either market, providing new predictions on a search channel for consumer welfare gains following a reduction in international trade costs and using novel data.

In addition, this paper relates to the literature on the firm supply-chain impacts following a trade liberalization in the absence of search frictions. Arkolakis et al. (2012) show that gains from trade are higher in models with intermediate goods. Tintelnot et al. (2018) and Fieler et al. (2018) build quantitative models to show that the gains from trade depend on domestic firm-to-firm linkages and how firms are directly or indirectly connected to the international market. Antras et al. (2017) build a quantitative model of global sourcing. ${ }^{7}$ I build on this literature by incorporating intermediate goods into a model of domestic and international sourcing whilst also including a search channel. Moreover, I consider not only firms' international sourcing decisions but also the interdependencies between this and domestic sourcing decisions.

Finally, the paper contributes to the empirical literature on firm-to-firm search externalities. The closest paper to the reduced-form work is Bisztray et al. (2018), which has extremely detailed geographic data on firms in Hungary. The authors show that firms in the same building sequentially add imports from the same country and in the same product category. The paper also relates to Kamal and Sundaram (2016), who show a similar effect for matched importer-exporter data but without detailed geographic data. Cai and Szeidl (2017) show that when firms are randomly allocated into different business groups they refer each other leading to a $9 \%$ increase in the number of suppliers. ${ }^{8}$ I

\footnotetext{
${ }^{6}$ Other important contributions on sourcing include Rauch (2001), Rauch and Trindade (2002), Rauch and Watson (2003). A parallel literature also exists on exporter search for buyer markets (See for instance Eaton et al. (2017), Allen (2014), Albornoz et al. (2012)).

${ }^{7} \mathrm{~A}$ connected literature considers the role of production networks in firm performance and the propagation of shocks (Lim (2017), Carvalho (2014), Carvalho (2014), Bernard and Moxnes (2018), Bernard et al. (2018)). Another important related literature considers the differences between firms which trade Bernard and Jensen (1999) and consider whether firms which trade become more productive Bustos (2011); Spray (2017a); Atkin et al. (2017)

${ }^{8} \mathrm{~A}$ number of related empirical papers highlight additional aspects of the search frictions among firms (Bernard et al. (2019), Startz (2016), Steinwender (2018), Fafchamps and Quinn (2016)).
} 
build on this literature in four ways. First, the Ugandan dataset contains details on both the geographic location of firms and the matched supplier which gives more detail than the existing literature. Second, I compare firms searching domestically to firms searching internationally, providing evidence of the comparative size of domestic and international externalities for the first time. Third, in addition to looking for a positive search externality, I also show results consistent with a negative search externality. Fourth, besides providing reduced-form evidence of search externalities, I also provide structural evidence of search externalities which differ between markets, which I use to show welfare consequences of different counterfactual experiments.

The remainder of this paper is organized as follows: Section 2 describes the dataset and the context of the trade cost reduction; Section 3 provides empirical empirical evidence of search externalities in Uganda; Section 4 sets out a simple two-period model of firmto-firm search and shows comparative statics; Section 5 presents the quantitative model; Section 6 structurally estimates the model; Section 7 provides counterfactual simulations; and Section 8 concludes.

\section{Data, Context and Descriptive Statistics}

\subsection{DATASETS}

The data used in this paper comes from four linked datasets collected by the Ugandan Revenue Authority (URA) which are administered for taxation purposes and cover the period 2010-2016. This data is confidential and is made available for the purposes of this research. Each tax dataset contains a unique tax identification number which allows the datasets to be linked across firms and time. The datasets contain the universe of firms paying tax in Uganda; consequently they are representative of the entire formal sector. It also contains the universe of importing firms in Uganda, as all firms choosing to import must go through a customs office and must be registered to pay tax. Inference on the 
informal sector is outside the scope of this study. ${ }^{9}$

The first dataset contains details on domestic firm transactions. Ugandan firms are required to record every transaction with any other tax-paying firm alongside the transacting firm's unique tax ID for Value-Added-Tax (VAT) purposes. This gives a line-by-line account of the good transacted, the value of the transaction, the date it took place, and the tax identification number of the linked firm. This dataset, therefore, constitutes a dynamic input-output matrix for the entire Ugandan formal economy. ${ }^{10}$

The second dataset contains transaction-level international trade data. The dataset includes variables of import origin, value, product and the matched foreign exporter on the other side of the transaction. ${ }^{11}$

The third dataset is monthly balance-sheet data from VAT records from 2010-2016. Ugandan firms are required to report on their total sales and total inputs each month. I winsorize these variables at the $5 \%$ level and collapse to annual frequency.

The fourth dataset is a firm registration dataset and contains descriptive details on the firm itself. This includes the ISIC industrial sector classification ${ }^{12}$ and a more general description of its main operations. It also includes firms' addresses which I show on a map of Uganda in Figure 1. ${ }^{13}$ I only include buyer firms which are registered as retailers in the firm registration dataset and suppliers which sell to retailers. This allows me to observe firms which are less likely to be in long supply-chains and can more easily be

\footnotetext{
${ }^{9}$ While I do not observe non-tax paying firms, this is not a major concern given tax paying firms in Uganda are much larger and more technically adept (Kathage, 2018) and represent the sample of firms I am most interested in. Between 2009-2011, 58\% of Uganda's workforce was working in the informal sector, $13 \%$ of informal-sector workers were paid employees, $23 \%$ were unpaid helpers and $63 \%$ were working proprietors (mainly subsistence farmers) (Overseas Development Institute, 2015). There is a possibility that there is greater missed data domestically to internationally given import customs checks are likely to be more thorough.

${ }^{10}$ It also allows a product-specific calculation of inputs, although this is not done for the time being given the complexity of the data management process since records are manually entered without product codes.

${ }^{11}$ There is also data on firm exports, although I do not use this for the purpose of this project given I am primarily interested in firm sourcing behaviour.

${ }^{12}$ Standard industrial classification of economic activities (ISIC) is a classification system for industry categories. The URA classifies firms at a 4 digit level.

${ }^{13}$ Address geo locations were mapped using google maps API
} 


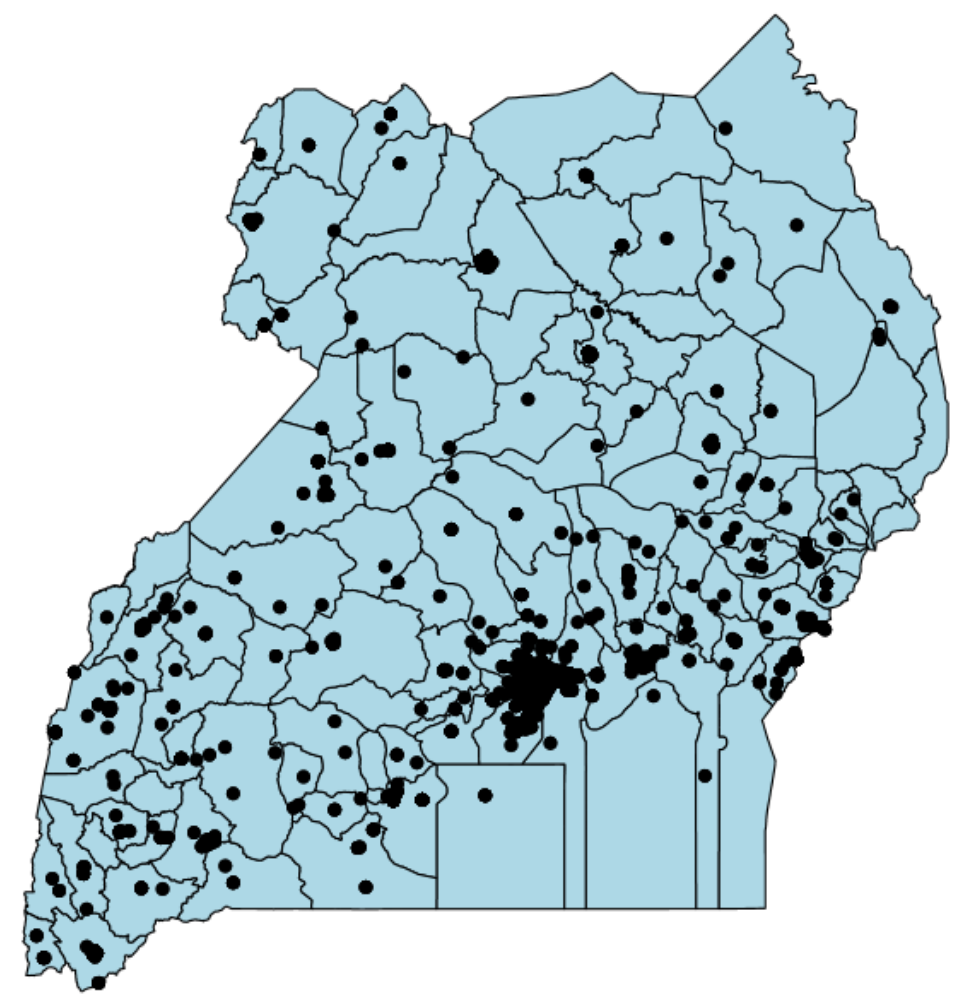

Notes: Each point on the graph represents a unique location, although there are likely to be multiple firms in each location. There are a small number of firms located on islands in lake Victoria located in the bottom right.

characterised as buyers or supplier relationships.

Descriptive statistics are presented in Table 1. The consolidated dataset contains 7,000 import buyers 13,000 domestic buyers, 24,000 foregn suppliers and 86,000 domestic suppliers. There are in total over 12 million transactions and over 490,000 firm-to-firm connections. The number of firms reduces by roughly two thirds If I restrict the sample to only look at buyers which are retailers. On average, retailers are younger have a lower wage bill and have lower sales.

To the best of my knowledge, this is the first paper to link VAT transaction level data with firm employee and importer-exporter matched customs data. This allows observations on the complete and dynamic picture of the formal economy of Uganda. As research using tax data remains rare, one potential concern might be that the data is inconsistent with other datasets. In Appendix A.2, I address this concern by comparing the tax data 
TABLE 1: Descriptive Statistics

\begin{tabular}{lrrrr}
\hline \hline Variable & \multicolumn{2}{c}{ Import Sample } & \multicolumn{2}{c}{ Domestic Sample } \\
& All firms & Retailers & All firms & Retailers \\
\hline Number of buyers & 6788 & 2663 & 12984 & 3265 \\
Number of suppliers & 24133 & 10008 & 86689 & 26139 \\
Number of buyers (> 3 matches) & 3373 & 1410 & 7294 & 1928 \\
Number of suppliers (> 3 matches) & 3451 & 1009 & 17293 & 7008 \\
Firm-to-firm connections & 71,000 & 23,000 & 420,000 & 116,000 \\
Transactions & $1.3 \mathrm{~m}$ & $0.42 \mathrm{~m}$ & $11 \mathrm{~m}$ & $2.4 \mathrm{~m}$ \\
Mean Age & 8.7 & 8.2 & 8.5 & 7.4 \\
Median Wage Bill (USH) & $422 \mathrm{~m}$ & $123 \mathrm{~m}$ & $283 \mathrm{~m}$ & $97 \mathrm{~m}$ \\
Median Sales (USH) & $8.6 \mathrm{~b}$ & $6.5 \mathrm{~b}$ & $5.6 \mathrm{~b}$ & $5.6 \mathrm{~b}$ \\
\hline
\end{tabular}

Notes: Data combined from Uganda administrative tax datasets from 2010-2016. The import sample comes from import trade data and the domestic sample comes from the VAT transaction dataset. Mean age comes from the firm registration dataset. Mean wage and sales comes from the firm balance sheet dataset.

used in this study to other freely-available data sources on firms in Uganda.

\subsection{UGANDAN ECONOMY}

Uganda is a landlocked country in East Africa which has experienced high and sustained growth driven by high investment levels and strong international trade performance. The economy is made up of a large services sector (56.6\%); agriculture, forestry and fishing (24.2\%); and industry (19.2\%) (World Bank, 2019).

Uganda is open to the external sector with imports reaching $25.9 \%$ as a share of GDP in 2016/17 (International Monetary Fund, 2019). The largest components of imports are consumables and capital goods for investment (World Bank, 2019).

As shown in Table 1, only a small proportion of Ugandan firms import. As shown in Table 1, importers are on average larger than firms who only source domestically, with median sales and wage bill 1.5 and 2.5 times higher, respectively. This is consistent with previous research on this topic (e.g. Bernard and Jensen (1999)).

As shown in Table 1, the retail sector is primarily made up of firms with lower sales and with a smaller wage bills than the average Ugandan firm. They are also younger on average. These firms import a wide variety of final products including building materials, 
food and beverages, and general merchandise. The biggest importing countries are China, India, UAE, Kenya and Japan.

On average, each Ugandan firm has 2.7 domestic suppliers. The sectors with the largest number of connections are in service and manufacturing industries including construction services, telecommunication services, accounting services, and the manufacturing of plastic products, metals, and paper products. ${ }^{14}$

Despite having a high import volume, Uganda has some of the highest transportation costs in the world. In 2017, Uganda ranked 136 out of 190 countries on World Bank's Trading Across Border Index (World Bank, 2016). The majority of goods entering Uganda must first transit through the port of Mombasa in Kenya. ${ }^{15}$ In 2010, the Mombasa port was described as having "persistent congestion", being "behind international standards" and facing issues of "corruption and incompetence" (Bulzomi et al., 2014). Once goods are cleared from the port, they are required to be transported over $1000 \mathrm{~km}$ by road through Kenya, before crossing the border into Uganda. A map of the main trade corridor, and location of the six weighbridge truck stops is shown in Figure 14 in Appendix A.1.

In 2011, Uganda implemented reforms to reduce the cost of importing. The main reforms were longer border opening hours and improved port infrastructure at the main port in Mombasa (World Bank, 2011). In addition, Uganda rehabilitated roads thanks to a large grant from the European Union and removed several weighbridges along the route (Bulzomi et al., 2014). The combination of these reforms led to a $25 \%$ fall in transport costs in 2011, which then reduced the cost of importing a 20-foot container from USD5807 to USD4396 (-24.3\%). As shown in Figure 2, this effect happened rapidly over one year and was later stable. The fall in transport costs corresponds with a rapid increase in the number of new importers. ${ }^{16}$ As shown in Appendix D, it also corresponds with an increase

\footnotetext{
${ }^{14}$ This topic is covered in detail in Spray and Wolf (2016)

${ }^{15}$ In 2010, $68 \%$ of Ugandan imports arrived from the Kenyan border. Based on customs dataset. $25 \%$ of imports arrived through the airport, and the remainder came through the Tanzanian, Rwandan, Congolese borders or through the lake port in Jinja.

${ }^{16}$ There is also an increase in exporting, although this happens slightly later, this is discussed in detail in Spray (2017b)
} 
Figure 2: Transport Costs and Imports

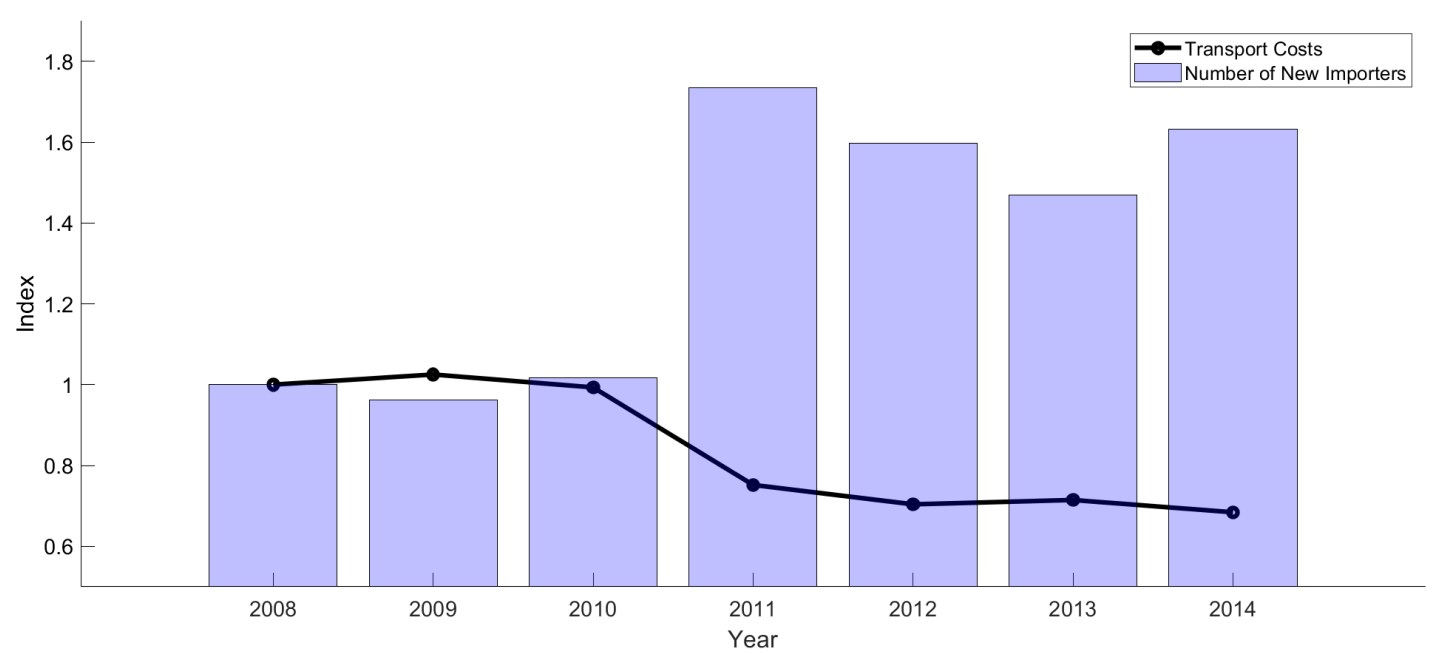

Notes: The black line shows transport cost in USD per 20-foot container from the World Bank's Trading Across Border Index between 2007-2014, the bars show the number of new importers. The data for the bars comes from customs dataset. Reforms took place between 2010 and 2011.

in the proportion of firms which are importers and in the number of foreign suppliers per firm.

In Section 7, I consider the welfare impact of this shock within a quantitative trade model incorporating search frictions and search externalities. However, first I show empirical evidence to motivate a focus on search frictions and externalities in this context.

\section{Empirical Evidence of Search Externalities}

\subsection{Motivating EVIDEnCE}

Figure 3 shows the percentage of supplier matches which have at least one buyer in the same neighborhood. The first bar shows that $21 \%$ of suppliers' new matches with domestic or foreign suppliers are in the same building as an existing customer.

This tight proximity between suppliers' customers is consistent with the fact that it is easier to sell to customers in similar locations. One explanation for this is that information about potential suppliers may diffuse more easily among closely located buyers. This could 
FiguRE 3: Percentage of suppliers' matches which have an existing buyer in location

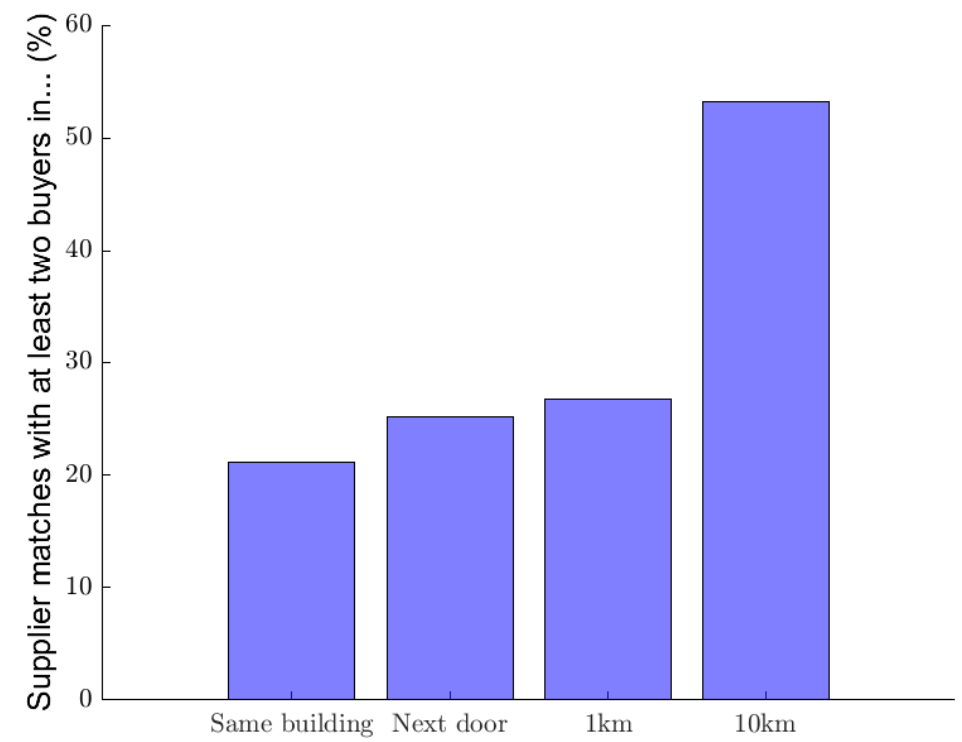

Notes: On the y-axis is the percentage of supplier matches with at least two buyer in the same location. On the x-axis, the location progressively gets wider away, such that Next door refers to the proportion of supplier matches with an existing buyer either in the same building or in the next-door building.

be because closely located buyers have stronger relationships or because suppliers may bump into potential buyers operating close to their existing customers. This narrative is supported by comparing the percentage of matches with a buyer in the same building $(21 \%)$ to the percentage of matches in the same or next-door buildings (25\%), an increase of just $4 \%$ from adding next-door buildings. Firms in the same building are unlikely to be substantially different to their next-door neighbors, except in the ease with which information can diffuse. However, even when moving from one building to the next, the diffusion of knowledge appears to reduce substantially.

While these results are consistent with a positive information spillover, they do not exploit the richness of the data, and have nothing to say on the possible negative externality. In the next section, I move into a more formal characterization of this effect. 


\subsection{EMPIRICAL STRATEGY}

In order to explain the empirical strategy, consider the following example. Two retailers in Kampala, $\{\mathrm{A}, \mathrm{B}\}$, are looking for a new supplier. Each firm can look for this supplier either locally or abroad. There are two ways $A$ 's search might influence $B^{\prime} s$ probability of matching; either $B$ may pass information to $A$ (a positive externality) or $B$ may crowd-out A's chance of matching (a negative externality).

If information is easier to diffuse among retailers located close to one another, then the spatial diffusion of firms can be used to identify different externalities. In order to test for a positive search externality, I consider whether one firm making a match increases the probability of geographically close firms making the same supplier match. To test for a negative externality, I consider whether one firm making a match decreases the probability of geographically distant firms making the same supplier match.

I begin by generating a dataset of every buyer-supplier-year triplet separately for domestic and international suppliers. Given that I observe over 13,000 domestic buyers and 86,000 domestic suppliers over 6 years, this generates a dataset with 6.8 billion observations.

However, many matches are unlikely to ever be formed. For instance, you would not expect an iron ore mine to supply a tea factory. Instead, I trim this dataset to obtain a sample of likely matches. First, I drop suppliers which have never sold to the buyer's ISIC 4-digit industry. Second, I drop any buyer or supplier which does not make at least three matches over the entire sample period. Third, I drop any observations from the sample following the first observed match. This restricts the sample to only consider the first-time matches between firms which are active and which are in sectors which are likely to trade. Finally, I consider only matches where the buyer is the retailer. This is consistent with the buyer-supplier relationship and not longer supply-chains. ${ }^{17}$

\footnotetext{
${ }^{17}$ In the appendix I extend this to all firms and not just retailers
} 


\subsection{MAIN SPECIFICATION}

The main specification is given by the linear probability model shown in equation 1

$$
Y_{i f t}=\mu_{1} X_{i f, t-1}^{\text {same-building }}+\mu_{2} X_{i f, t-1}^{\text {nextdoor }}+\gamma X_{i f, t-1}^{\text {other-city }}+\alpha_{i}+\delta_{t}+u_{i f t}
$$

where $Y_{\text {ift }}$ is a dummy $=1$ if buyer $i$ adds supplier $f$ for the first-time in period

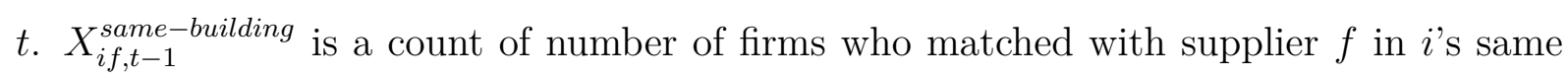
building in period $t-1 . X_{i f, t-1}^{\text {nextdoor }}$ is a count of number of firms who matched with supplier $f$ in $i$ 's nextdoor building in period $t-1 .^{18} X_{i, t-1}^{\text {other-city }}$ is a count of number of firms who added supplier $f$ in $t-1$ but are not in $i$ 's city.

If information diffuses among firms about suppliers, we would expect these effects to occur more strongly among geographically closer firms. Therefore, $\mu_{1}>0$ would be consistent with a positive externality.

It is, however, possible that firms located in the same location may be hit by the same shocks. This motivates the inclusion of the control for firms in a next-door building. Given that one might expect firms in the same building to be structurally very similar to those located in next-door buildings in all respects except that information is harder to diffuse across buildings than within buildings. Results would be consistent with a positive spillover if $\mu_{1}>\mu_{2}>0$.

If suppliers have a limited capacity to add multiple buyers at once, then firms making matches elsewhere in the country should decrease the probability of buyers in other locations making a match. Therefore, $\gamma<0$ would be consistent with a negative congestion externality.

I include buyer and time fixed effects $\left(\alpha_{i}\right.$ and $\left.\delta_{t}\right)$ which control for unobserved buyer characteristics and time trends.

I consider domestic and international suppliers in separate regressions, and test whether

\footnotetext{
${ }^{18}$ The results are also robust to running alternative functional forms showing results are robust to including a continuous measure of the number of new buyers in a neighborhood, changing the definition of a neighborhood and are available upon request.
} 
the respective coefficients are different.

\subsection{Results}

TABLE 2: Foreign suppliers

\begin{tabular}{|c|c|c|}
\hline & $\begin{array}{l}(1) \\
Y_{i f t}\end{array}$ & $\begin{array}{l}(2) \\
Y_{\text {ift }}\end{array}$ \\
\hline$X_{i f, t-1}^{\text {same-building }}$ & $\begin{array}{c}0.0847^{* * *} \\
(0.0262)\end{array}$ & $\begin{array}{c}0.0848^{* * *} \\
(0.0263)\end{array}$ \\
\hline$X_{i f, t-1}^{\text {nextdoor }}$ & & $\begin{array}{l}0.000685 \\
(0.00437)\end{array}$ \\
\hline$X_{i f, t-1}^{\text {other-city }}$ & $\begin{array}{l}-0.00106 \\
(0.00173)\end{array}$ & $\begin{array}{l}-0.00108 \\
(0.00174)\end{array}$ \\
\hline $\begin{array}{l}\text { Observations } \\
\text { Year and Firm FE }\end{array}$ & $\begin{array}{c}4197300 \\
\text { YES }\end{array}$ & $\begin{array}{l}4197300 \\
\text { YES }\end{array}$ \\
\hline \multicolumn{3}{|c|}{$\begin{array}{l}\text { Notes: Unit of observation is buyer } i \text {, supplier } f \\
\text { and year } t \text {. Dependent variable } Y_{i f t} \text { indicates a first } \\
\text { match took place between buyer and supplier. } X_{i f t}^{k} \\
\text { is a count of buyers in region } k \text { which added supplier } \\
f \text { in } t-1 \text {. Coefficients are multiplied by } 100 \text { to read } \\
\text { as percentage point marginal effects. Standard er- } \\
\text { rors in parentheses are clustered at the buyer level. } \\
{ }^{*} p<0.1,{ }^{* *} p<0.05,{ }^{* * *} p<0.01\end{array}$} \\
\hline
\end{tabular}

As can be seen in column 1 of Table 2, each additional importer using foreign supplier $f$ within the same building increases the probability of buyer $i$ matching with supplier $f$ by 0.085 percentage points. This is a significant magnitude given that the baseline probability of a match is very low: 0.0039 for foreign suppliers and 0.0040 for domestic suppliers samples. Column 2 shows that a firm in the same building adding a new supplier has a much larger marginal effect, when compared to a firm in a next-door building adding a new supplier ( $0.085 \%$ vs. $0.0007 \%$, respectively). This is consistent with a local information spillover among firms in the same building, but that this becomes more difficult across buildings.

Evidence on negative spillovers is also consistent across specifications. Where an additional buyer being added in a different city to buyer $i$ in the previous year no statistically significant impact on new matches. 
TABLE 3: Domestic suppliers

\begin{tabular}{|c|c|c|}
\hline & $\overline{(1)}$ & $\overline{(2)}$ \\
\hline & $Y_{\text {ift }}$ & $Y_{\text {ift }}$ \\
\hline$X_{i f, t-1}^{\text {same-building }}$ & $\begin{array}{l}0.00398 \\
(0.0271)\end{array}$ & $\begin{array}{l}0.00325 \\
(0.0277)\end{array}$ \\
\hline$X_{i f, t-1}^{n e x t d o o r}$ & & $\begin{array}{c}-0.00146 \\
(0.00430)\end{array}$ \\
\hline$X_{i f, t-1}^{\text {other-city }}$ & $\begin{array}{c}-0.00347^{* * *} \\
(0.000116)\end{array}$ & $\begin{array}{c}-0.00329^{* * *} \\
(0.00124)\end{array}$ \\
\hline Observations & 11275450 & 11275450 \\
\hline Year and Firm FE & YES & YES \\
\hline $\begin{array}{l}\text { Notes: Unit of observat } \\
\text { year } t \text {. Dependent varia } \\
\text { took place between buye } \\
\text { of buyers in region } k \text { wl } \\
\text { Coefficients are multiplie } \\
\text { point marginal effects. } \\
\text { are clustered at the buy } \\
* * * \quad p<0.01\end{array}$ & $\begin{array}{l}\text { on is buyer } i \text {, } \\
\text { le } Y_{\text {ift }} \text { indicat } \\
\text { and supplier. } \\
\text { ch added supp } \\
\text { by } 100 \text { to rea } \\
\text { tandard errors } \\
\text { level }\end{array}$ & $\begin{array}{l}\text { upplier } f \text { and } \\
\text { a first match } \\
X_{i f t}^{k} \text { is a count } \\
\text { ier } f \text { in } t-1 \\
\text { as percentage } \\
\text { in parentheses }\end{array}$ \\
\hline
\end{tabular}

In Table 3, I show results for the same specification run on the sample of domestic suppliers. As in the import case, having an additional buyer in the same building increases the probability of buyer $i$ matching with supplier $f$. Unlike the import case, this effect is not significantly different from zero. Additionally, the magnitude of this positive coefficient is in both cases smaller than in the import case.

Unlike on the import side, evidence in Table 3 is consistent with congestion effects among domestic suppliers. In all specifications, an additional buyer in a different city in the previous year decreases the probability of the firm matching by $0.003 \%$. This is statistically significant at the $1 \%$ level.

Taking the results from Tables 2 and 3 together provides evidence consistent with a positive externality to search in international markets and a negative externality to search in the domestic market. 


\subsection{Mechanisms and Alternative Explanations}

I now consider two main possible alternative explanations for these results; either that very local shocks are driving results or that spillovers do exist, but that they are not search related. The full detail is provided in Appendix D.2.

If firms in the same building were systematically different to firms in next-door buildings, then this might raise a concern that local shocks to specific industries drive results. To address this concern, in Appendix Table 12 I compare the proportion of firms in the same ISIC 4-digit sector in the same building to those in the next-door building. While there is a small difference, it is not statistically significant. However, when I look at firms further away, I do see this difference increasing. I therefore conclude that there is some firm agglomeration, but that it is happening at a block level and not at a building level. Moreover, the fact that the agglomeration decreases over space, but that the impact of an additional buyer in the neighborhood does not dramatically decrease between columns 1 and 3 of Table 10 suggests this is not a major concern.

A second alternative explanation is that a spillover is taking place, but that it is not search related. To allay these concerns, I test if the marginal effect is smaller among firms where one would expect search frictions to be less prevalent. In Appendix Table 13, I interact the independent variables with whether the foreign supplier exported from the East African Community (EAC). This is because one would expect search frictions to be smaller in local neighbors such as Kenya when compared to more distant locations.

Another prediction consistent with search frictions, is that suppliers which are not supply-constrained will be able to match with multiple buyers, and so we should not observe a negative congestion effect. This is why we did not expect to find a strong congestion externality on foreign suppliers, given international suppliers are characterized by being large firms with cheap access to credit and multiple customers. Results in Appendix Table 14 show that domestic suppliers which are exporters, and hence less

supply constrained, have a smaller negative effect from making a match elsewhere in the country. This is again consistent with the search narrative. 


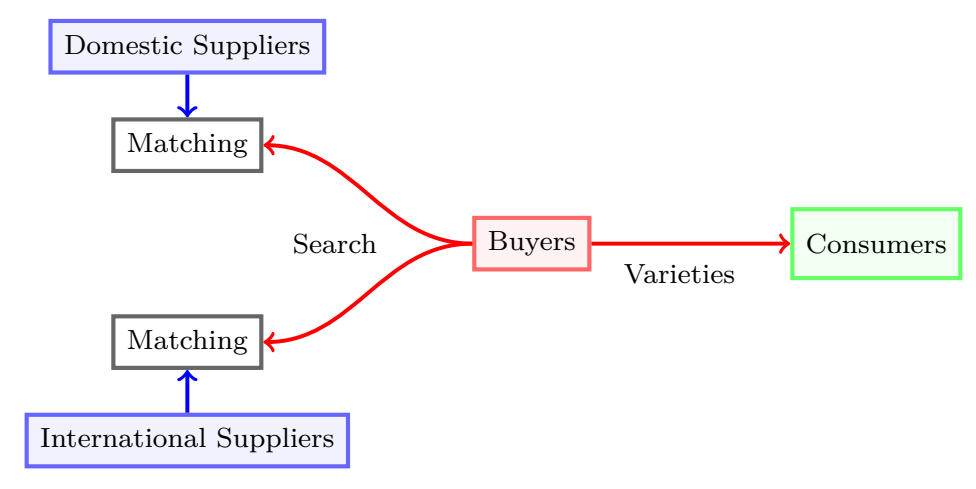

Figure 4: Model Environment

\section{A Simple Model of Firm-to-Firm Search in Two Markets}

Having demonstrated that search externalities may differ between domestic and international markets, I now illustrate through a simple model how these externalities can impact welfare in the context of a trade cost reduction.

The simple model is shown graphically in Figure 4. Buyers sell a single differentiated product to consumers in a frictionless retail market. Buyers purchase these products from suppliers, who are either domestic or international, ${ }^{19}$ and each produces one differentiated product. International suppliers produce a higher quality product, but must pay a higher transportation cost. Buyers and suppliers cannot costlessly match, but must instead undertake search to find a match. In both markets, a match between a buyer and a supplier depends on the intensity of search effort and the equilibrium market tightness. In order to incorporate differences in search externalities between markets, I allow the matching technology to differ when looking for domestic or international suppliers.

I demonstrate the main mechanisms of the model by showing comparative statics of a reduction in trade costs leading to a reallocation of search between markets, but with some mitigation due to congestion. ${ }^{20}$

\footnotetext{
${ }^{19}$ International here implies a foreign exporter

${ }^{20}$ The simple model, however, misses some salient features observed in the data. In order to make the model match key moments from the Ugandan data, I extend the framework in Section 5 to include a number of these features and estimate the quantitative model in Section 6.
} 


\subsection{Buyers, Suppliers And Consumers}

There is a measure $B$ continuum of buyers, measure $S_{D}$ continuum of domestic suppliers and measure $S_{I}$ continuum of international suppliers. For simplicity, I assume for the simple model that $S_{D}=S_{I}=S$.

Suppliers produce differentiated products which they sell to buyers once they match. Let $B\left(s_{I}\right)$ denote the set of buyers who match with international suppliers. Similarly, let $B\left(s_{D}\right)$ denote the set of buyers who match with domestic suppliers. For simplicity I assume all suppliers have the same marginal cost.

Buyers pay an iceberg trade cost $\tau_{I}$ on each unit of international goods and iceberg trade $\operatorname{cost} \tau_{D}$ on each unit of domestic goods, where I normalize $\tau_{D}=1$.

Buyers begin with marginal cost $c$ and no matches. Buyers have a fixed search intensity $\sigma$ but choose the proportion of search they exert domestically, $a$ such that $a \in[0,1]$, and internationally, $1-a$.

Consumers demand differentiated products from buyers $b$ with a CES utility function, which shows their taste-for-variety over products sold by buyers

$$
C=\left[\int_{b \in B\left(s_{I}\right)} \psi_{I} C_{b}^{\frac{\eta-1}{\eta}}+\int_{b \in B\left(s_{D}\right)} C_{b}^{\frac{\eta-1}{\eta}}\right]^{\frac{\eta}{\eta-1}}
$$

where I assume all international products have the same demand shifter, $I$, and all domestic products have the same demand shifter, ${ }_{D}$, which I normalize to 1 . If imports are higher quality products, we might expect ${ }_{I}>1$ for imported goods, although I do not impose this. $\eta>1$ is the elasticity of substitution between goods which does not vary between imports and domestic products.

\subsection{Pricing And Division of Profits}

In period one, buyers search and matches materialize. In period two, buyers compete using Bertrand competition in the retail market. This leads to the standard CES constant 
mark-up rule

$$
\frac{p_{b}-c_{b}}{p_{b}}=\frac{1}{\eta}
$$

where $p_{b}$ is the price charged by buyer $b$.

Substituting the mark-up into the profit function yields the instantaneous profit flow for a buyer and a matched supplier which depends on whether the supplier is domestic or international

$$
\pi\left(s_{L}\right)=\frac{E}{\eta P^{1-\eta}}\left[\left(\frac{\eta}{\eta-1}\right) \frac{\tau_{L} c}{L}\right]^{1-\eta} \quad \text { for } L \in\{D, I\},
$$

where $P$ is the standard CES aggregate price index and $E$ is household expenditure. Once I make the standard CES assumption that the elasticity of substitution $\eta>1$, the profit function behaves as one would expect - increasing in the aggregate price index, decreasing in marginal cost. If there is a domestic good then $\tau_{D}=\psi_{D}=1$. For higher international trade costs $\left(\tau_{I}\right)$ or smaller international demand shifter $\left(\psi_{I}\right)$ profits from matching with an international supplier are smaller.

I assume profits are split via Nash bargaining where $\Lambda \in[0,1]$ is the bargaining coefficient for the seller and $1-\Lambda$ is the bargaining coefficient for the buyer. This assumption means I do not need to consider inefficiencies lost due to double marginalization. ${ }^{21}$

\subsection{SEARCH AND MatChing}

I assume two aggregate matching functions which are homogeneous of degree one in the search of buyers and sellers, respectively. In the simple model, all sellers search such that their aggregate search is simply given by their mass $S$. The aggregate buyers' search in each market is given by the mass of buyers multiplied by the amount they search in each

\footnotetext{
${ }^{21}$ In practice, Bernard and Dhingra (2015) show this assumption may not hold, but it is a necessary simplification for the purposes of this paper as firm pricing is not a main feature of the paper's focus.
} 
market, such that

$$
\begin{aligned}
& B_{D}=a \sigma B \\
& B_{I}=(1-a) \sigma B .
\end{aligned}
$$

Following the labor literature, I assume that the aggregate measure of matches per unit time $\left(X^{D}, X^{I}\right)$ is homogeneous of degree one and increasing in the aggregate search of buyers and suppliers

$$
\begin{aligned}
& X^{D}=S^{\gamma_{S}} B_{D}^{\gamma_{B}} \\
& X^{I}=S^{\beta_{S}} B_{I}^{\beta_{B}} .
\end{aligned}
$$

The matching function exponents are key objects in the model. A positive externality to search would be indicated by high $\gamma_{S}, \gamma_{B}$ and $\beta_{S}, \beta_{B}$. This is because, at the margin, an increase in buyers or sellers will lead to a large increase in the number of matches. There are increasing returns to scale in domestic matching if $\gamma_{S}+\gamma_{B}>1$, in which case an increase in the mass of firms by $10 \%$ would have a greater than $10 \%$ increase in the number of matches. ${ }^{22}$ By contrast, a congestion externality to search would be indicated by low $\gamma_{S}, \gamma_{B}$ and $\beta_{S}, \beta_{B}$, as more firms entering leads to very few new matches. There are decreasing returns to scale in domestic matching if $\gamma_{S}+\gamma_{B}<1$. A low $\gamma_{S}$ would indicate that congestion is largely on the domestic supplier-side. Whereas, a low $\gamma_{B}$ would indicate that there is high congestion among domestic buyers. It is common in the labor literature to assume a constant returns to scale matching function, as this guarantees a single equilibrium and has some empirical support (Petrongolo and Pissarides, 2001). However, this has not been as extensively tested in firm-to-firm search. In Section 3, I show reduced-form evidence on the relative size of search externalities between markets. In Section 6, I structurally estimate the exponents in a richer version of the simple model

\footnotetext{
${ }^{22}$ Allowing for the matching function to not be constant returns to scale generates a possibility for multiple equilibria (Petrongolo and Pissarides, 2001). For simplicity, I assume that firms obtain an equilibrium with the highest level of search.
} 
to verify reduced-form results and to demonstrate further mechanisms within the model.

The match flow per unit of buyer search $\theta$ is a measure of market tightness and is defined separately in the domestic and international markets, given by

$$
\theta_{D}=\frac{S^{\gamma_{S}} B_{D}^{\gamma_{B}}}{B_{D}} \quad \theta_{I}=\frac{S^{\beta_{S}} B_{I}^{\beta_{B}}}{B_{I}}
$$

A higher value of $\theta$ simply indicates that the hazard-rate of finding a match is higher.

\subsection{Optimal SeArCh}

Buyers solve a maximization problem by picking an optimal search intensity in the domestic market $a$ to maximize profits

$$
\max _{a}\left\{a \sigma \theta_{D} \Lambda \pi\left(s_{D}\right)+(1-a) \sigma \theta_{I} \Lambda \pi\left(s_{I}\right)-k(a)\right\}
$$

where $a \sigma \theta_{D}$ and $(1-a) \sigma \theta_{I}$ are the endogenous hazard rates of making a domestic and international match, respectively. $k$ is a convex search cost on the amount that buyers search in each market such that $\frac{\partial^{2} k}{\partial a^{2}}>0$ and $k$ is minimized at $a=\frac{1}{2} \cdot{ }^{23}$ The rationale for this assumption is that it is relatively easy to undertake a light search in either market by, for instance, browsing the internet. However, undertaking a comprehensive search might involve travel or hiring a consultant, which would increase costs rapidly.

Taking the first order condition of Equation 8 yields a policy function which determines the optimal level of domestic search depending on the relative market tightness, the difference in profit from a domestic and an international supplier, and the change in search costs.

$$
\sigma \theta_{D} \Lambda \pi\left(s_{D}\right)-\sigma \theta_{I} \Lambda \pi\left(s_{I}\right)-\frac{\partial k}{\partial a}=0
$$

The intuition behind Equation 9 is that the firm wishes to choose their proportion of

\footnotetext{
${ }^{23}$ Picking the minimum point at $\frac{1}{2}$ is based on the assumption that searching equally in both markets is the minimum cost. Changing this to an alternative minimum would not alter results.
} 
domestic search to equate the profit from matching with a domestic supplier multiplied by the probability of a domestic match with the profit from matching with a international supplier multiplied by the probability of a international match.

\subsection{Comparative Statics}

To demonstrate the main search channel in the model, I present comparative statics of how firms respond to a reduction in transportation costs.

\subsubsection{BUYER SEARCH DECISIONS}

The first comparative static shows how the proportion of search intensity in the domestic market changes when international trade costs change. In order to obtain this comparative static, I totally differentiate equation 9 as shown in Appendix C, which yields equation 10.

$$
\begin{aligned}
\frac{\partial a}{\partial \tau_{I}} & =\frac{-\sigma \theta_{I} \Lambda \frac{\partial \pi\left(s_{I}\right)}{\partial \tau_{I}}}{\sigma \frac{\partial \theta_{I}}{\partial a} \Lambda \pi\left(s_{I}\right)-\sigma \frac{\partial \theta_{D}}{\partial a} \Lambda \pi\left(s_{D}\right)+\frac{\partial^{2} k}{\partial a^{2}}} \\
& =\frac{-\sigma \theta_{I} \frac{\partial \Lambda \pi\left(s_{I}\right)}{\partial \tau_{I}}}{\sigma^{2}\left(1-\beta^{B}\right) \theta_{I} B_{I} \Lambda \pi\left(s_{I}\right)+\sigma^{2}\left(1-\gamma^{B}\right) \theta_{D} B_{D} \Lambda \pi\left(s_{D}\right)+\frac{\partial^{2} k}{\partial a^{2}}}
\end{aligned}
$$

For the purposes of exposition, I discuss the case of a fall in transport costs to match the case study of Uganda. The numerator of equation 10 shows the direct effect of a change in trade costs; when trade costs decrease, the proportion of domestic search $(a)$ falls as returns to importing increases.

This is mitigated by two main forces. First, as firms increase import search, the international market becomes tighter driven by international congestion $\frac{\partial \theta_{I}}{\partial a}$. Second, as firms move out of the domestic market, domestic market-tightness decreases $\frac{\partial \theta_{D}}{\partial a}$. Together, these forces reduce the amount of reallocation towards imports following the international trade cost reduction. ${ }^{24}$

To reinforce the idea, consider a positive search externality in the international market

\footnotetext{
${ }^{24} \mathrm{In}$ addition to these two forces there is a third force coming from the convexity of the search costs
} 
( $\beta_{B}$ is large). Assuming that $\beta_{B}<1$, then each additional buyer entering the international market reduces the probability of other firms matching, but only by a small amount. Therefore, a substantial volume of buyers can be absorbed by the international market before market-tightness increases sufficiently to stop this flow.

If $\beta_{B}>1$, then each additional buyer joining the international market actually increases the chance of existing buyers matching. Even in this case, the model predicts that not all firms will search internationally, as buyers have convex search costs and there would be a reduction in market-tightness in the domestic market, as discussed below.

If there is a negative externality in the domestic market then $\gamma$ would be small. When buyers leave the domestic market, this causes a large reduction in market tightness in the domestic market. Consequently, it becomes easier for firms to match domestically, causing a smaller reallocation towards imports following the trade cost reduction.

\subsubsection{Consumer Welfare and Matching Efficiency}

The second comparative static concerns consumer welfare. Given all buyers are ex-ante identical, I can rewrite consumer welfare as the consumption from each buyer $(C)$ multiplied by the matching probability of each type $(A)$. $A$ is made up of the probability of a domestic match $\left(a \sigma \theta_{D}\right)$ plus the probability of an international match $\left((1-a) \sigma \theta_{I}\right)$ multiplied by the international match demand shifter $\psi_{I}$.

$$
\begin{aligned}
W(a) & =\left[\int_{b \in B\left(s_{I}\right)} \psi_{I} C_{b}^{\frac{\eta-1}{\eta}}+\int_{b \in B\left(s_{D}\right)} C_{b}^{\frac{\eta-1}{\eta}}\right]^{\frac{\eta}{\eta-1}} \\
& =\underbrace{\left[a \sigma \theta_{D}+I_{I}(1-a) \sigma \theta_{I}\right]}_{A} \underbrace{\left[\int_{b \in B} C_{b}^{\frac{\eta-1}{\eta}}\right]^{\frac{\eta}{\eta-1}}}_{C}
\end{aligned}
$$

The impact on welfare is therefore split into two parts. The first part is due to a reduction in trade costs leading to higher consumption acting through lower marginal costs $\frac{\partial C}{\partial \tau_{I}}<0$. Meanwhile, the second part considers how the matching probability changes as trade costs change $\frac{\partial A}{\partial \tau_{I}}$. As shown in Appendix C.1.2, the change in welfare from matching 
following a fall in trade costs will be greater than zero if and only if the inequality in equation 12 holds.

$$
\frac{\partial A}{\partial \tau_{I}}<0 \Longleftrightarrow a^{\gamma_{B}-1}<(1-a)^{\beta_{B}-1} \psi_{I} S^{\beta_{S}-\gamma_{S}} B^{\beta_{B}-\gamma_{B}} \frac{\beta_{B}}{\gamma_{B}}
$$

Equation 12 shows that for sufficiently large $a$ and $\psi_{I} \geq 1$, the change in welfare due to matching depends on the relative size of the matching exponents. If $\gamma_{B}<\beta_{B}$ and $\gamma_{S}<\beta_{S}$ then the returns to search are higher in the international market. Consequently, a fall in trade cost will increase welfare, given firms will move from matching in the decreasing returns to scale domestic market to the increasing returns to scale international market. The intuition for this result is that a reallocation of search leads to more matches for the same search intensity. Given consumers have a taste-for-variety, this generates an increase in consumer welfare. ${ }^{25}$

In summary, following a fall in trade costs, both the level of reallocation between markets and the degree to which consumer welfare increases depend on the relative size of search externalities in domestic and international markets.

\section{A Quantitative Model of Buyer-Supplier Search in Two MARKETS}

I now extend the simple framework to build a full dynamic quantitative model of optimal search among heterogeneous buyers and suppliers. This is done for three reasons. First, the structurally estimated parameters substantiate the reduced-form findings using a dif-

\footnotetext{
${ }^{25}$ An alternative consideration is to compare welfare in the decentralized market economy to the level of welfare should a social planner pick the optimal level of search in the presence of search frictions. This is similar to the Hosios (1990) condition, which shows in a wide array of search models that the socially optimal level of search occurs when buyers' share of the joint match surplus equals the elasticity of the matching function with respect to buyers (Mangin and Julien, 2018). However, the model does not fall into this class of models given the matching function is not constant returns to scale and there are two search markets.
} 
ferent yet complementary methodology. ${ }^{26}$ Second, the structural model elucidates key mechanisms in how firms in Uganda respond to the international trade cost reduction. Third, it provides a quantitative estimate of the role of search externalities in welfare relative to a counterfactual experiment where I shut down this channel.

The simple model presented in Section 4 highlights the key mechanism, but misses a number of salient features in the data. The full model builds on the dynamic empirical model developed by Eaton, Jinkins, Tybout and Xu (2016), adding international and domestic suppliers, and different search costs and matching functions.

There are three main extensions to the simple model. First, the model is made dynamic to allow firms to make multiple matches over time. Second, the model includes both buyer and seller search to capture both sides of the market. Third, the model incorporates buyer heterogeneity to match the observation that only a subset of the most productive firms in Uganda import.

In order to minimize repetition, the next subsection lays out the extensions to the simple model. Alternatively, Appendix B includes a full treatment of the model.

\subsection{Buyers, Suppliers And Consumers}

Firm heterogeneity is introduced by assuming there are $\Gamma$ buyer types indexed $i \in$ $\{1,2, \ldots, \Gamma\}$ with marginal cost $c_{i}$ drawn from a known distribution, and match with $\mathbf{s}=\left\{s_{I}, s_{D}\right\}$ suppliers. Buyer types are denoted by $i$.

To rationalise firms stocking multiple goods, consumers have a nested CES utility function which shows their taste-for-variety over buyers $(b)$ and products $(x)$, such that

$$
C=\left[\int_{b \in B} C_{b}^{\frac{\eta-1}{\eta}}\right]^{\frac{\eta}{\eta-1}}
$$

\footnotetext{
${ }^{26}$ The reduced-form methodology has the advantage of being clearer where the estimated coefficients come from. However, in this paper the reduced-form structure is restrictive and one might expect that there are multiple channels for search externalities to pass which are not picked up by the reduced-form. I therefore turn to a structural model which allows a more clearly model-driven pass through of externalities and has the large advantage of allowing the consideration of policy counterfactuals.
} 


$$
C_{b}=\left[\sum_{x \in J\left(s_{I}\right)_{b}}\left(\psi_{I} C_{b}^{x}\right)^{\frac{\alpha-1}{\alpha}}+\sum_{x \in J\left(s_{D}\right)_{b}}\left(C_{b}^{x}\right)^{\frac{\alpha-1}{\alpha}}\right]^{\frac{\alpha}{\alpha-1}},
$$

where $J\left(s_{I}\right)_{b}$ is the set of international products $x$ offered by buyer $b$ and $J\left(s_{D}\right)_{b}$ is the set of domestic products $x$ offered by buyer $b, C_{b}^{x}$ is consumption of product $x$ from buyer $b$, and $C_{b}$ is consumption of the set of products offered by $b . \eta$ and $\alpha$ are the elasticities of substitution among products and buyers, respectively.

\subsection{Pricing and Division of Profits}

As buyers now match with multiple suppliers, they sell multiple goods. They, therefore, internalize the price set on one good on the demand of their other goods. This yields a first order condition on prices given by

$$
q_{x b}+\sum_{x^{\prime} \in J_{b}} \frac{\partial q_{x^{\prime} b}}{\partial p_{x b}}\left(p_{x^{\prime} b}-c_{x^{\prime} b}\right)=0 \quad \forall x \in J_{b}
$$

where $c_{x^{\prime} b}$ is the marginal cost of supplying product $x^{\prime}$ to consumers through buyer $b$.

The instantaneous profit flow created by buyer $b$ and its set of suppliers is now given by a summation over the profit provided by each product $x$ in buyer $b$ 's bundle $\left(J_{b}\right)$, such that

$$
\left.\pi_{b}(\mathbf{s})=\frac{E}{\eta P^{1-\eta}}\left[\sum_{x \in J_{b}} \frac{\eta}{\eta-1}\right)^{1-\alpha} \tau_{L} \tilde{c}_{b}^{1-\alpha}\right]^{\frac{1-\eta}{1-\alpha}}
$$

for $L \in\{D, I\}$ and where $\tilde{c}_{b}=c_{b} / \psi_{L}$ is the quality-adjusted marginal cost, $\mathbf{s}=\left\{s_{I}, s_{D}\right\}$ is a vector of the number of international and domestic suppliers. ${ }^{27}$ If the buyer matches with a domestic supplier then $\tau_{D}=\psi_{D}=1$. For higher international trade $\operatorname{costs}\left(\tau_{I}\right)$ or smaller international demand shifter $\left(\psi_{I}\right)$ profits from matching with an international supplier are smaller.

\footnotetext{
${ }^{27}$ As long as $\alpha>\eta>1$, then the profit function is increasing in the aggregate price index and decreasing in marginal cost. This condition also ensures that there are diminishing returns to the number of suppliers, given that adding a new supplier appears in the summation $x \in J_{b}$ which leads to an increase in profit but at a decreasing rate, as long as the exponent $\frac{1-\eta}{1-\alpha}<1$. In this way profit depends on the number of suppliers, however, this is not to be confused with diminishing returns to scale in the matching function discussed in Section 5.3.
} 
As buyers now have multiple suppliers, division of profits becomes more complex. I assume Stole and Zwiebel (1996) bargaining which gives each seller a profit flow $z_{j i}$ equal to their bargaining share multiplied by their marginal contribution to profit which depends on whether the good is domestic or international $L \in\{D, L\} .^{28}$

$$
\begin{aligned}
z_{j i}(\mathbf{s}) & =\Lambda \frac{\partial \pi_{i}^{T}(\mathbf{s})}{\partial s_{L}} \\
& \left.=\frac{\Lambda}{\alpha-1} \frac{\eta}{\eta-1}\right)^{-\eta} \frac{E}{P^{1-\eta}}\left[\sum_{j \in J_{b}} \tau_{L} \tilde{c}_{i}^{1-\alpha}\right]^{\frac{\alpha-\eta}{1-\alpha}} \tau_{L} \tilde{c}_{i}^{1-\alpha}
\end{aligned}
$$

Equation 17 is very close to being a structural equation which would be estimatable in the data, therefore allowing the recovery of key parameters. However, the seller's profit $z_{j i}$ is not observable in the data. Instead, the data shows a firm-to-firm transaction which includes both profit and compensation for marginal costs in production of each good. If a constant fraction $\lambda$ of the variable costs is attributable to the seller, ${ }^{29}$ then the revenue transfer can be expressed between firms $r_{j i}$ in terms of fixed effects and observables

$$
\left.\left.r_{j i}(\mathbf{s})=\left(h_{j \mid i}\right)^{\frac{\alpha-\eta}{\alpha-1}} \frac{E}{P^{1-\eta}} \frac{\eta}{\eta-1}\right)^{-\eta} \tau_{L} \tilde{c}_{j i}\right)^{1-\eta}\left[\frac{B}{\alpha-1}+\lambda\right],
$$

where $r_{j i}$ is the revenue for seller $j$ from buyer $i, h_{j \mid i}=\frac{\tau_{L} \tilde{c}_{j}^{1-\alpha}}{\sum_{l=1}^{J} s_{l} \tau_{L} \tilde{c}_{i}^{1-\alpha}}$ is the within buyer- $i$ revenue share of a type- $j$ seller, $\lambda$ is the seller's fraction of marginal cost. Equation 18 is a structural equation which I estimate from the data in order to obtain elasticity of substitution parameters $\eta$.

\subsection{SEARCH AND Matching}

Relative to the simple model, modelling search-and-matching is made more complex by the addition of a search intensity choice for buyers and suppliers $\left(\sigma^{B}, \sigma^{S}\right.$ respectively) and

\footnotetext{
${ }^{28}$ Stole and Zwiebel (1996) is a generalization of Rubinstein bargaining to multiple firms based on Shapley value which gives firms a constant fraction of revenue

${ }^{29}$ This assumption only influences the estimation of the structural equation for the purpose of extracting the elasticity of substitution parameters. In all other aspects I consider the buyer and supplier to be jointly maximising profits.
} 
given that buyers have a choice on the proportion of search done domestically $(a){ }^{30}$

A type $=i$ firm's visibility $(H)$ in domestic and international markets is given respectively as

$$
\begin{aligned}
& H_{i, D}^{B}(\mathbf{s})=a_{i}(\mathbf{s}) \sigma_{i}^{B}(\mathbf{s}) M_{i}^{B}(\mathbf{s}) \\
& H_{i, I}^{B}(\mathbf{s})=\left(1-a_{i}(\mathbf{s})\right) \sigma_{i}^{B}(\mathbf{s}) M_{i}^{B}(\mathbf{s}),
\end{aligned}
$$

where $M_{i}^{B}\left(s_{D}, s_{I}\right)$ is a measure of type- $i$ buyers with s sellers. Intuitively, buyers of type- $i$ are more visible if they are searching more $\left(a_{i} \sigma_{i},\left(1-a_{i}\right) \sigma_{i}\right)$ and if there is a larger mass of them $\left(M_{i}^{B}\right)$.

The overall visibility of buyers in the domestic and international market is a summation over all buyer types and for any number of existing matches.

$$
H_{L}^{B}=\sum_{i=1}^{I} \sum_{s_{L}=0}^{s_{L_{\max }}} H_{i, L}^{B}(\mathbf{s}) \text { for } L \in\{D, I\}
$$

Domestic and international sellers' visibility $\left(H_{D}^{S}, H_{I}^{S}\right)$ are defined symmetrically to buyers

$$
\begin{aligned}
& H_{D}^{S}(n)=\sigma_{D}^{S}(n) M_{D}^{S}(n) \\
& H_{I}^{S}(n)=\sigma_{I}^{S}(n) M_{I}^{S}(n) .
\end{aligned}
$$

The matching function is similar to the simple model, but is now increasing in buyer and seller visibility

$$
\begin{aligned}
& X_{D}\left(H_{D}^{S}, H_{D}^{B}\right)=\left(H_{D}^{B}\right)^{\gamma_{B}}\left(H_{D}^{S}\right)^{\gamma_{S}} \\
& X_{I}\left(H_{I}^{S}, H_{I}^{B}\right)=\left(H_{I}^{B}\right)^{\beta_{B}}\left(H_{I}^{S}\right)^{\beta_{S}} .
\end{aligned}
$$

As in the simple model discussed in Section 4.3, the matching function exponents are key objects in the model. A positive externality to search would be indicated by high

\footnotetext{
${ }^{30}$ Where as in the simple model $a \in[0,1]$ and the amount of search internationally is $1-a$.
} 
$\gamma_{S}, \gamma_{B}$ and $\beta_{S}, \beta_{B}$

The match flow per unit of buyer visibility $\theta$ is a measure of market tightness and is defined separately in the domestic and international markets, given by

$$
\theta_{D}=\frac{X_{D}\left(H_{D}^{S}, H_{D}^{B}\right)}{H_{D}^{B}} \quad \theta_{I}=\frac{X_{I}\left(H_{I}^{S}, H_{I}^{B}\right)}{H_{D}^{B}} .
$$

A higher value of $\theta$ simply indicates that the hazard-rate of finding a match is higher. ${ }^{31}$

\subsection{Search Cost}

In order to make sure that buyers do not enter a sorting equilibrium of only searching domestically or internationally, I assume positive and convex search $\operatorname{costs}^{32}$ with a fixed cost of international search $F_{I}$ only paid if the firm chooses to search internationally.

$$
k^{B}=\left(\left(a \sigma^{B}\right)^{v}+\left((1-a) \sigma^{B}\right)^{v}\right)^{v}+F_{I}, \quad v>1
$$

I structurally estimate $F_{I}$ in Section 6 .

Sellers have a parallel set of search costs which are convex in the seller search intensity

$$
k_{L}^{S}=\left(\sigma^{S}\right)^{v}, \quad \text { for } L \in\{D, I\} \text { and } v>1 \text {, }
$$

which for simplicity are assumed to be the same for domestic and international suppliers.

\footnotetext{
${ }^{31} \theta_{S_{L}}$ is defined symmetrically for $L \in\{D, I\}$ type suppliers.

${ }^{32}$ See Section 4.4 for further justification of this assumption.
} 


\subsection{Optimal Search}

Buyers solve the following maximization problem by picking their optimal search intensity $\sigma$ and the proportion of that search intensity in the domestic market $a$

$$
\begin{aligned}
& V_{i}^{B}(\mathbf{s})= \\
& \max _{a, \sigma^{B}}\left\{\frac{\pi_{i}^{B}(\mathbf{s})-k^{B}\left(a_{i}, \sigma_{i}^{B}\right)+s_{D} \delta V_{i}^{B}\left(s_{D}-1\right)+a \sigma^{B} \theta_{D}^{B} V_{i}^{B}\left(s_{D}+1\right)+s_{I} \delta V_{i}^{B}\left(s_{I}-1\right)+(1-a) \sigma^{B} \theta_{I}^{B} V_{i}^{B}\left(s_{I}+1\right)}{\rho+s_{D} \delta+s_{I} \delta+a \sigma^{B} \theta_{D}^{B}+(1-a) \sigma^{B} \theta_{I}^{B}}\right\},
\end{aligned}
$$

where $V_{i}^{B}(\mathbf{s})$ is the present value of a type- $i$ buyer that is matches with vector $\mathbf{s} \in$ $\left\{s_{I}, s_{D}\right\}$ sellers, $\rho$ time preferences, $\delta$ is an exogenously given link death parameter.

Buyers receive profit equal to gross profit minus search costs, $\left(\pi_{i}^{B}(\mathbf{s})-k^{B}\left(a_{i}, \sigma_{i}^{B}\right)\right)$, until one of four events occurs with an endogenously given hazard: either (i) a buyer drops a domestic supplier $\left(V_{i}^{B}\left(s_{D}-1\right)\right)$, (ii) adds a domestic supplier $\left(V_{i}^{B}\left(s_{D}+1\right)\right)$, (iii) drops an international supplier $\left(V_{i}^{B}\left(s_{I}-1\right)\right)$, or (iv) adds an international supplier $\left(V_{i}^{B}\left(s_{D}+1\right)\right)$.

This yields policy functions for optimal search and the proportion of search in the domestic market where the change in cost of search is equal to the change in the value function from adding an additional domestic or international supplier multiplied by the hazard of these events occurring

$$
\begin{aligned}
& \frac{\partial k^{B}\left(\sigma^{B}, a\right)}{\partial \sigma^{B}} \leq a \theta_{D}^{B} \Delta_{s_{D}} V_{i}^{B}+(1-a) \theta_{I}^{B} \Delta_{s_{I}} V_{i}^{B} \\
& \frac{\partial k^{B}\left(\sigma^{B}, a\right)}{\partial a} \leq \sigma^{B} \theta_{D}^{B} \Delta_{s_{D}} V_{i}^{B}-\sigma^{B} \theta_{I}^{B} \Delta_{s_{I}} V_{i}^{B}
\end{aligned}
$$

where $\Delta_{s_{L}} V_{i}^{B}=V_{i}^{B}\left(s_{L}+1\right)-V_{i}^{B}\left(s_{L}\right)$ for $L \in\{D, I\}$. Equation 28 and 29 hold with equality when a firm searches both internationally and domestically $(a<1)$.

Suppliers solve a parallel problem, where the value $V$ to any seller matching with a 
type- $i$ buyer who has s suppliers depends on their type $L$ and is given by

$$
\begin{aligned}
V_{D, i, s}^{S} & =\frac{r_{i}(\mathbf{s})+\left(s_{D}-1\right) \delta V_{D, i, s_{D}-1}^{S}\left(s_{D}-1\right)+a_{i} \sigma_{i}^{B} \theta_{D}^{B} V_{D, i, s_{D}+1}^{S}}{\rho+s_{D} \delta+a_{i} \sigma_{i}^{B}(\mathbf{s}) \theta_{D}^{B}} \\
V_{I, i, s}^{S} & =\frac{r_{i}(\mathbf{s})+\left(s_{I}-1\right) \delta V_{I, i, s_{I}-1}^{S}\left(s_{I}-1\right)+\left(1-a_{i}\right) \sigma_{i}^{B} \theta_{I}^{B} V_{I, i, s_{I}+1}^{S}}{\rho+s_{I} \delta+\left(1-a_{i}\right) \sigma_{i}^{B}(\mathbf{s}) \theta_{I}^{B}}
\end{aligned}
$$

Intuitively, the supplier gets revenue $r_{i}(\mathbf{s})$ as defined in equation 18, until they either lose a match with probability $\left(s_{L}-1\right) \delta$ or gain a match with probability depending on whether the supplier is domestic or international $a_{i} \sigma^{B} \theta_{D}^{B},\left(1-a_{i}\right) \sigma_{i}^{B} \theta_{I}^{B}$. Taking expected value of a match is a summation over buyer types:

$$
V_{L}^{S}=\sum_{i} \sum_{s=0}^{\infty} V_{L, i, s+1}^{S} P_{i}^{B}(\mathbf{s}), \quad \text { for } € \in\{D, I\}
$$

where $P_{i}^{B}(\mathbf{s})=H_{i}^{B}(\mathbf{s}) / H^{B}$ is the share of matches involving buyers of type $-i$ with $\mathbf{s}$ sellers.

Optimal seller search is then given by a parallel set of policy functions

$$
\begin{aligned}
& \frac{\partial k_{D}^{S}\left(\sigma_{D}^{S}, s_{D}\right)}{\partial \sigma_{D}^{S}}=\theta_{D}^{S} V_{D}^{S} \\
& \frac{\partial k_{I}^{S}\left(\sigma_{I}^{S}, s_{I}\right)}{\partial \sigma_{I}^{S}}=\theta_{I}^{S} V_{I}^{S}
\end{aligned}
$$

The optimal level of seller search is, therefore, the expected value of a new relationship multiplied by the probability of a match. 


\subsubsection{EqUILIBRIUM}

The model is completed via an equation of motion, where the change in the mass of buyers with $\mathbf{s}$ sellers is given by,

$$
\begin{aligned}
\dot{M}_{i}^{B}(s)= & {[\underbrace{a_{i} \sigma_{i}^{B} \theta_{D}^{B} M_{i}^{B}\left(s_{D}-1, s_{I}\right)}_{i}+\underbrace{\delta\left(s_{D}+1\right) M_{i}^{B}\left(s_{D}+1, s_{I}\right)}_{i i}+\underbrace{\left(1-a_{i}\right) \sigma_{i}^{B} \theta_{I}^{B} M_{i}^{B}\left(s_{D}, s_{I}-1\right)}_{i i i}} \\
& +\underbrace{\delta\left(s_{I}+1\right) M_{i}^{B}\left(s_{I}+1, s_{D}\right)}_{i v}]-[\underbrace{a_{i} \sigma_{i}^{B} \theta_{D}^{B}}_{v}+\underbrace{\delta s_{D}}_{v i}+\underbrace{\left(1-a_{i}\right) \sigma_{i}^{B} \theta_{I}^{B}}_{v i i}+\underbrace{\delta s_{I}}_{v i i i}] M_{i}^{B}\left(s_{D}, s_{I}\right) .
\end{aligned}
$$

Equation 34 shows the change in mass of type- $i$ buyers with $\mathbf{s}$ sellers is equal to flows in $(i+i i+i i i+i v)$ minus flows out $(v+v i+v i i+v i i i)$. Flows in is made up of the mass of type $-i$ buyers who have: $(i) s_{D}-1$ suppliers multiplied by the probability of adding a domestic supplier; $(i i) s_{D}+1$ suppliers multiplied by the probability of losing a domestic supplier; (iii) $s_{I}-1$ suppliers multiplied by the probability of adding a international supplier; $(i v)$ $s_{I}+1$ suppliers multiplied by the probability of losing a international supplier. Flows out is made up of the mass of type- $i$ buyers who have s suppliers multiplied by the probability of: $(v)$ adding a domestic supplier; (vi) losing a domestic supplier; (vii) adding a international supplier; (viii) losing a international supplier. Finally, the measure of buyers of type $-i$ with $s_{L}=0$ is given by

$$
\begin{array}{r}
\dot{M}_{i}^{B}\left(0, s_{I}\right)=\left[\delta M_{i}^{B}\left(1, s_{I}\right)+\left(1-a_{i}\right) \sigma_{i}^{B} \theta_{I}^{B} M_{i}^{B}\left(0, s_{I}-1\right)+\delta\left(s_{I}+1\right) M_{i}^{B}\left(0, s_{I}\right)\right] \\
-\left[a_{i} \sigma_{i}^{B} \theta_{D}^{B}+\left(1-a_{i}\right) \sigma_{i}^{B} \theta_{I}^{B}+\delta s_{I}\right] M_{i}^{B}\left(0, s_{I}\right) . \\
\dot{M}_{i}^{B}\left(s_{D}, 0\right)=\left[\delta M_{i}^{B}\left(s_{D}, 0\right)+a_{i} \sigma_{i}^{B} \theta_{D}^{B} M_{i}^{B}\left(s_{D}-1,0\right)+\delta\left(s_{D}+1\right) M_{i}^{B}\left(s_{D}, 0\right)\right] \\
-\left[\left(1-a_{i}\right) \sigma_{i}^{B} \theta_{I}^{B}+a_{i} \sigma_{i}^{B} \theta_{D}^{B}+\delta s_{D}\right] M_{i}^{B}\left(s_{D}, 0\right) .
\end{array}
$$


A symmetric set of equations exists for suppliers.

I look for a stationary equilibrium at the steady state, I set $\dot{M}_{i}^{B}(s)=\dot{M}_{j}^{S}(n)=0$ and solve the system of equations for all buyer types and suppliers given in equations 34, 35 and 36. I treat each buyer type as exogenously given.

\section{Estimation}

Model estimation takes place in three steps: 1) Estimating the transfer equation to obtain elasticity of substitution parameters; 2) Externally calibrating parameters using the literature, and; 3) Structurally estimating the model using simulated method of moments.

\subsection{Estimating TRANSFER EQUATION}

I estimate a transfer equation between buyers and suppliers in order to identify the elasticities of substitution between buyers. I estimate the structural equation 18 via Ordinary Least Squares (OLS). Equation 18 relates the revenue passed between buyers and suppliers $\left(r_{j i}\right)$ to the within buyer $-i$ revenue share of seller $j$. When taking logs and adding time dummies $\left(d_{t}\right)$ and a stochastic noise parameter $(\epsilon)$, I can recover the coefficient on $\ln h_{j \mid i}$ which incorporates the elasticity of substitution between products $(\alpha)$ and elasticity of substitution across buyers $(\eta)$

$$
\ln r_{j i}(\mathbf{s})=\frac{\eta-1}{\alpha-1} \ln h_{j \mid i}+1-\eta \ln \tilde{c}_{j i}+d_{t}+\epsilon_{j i t}
$$

where $r_{j i}$ is the revenue passed from buyer $i$ to supplier $j$ and $h_{j \mid i}$ is the within buyer- $i$ revenue share of seller $j .^{33}$

In order to address the term $\ln \tilde{c}_{j i}$, I include different fixed effects options. I address the concern that there is comovement in $\ln h_{j \mid i}$ and $\ln r_{j i}$, not driven by the components of the model, by using an instrument for $\ln h_{j \mid i}$ which is equal to a share-weighted average of the number of buyers of the other sellers at buyer $j$. The instrument should be correlated

\footnotetext{
${ }^{33}$ This is the same methodology as used in Eaton, Jinkins, Tybout and Xu (2016).
} 
TABLE 4: Estimating the transfer equation

\begin{tabular}{lccc}
\hline \hline & $(1)$ & $(2)$ & $(3)$ \\
& OLS-FE & IV-FE & OLS-FE \\
\hline $\ln h_{j \mid i, t}$ & $0.882^{* * *}$ & $0.910^{* * *}$ & \\
& $(0.0360)$ & $(0.0411)$ & \\
$\ln n_{i t}$ & & & $-0.275^{* * *}$ \\
& & & $(0.0369)$ \\
\hline Match FE & yes & yes & no \\
Buyer FE & no & no & yes \\
Importer FE & no & no & yes \\
Year FE & yes & yes & yes \\
$\mathrm{N}$ & 34016 & 34016 & 34016 \\
\hline \hline
\end{tabular}

Notes: Unit of observation is buyer $i$ supplier $j$ and year $t$. Standard errors in parentheses clustered at the buyer level. ${ }^{*} p<0.1,{ }^{* *} p<0.05,{ }^{* * *} p<0.01$

with $h$ through common shocks for similar products but should not influence revenue through any other channel.

I also run a separate model where I assume that all suppliers are identical except in allowing fixed effects to differ between import and domestic suppliers. In this case, I include just the log of the number of suppliers as the explanatory variable.

The first result from Table 4 is that the coefficient $\frac{\alpha-\eta}{\alpha-1}<1$. Therefore, I conclude, that the elasticity of substitution across varieties $(\alpha)$ exceeds the elasticity of substitution across buyers $(\eta)$. Therefore, as shown in equation 16, there are decreasing returns to adding new suppliers. ${ }^{34}$ Note that this is not to be confused with returns to scale in the matching function, which I estimate within the model. In column 2 of Table 4, I adopt the IV strategy and observe that the estimate increases but remains below 1 .

Finally in column 3, I estimate the transfer equation including the broadest array of fixed effects (buyer, supplier, year). Intuitively, for a given buyer adding another supplier lowers the revenue transferred to all other suppliers. As shown in Appendix equation C.11, the coefficient on $\ln n$ is equal to $-\frac{\alpha-\eta}{\alpha-1}$. Therefore, the coefficients across all specifications

\footnotetext{
${ }^{34}$ As discussed after equation 16, this condition ensures that there are diminishing returns to the number of suppliers, given that adding a new supplier appears in the summation $x \in J_{b}$ which leads to an increase in profit but at a decreasing rate, as long as the exponent $\frac{1-\eta}{1-\alpha}<1$.
} 
TABle 5: Model Parameters

\begin{tabular}{|c|c|c|c|c|}
\hline & Externally Calibrated Parameter & Value & & Data source \\
\hline$\alpha$ & Elasticity of sub. products & 4.35 & & Eaton et al. (2016) \\
\hline$\eta$ & Elasticity of sub. buyers & 3.45 & & Estimated in transfer equation \\
\hline$\Lambda$ & Bargaining coefficient & 0.5 & & Eaton et al. (2016) \\
\hline$v$ & Convexity of search cost & 2 & & Eaton et al. (2016) \\
\hline$\delta$ & Death parameter & 0.4 & & Calculated in data \\
\hline$\tau$ & Iceberg trade cost & 1.45 & & Atkeson and Burstein (2008) \\
\hline$\kappa$ & Pareto shape parameter & 1.45 & & Melitz and Redding (2015) \\
\hline$\rho$ & Time preference & 0.05 & & Eaton et al. (2016) \\
\hline & Internally Calibrated Parameter & Value & & Most important moment \\
\hline$I$ & Import premium & 1.14 & $(0.080)$ & Ratio of imports to domestic among importers \\
\hline$F$ & International fixed cost & 0.26 & $(0.027)$ & Prop of firms import \\
\hline$\gamma_{B}$ & D buyer matching $\mathrm{CD}$ share & 0.49 & $(0.025)$ & Prob. of a new match for dom. buyer \\
\hline$\gamma_{S}$ & D supplier matching CD share & 0.46 & $(0.045)$ & Prob. of a new match for dom. supplier \\
\hline$\beta_{B}$ & I buyer matching CD share & 0.56 & $(0.049)$ & Prob. of a new match for imp. buyer \\
\hline$\beta_{S}$ & I supplier matching CD share & 0.70 & $(0.052)$ & Prob. of a new match for imp. supplier \\
\hline
\end{tabular}

Notes: Standard errors in parentheses calculated via slope method.

are broadly similar. I use the estimate from column 3 as my preferred estimate.

\subsection{EXternally CALIBRATED PARAMETERS}

There are 8 parameters that are externally calibrated. The elasticity of substitution with respect to products $\alpha$ is set to 4.35 as in Eaton, Jinkins, Tybout and Xu (2016) and as estimated in Hottman et al. (2016). Using $\alpha=4.35$, I can infer from column 3 of Table 4 that $\eta=3.45 .{ }^{35}$ Firms' productivities are assumed to be Pareto distributed with shape parameter $\kappa=4.25$ following Melitz and Redding (2015). The remaining parameters are adopted from the literature and are displayed in Table 5.

\subsection{INTERNALLY CALIBRATED PARAMETERS}

I structurally estimate 6 key parameters of the model $\left(\xi=\left\{F, \psi_{I}, \gamma^{S}, \gamma^{B}, \beta^{S}, \beta^{B}\right\}\right)$ using Simulated Method of Moments (SMM). This method selects the model parameters to minimize the difference between the simulated model generated moments and the moments in the data, by minimizing the following objective function

\footnotetext{
${ }^{35}$ This is very similar to the value estimated Eaton, Jinkins, Tybout and Xu (2016). using Colombian data finding a coefficient of -0.382 for rubber products and -0.289 for textiles. They take a middle point of these estimates to obtain -0.3 which works out as an et $a=3.35$
} 
TABle 6: Model fit

\begin{tabular}{lrr}
\hline \hline Moment & Model Value & Data Value \\
\hline Ratio of imports to domestic among importers & 0.59 & 0.59 \\
Proportion of firms which import & 0.20 & 0.21 \\
Mass of international suppliers & 0.30 & 0.21 \\
Mass of domestic suppliers & 0.26 & 0.34 \\
Mass of international buyers & 0.06 & 0.08 \\
Mass of domestic buyer & 0.30 & 0.20 \\
Prob. of a new match for international suppliers & 0.23 & 0.26 \\
Prob. of a new match for domestic supplier & 0.14 & 0.22 \\
Prob. of a new match for international buyer & 0.30 & 0.38 \\
Prob. of a new match for domestic buyer & 0.27 & 0.24 \\
\hline
\end{tabular}

Notes: Table shows model generated moments and corresponding data moments. The ratio of imports to domestic among importers is calculated by dividing the total import value by the total value of inputs (imports + domestic goods). The proportion of firms which import is simply the proportion of buyers which imported in 2010 divided by the total number of buyers. The probability of a new match for an each type of buyer and supplier is calculated by seeing the proportion of firms which add a new match. The number of active firms is calculated as the number of firms in the dataset with positive sales in 2010 and is divided by the total number which are ever active in the dataset.

$$
\hat{\zeta}=\operatorname{argmin}_{\zeta} \mathscr{L}(\zeta)=\operatorname{argmin}_{\zeta} \frac{1}{N}\left[M_{m}(\zeta)-M_{d}\right]^{\prime} W_{N} \frac{1}{N}\left[M_{m}(\zeta)-M_{d}\right]
$$

where $\zeta$ is a vector of moments to be targeted internally, $\mathscr{L}(\zeta)$ quadratic loss function to be minimized, $M_{m}(\zeta)$ vector of model moments, $M_{d}$ vector of corresponding data counterparts of the moments of interest, $M_{m}(\zeta)-M_{d}$ is the orthogonality condition and $W_{N}$ is a positive semi-definite weighting matrix which for simplicity is the identity matrix.

As shown in Table 6, I obtain 10 moments from the data using periods prior to the trade cost reduction. Intuitively, the proportion of buyers which are importers and the ratio of imports to domestic inputs among importers ties down the import premium and the import fixed cost. The mass of active firms ties down the domestic fixed cost. Each of the matching parameters are tied down by the combination of the probability of a new match for their type (domestic, international, buyer, supplier) and also the mass of active buyers and suppliers of their type in the population.

The results are given in Table 5. Importantly, I find that imports have a 1.14 times 
quality premium over domestic goods which is consistent with imported goods being of a higher standard. However, fixed costs of searching for imports are significant and represent approximately a quarter of the average firm's annual import volume.

The most important parameters are the matching coefficients $\gamma$ and $\beta$. Consistent with the reduced form evidence, I find that there are decreasing returns to search in the domestic market $\left(\gamma^{S}+\gamma^{B}<1\right)$. By contrast, there are increasing returns to search in the international market $\left(\beta^{S}+\beta^{B}>1\right)$. In Section 7 , I show numerically that this results in higher consumer welfare following a fall in transport costs.

\subsection{Model Fit}

Table 6 compares the simulated model moments with their data counterparts, highlighting a close fit. The model also does well in matching untargeted moments. For example, as shown in the top two charts of Figure 5, the model's generated mass distribution of buyers with different numbers of domestic and international suppliers closely matches its data counterpart.

However, as shown in the bottom two charts of Figure 5, the model does less well in matching the distribution of supplier with different numbers of buyers. Although the shape of the distribution is similar, the model overestimates the density of suppliers with a small number of buyers. This is because the model has less flexibility on the supplier side relative to the buyer side given I assume all buyers have the same marginal costs. It is also consistent with fit of the quantitative model in Lim (2017) which also underpredicts the extent of connections of the most connected firms.

\subsection{Heterogeneity}

In addition to the model's aggregate predictions, it also demonstrates that firms behave differently depending on their marginal cost. In Figure 6, I group firms into marginal cost bins from 1 to 10 on the x-axis, and show the average level of search for each firm in each bin in international (red) and domestic markets (blue) on the y-axis. Due to 
Figure 5: Model fit: buyer and supplier out-degree
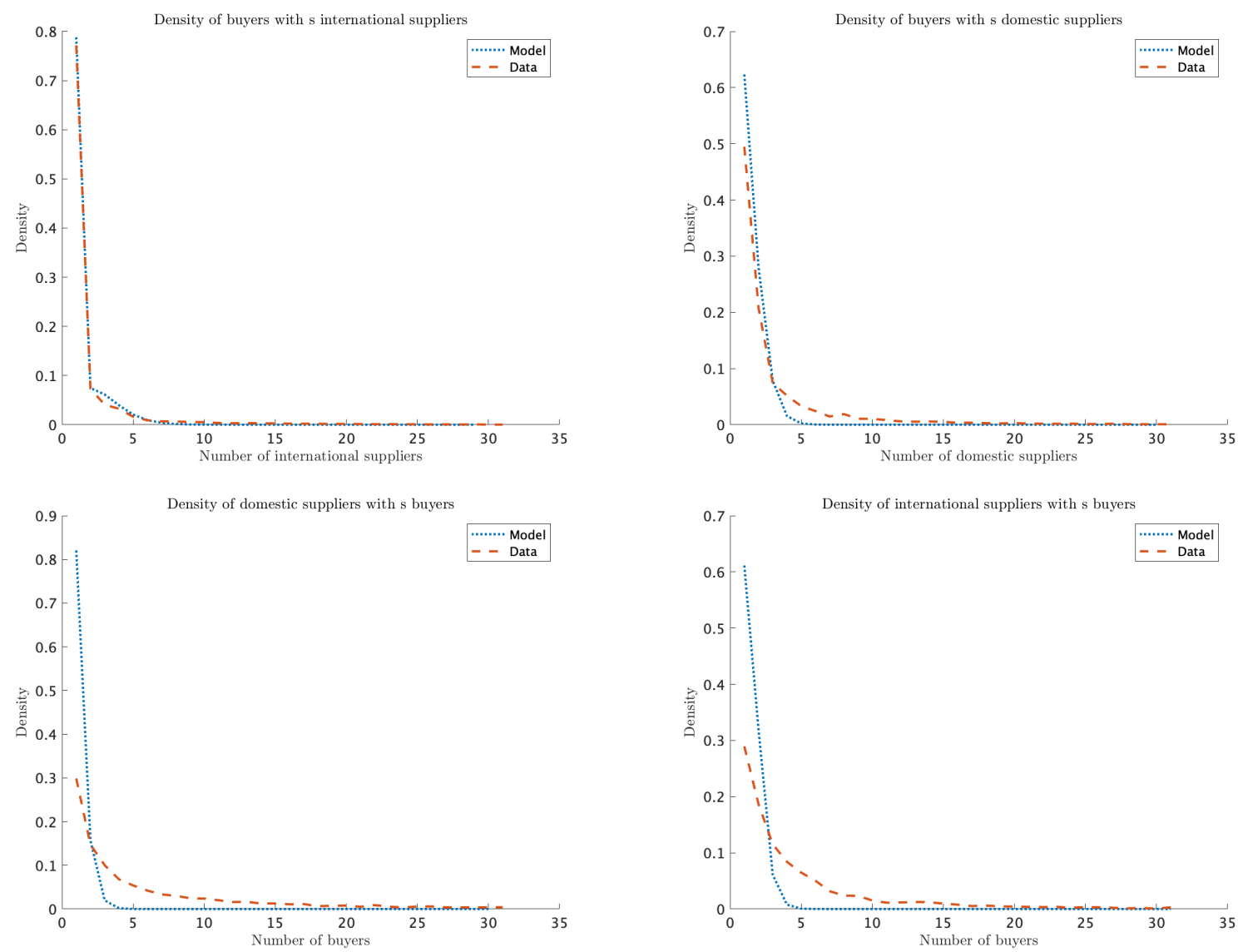

Notes: The top two figures shows the density of buyers with different numbers of international and domestic suppliers, respectively. the bottom two figures shows density of international and domestic suppliers with different numbers buyers. The blue lines show the model predicted density and the orange lines show the true value observed in the data.

the large fixed cost of importing, only the lowest marginal cost firms choose to search internationally. These firms also search domestically due to the convex costs to searching in each market.

Firms just below the threshold of paying the import fixed cost end up spending more on searching in the domestic market than the lower marginal cost firm, causing the peak in domestic search for firms in the second marginal cost bin. This is because, the lower marginal cost firms (in marginal cost group 1) have higher convex search costs given that they search both domestically and internationally. Following this peak, as marginal costs increase, firms spend progressively less on search given the diminishing marginal returns to adding new suppliers is more binding to firms with higher marginal cost. 
Figure 6: Search by marginal cost

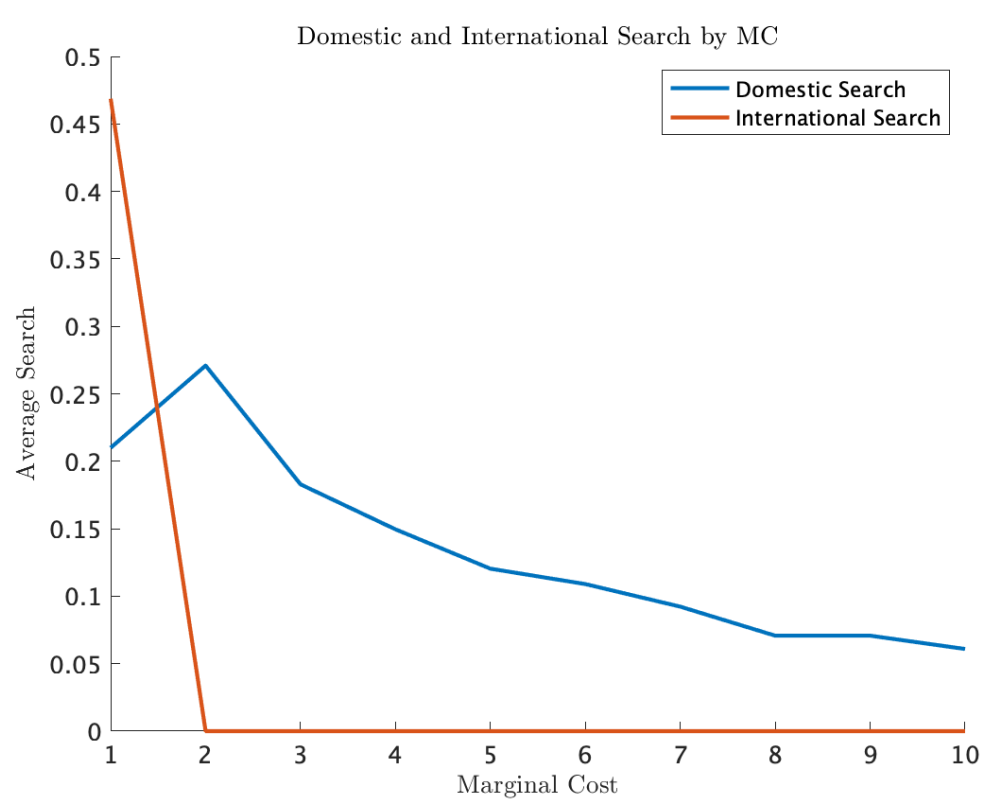

Notes: The x-axis breaks buyers into 10 different marginal cost bins, where 1 indicates the lowest marginal costs and 10 equals the highest marginal costs. The y-axis shows the average search undertaken by buyers in each of these groups. The solid red and blue lines show the amount of domestic and international search, respectively, before the trade cost reduction.

\section{Counterfactual Simulations}

I now test the external validity of the model by simulating a reduction in transport costs to match the observed reduction in East African trade costs shown in Section 2. I then demonstrate the role of search externalities through two counterfactual experiments.

\subsection{Experiment 1: Transport COST REDUCtion Under StRUCturally ESTIMATED PARAMETERS}

As discussed in Section 2, between 2010 and 2011, the cost to import a shipping container into Uganda fell rapidly by $25 \%$ driven by policy at the East African Community level.

Results from simulating this reduction in the model are shown in Table 7. The proportion of firms that import increases from $21.2 \%$ to $24.6 \%$, as it becomes profitable for more firms to pay the fixed cost of importing. The average import search intensity increases by 
TABLE 7: Outcomes from $25 \%$ transport cost reduction

\begin{tabular}{lrrrr}
\hline Outcome & High $\tau$ & Low $\tau$ & Change & Data \\
\hline Percentage of Importers & 21.2 & 24.6 & $16 \%$ & $14 \%$ \\
Av. Foreign Suppliers & 2.10 & 2.37 & $13 \%$ & $16 \%$ \\
Av. Domestic Suppliers & 2.90 & 2.78 & $-4.2 \%$ & $-1.6 \%$ \\
Domestic Search $(a \sigma)$ & 0.12 & 0.11 & $-3.1 \%$ & \\
Import Search $((1-a) \sigma)$ & 0.71 & 0.84 & $19 \%$ & \\
\hline Consumer Welfare & & & $3.7 \%$ & \\
\hline \hline
\end{tabular}

Notes: Table shows the model generated outcome variables under the high and low trade cost equilibriums and the percentage change. This is compared to the observed percentage change in the real data. Average refers to the average number of suppliers over all firms.

$19 \%$ and domestic search intensity decreases by $3 \%$. The large increase in import search translates into a $13 \%$ increase in the average number of foreign suppliers.

The aggregate figures hide important heterogeneity which demonstrates the influence of search externalities. It also maps to the descriptive statistics shown in Section 2 and the comparative statics shown in 4.5. As shown in Figure 7, firms in the second marginal cost group become importers and existing importers increase their search leading to the average number of foreign suppliers increasing from 2.1 to 2.4. As they do this, they are pushed up their convex search cost constraint and so reduce the amount they search domestically (domestic search for marginal cost bin 2 firms decreases from 0.27 to 0.18 ). This then increases market tightness in the international market and reduces market tightness in the domestic market. Consequently, higher marginal cost firms, which do not import, increase their domestic search as the probability of finding a domestic match increases (average search for firms in marginal cost bin 3 increases from 0.18 to 0.21 ).

Table 7 also reports the observed changes in firm outcomes as seen in the Government of Uganda tax data. The observed change is the same direction and of a similar magnitude to that seen in the simulation. The main disparity is in domestic suppliers, where the reduction is overestimated by the model. This is because there was growth in the domestic economy outside of the influence of the trade cost reduction. As the results from the trade cost reduction were not used in the parametrization of the model, the fit to the observed shift provides external validity to the model. 
Figure 7: Search by marginal cost

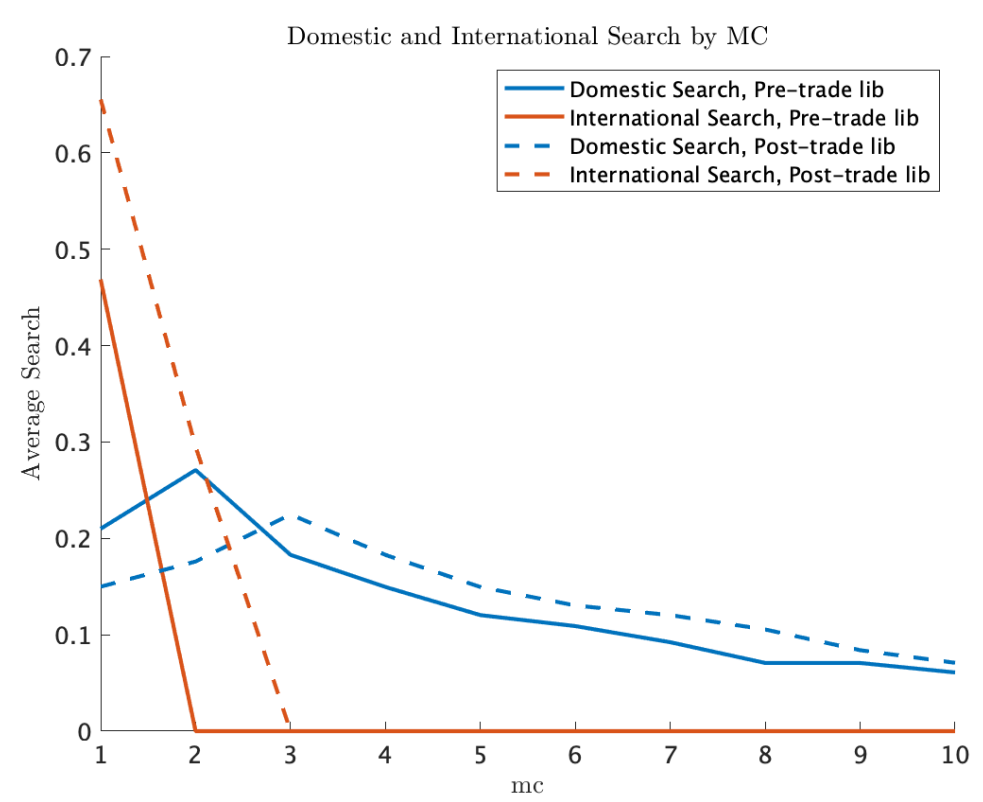

Notes: The x-axis breaks buyers into 10 different marginal cost bins, where 1 indicates the lowest marginal costs and 10 equals the highest marginal costs. The y-axis shows the average search undertaken by buyers in each of these groups. The solid red and blue lines show the amount of domestic and international search, respectively, before the trade cost reduction. The red and blue dashed lines show the amount of domestic and international search, respectively, after the trade cost reduction.

Figures 8 and 9 provide more detail on the change in the distribution of firm size. The trade cost reduction lead to an increase in the number of international suppliers for firms of all sizes.

Finally, the model shows that a $25 \%$ transport cost reduction led to a $3.7 \%$ increase in consumer welfare. As shown in Section 4.5, this is due to: i) the lower marginal cost of importing having an income effect, and ii) the increase in matching efficiency from moving to the increasing returns to scale international market. ${ }^{36}$

\footnotetext{
${ }^{36}$ An extension would consider the short and long-run effects from the intervention. In the short-run, the model predicts that the reallocation of search towards the international market frees up space in the domestic market given domestic suppliers can now re-match. However, in the long-run these firms may no longer be profitable causing firm exit and reversing the gains from a reduction in domestic market tightness. This could be incorporated into the model with a fixed-cost on suppliers.
} 
Figure 8: Mass of firms with $S_{I}$ international suppliers

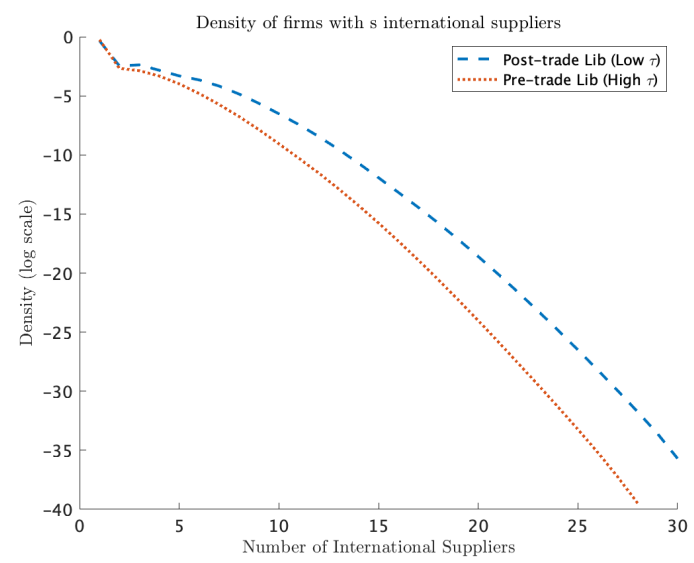

Figure 9: Mass of firms with $S_{D}$ domestic suppliers

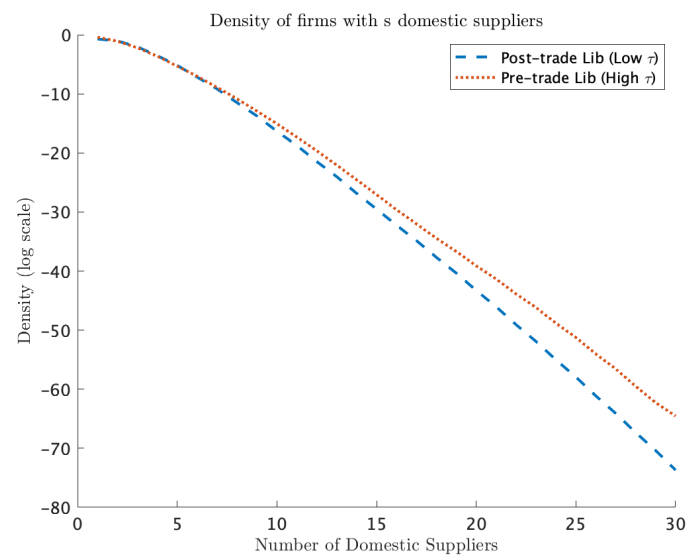

Notes: Figures show model predictions on the density of buyers with different number of suppliers before and after the trade cost fall. the left hand panel shows the density of buyers with $s_{I}$ international suppliers and the right hand panel shows the density of buyers with $s_{D}$ domestic suppliers. The orange line shows the density prior to the trade cost fall and the blue line shows the density after the trade cost fall.

\subsection{EXPERIMENT 2: TrANSPORT COST REDUCTION UNDER CONSTANT RETURNS TO}

\section{SCALE MATCHING FUNCTION}

The second counterfactual experiment tests how much search externalities influence consumer welfare. I shut down the difference in search externalities between markets by assuming that both markets have the same constant returns to scale matching function.

Table 8 compares the results of the second experiment to those with structurally estimated matching parameters. When both matching functions are constant returns to scale, the most obvious difference between the two experiments is the smaller magnitude by which the average number of foreign suppliers increases (9\% vs. 13\%). This is due to the import market becoming tighter, making it relatively harder for firms to match for each unit of search.

Domestic search also decreases in the CRS experiment. This leads to a larger reduction in the average number of domestic suppliers suppliers $(-4.2 \%$ vs. $-6.1 \%)$. This is because the reduction in search domestically does not have the mitigating effect of reducing congestion in the domestic search market.

Figure 10 shows the average number of suppliers for buyers on the y-axis, and different 
TABLE 8: Outcomes from 25\% transport cost reduction under different matching functions

\begin{tabular}{rrrr}
\hline \hline Outcome & Change IRS & Change CRS & Real Change \\
\hline Percentage of Importers & $16 \%$ & $13 \%$ & $16 \%$ \\
Av. Foreign Suppliers & $13 \%$ & $9 \%$ & $16 \%$ \\
Av. Domestic Suppliers & $-4.2 \%$ & $-6.1 \%$ & $-1.6 \%$ \\
Domestic Search $(a \sigma)$ & $-3.1 \%$ & $-4.1 \%$ & \\
Import Search $((1-a) \sigma)$ & $19 \%$ & $16 \%$ & \\
\hline Consumer Welfare & $3.7 \%$ & $3.3 \%$ & \\
\hline \hline
\end{tabular}

Notes: Table shows the change in the model generated outcome variables under the model estimated parameters on the matching function which allow different externalities between both markets (IRS), under the case where the matching function is assumed to be constant returns to scale for both markets (CRS), and the observed change in the data. Average refers to the average number of suppliers over all firms.

trade cost reductions on the x-axis. This is plotted for both the case of different search externalities (IRS) and where both matching functions are constant returns to scale (CRS). Figure 10 shows that for larger trade cost reductions, the difference in the predicted number of suppliers diverges. For a $10 \%$ reduction in transport costs the average number of international suppliers increases by $2.7 \%$ in the increasing returns to scale simulation and $1.8 \%$ in the constant returns to scale model. Whereas for a $25 \%$ reduction in search costs the average number of international suppliers increases by $13 \%$ in the increasing returns to scale simulation and $9 \%$ in the constant returns to scale model, a larger difference. This non-linearity in the model is due to the non-linearity in the two matching function - as more firms switch into the increasing returns to scale sector from the decreasing returns to scale sector there is an increasingly large impact on matching efficiency.

This non-linearity is also shown in Figure 11, where consumer welfare is increasing as trade costs fall, and is increasing more rapidly in the simulation which allows for different externalities. A $25 \%$ reduction in trade costs results in a $12 \%$ larger increase in consumer welfare in the simulation with different search externalities, compared to the simulation with the same externalities in both markets. 
Figure 10: Average number of international and domestic suppliers for different reductions in trade costs when search externalities are shut down (CRS) compared to structurally estimated parameters (IRS)
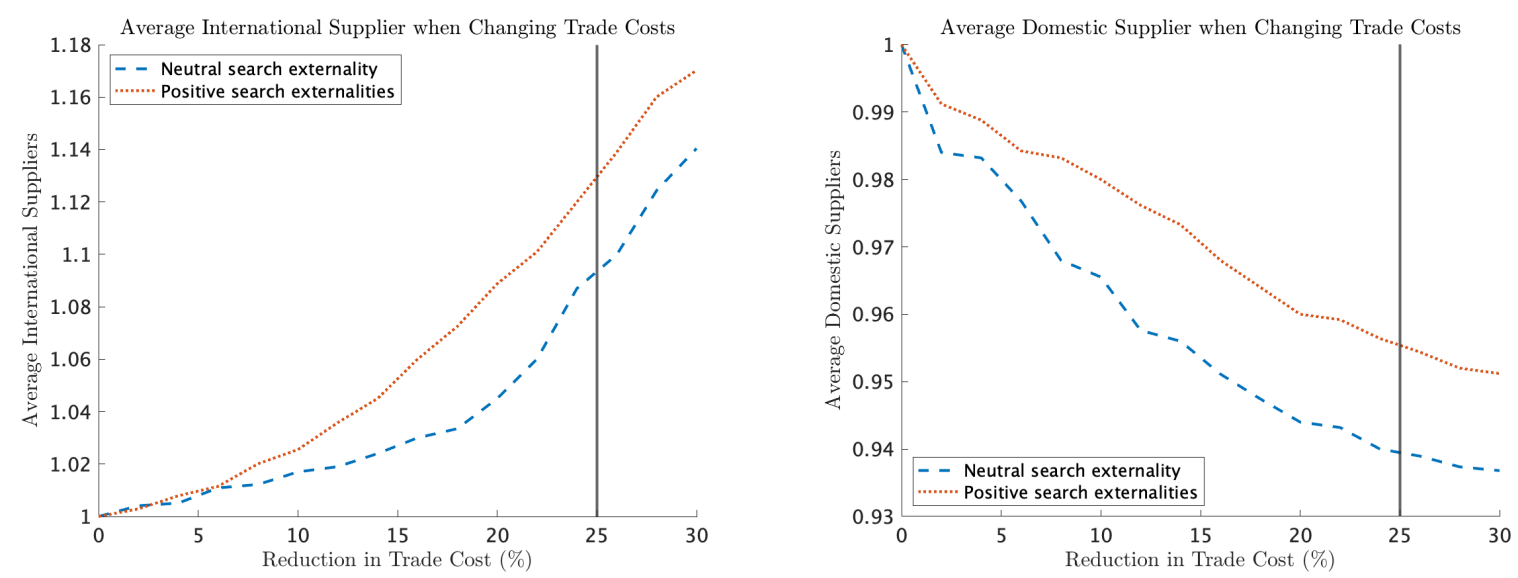

Notes: The y-axis shows the change in the average number of suppliers where the baseline is normalized to 1. The $\mathrm{x}$-axis shows the reduction in trade costs from 0 to $30 \%$. The orange line (IRS) shows the change in the average number of suppliers when the model is estimated using the structurally estimated parameters which allows for increasing returns to scale in matching internationally and decreasing returns to scale in matching domestically. The blue line (CRS) shows the change in the average number of suppliers when the model is estimated shutting down differences in the returns to scale in matching between domestic and international markets.

TABLE 9: Outcomes from 25\% search cost reduction

\begin{tabular}{rrr}
\hline \hline & $\begin{array}{r}\text { Change following 25\% decrease } \\
\text { Outcome }\end{array}$ & $\begin{array}{r}\text { Change following 25\% decrease } \\
\text { in import search costs }\end{array}$ \\
\hline Percentage of Importers & $-0.30 \%$ & $14.4 \%$ \\
Av. Foreign Suppliers & $-0.52 \%$ & $19.1 \%$ \\
Av. Domestic Suppliers & $10.5 \%$ & $-3.50 \%$ \\
Domestic Search $(a \sigma)$ & $10.2 \%$ & $-1.82 \%$ \\
Import Search $((1-a) \sigma)$ & $-0.90 \%$ & $30.6 \%$ \\
\hline Consumer Welfare & $2.2 \%$ & $3.7 \%$ \\
\hline
\end{tabular}

Notes: Table shows the change in the model generated outcome variables under a $25 \%$ decrease in domestic search costs and a $25 \%$ decrease in international search costs. Average refers to the average number of suppliers over all firms.

\subsection{EXPERIMENT 3: SeArCh COST REDUCtion}

In experiment 3, I simulate the Ugandan government's stated target for 2019 to reduce search costs for suppliers by $25 \%$ (Government of Uganda, 2019). The specific sub targets are i) establishing a internet platform support programme (e.g. organize quarterly trainings on the use of Ali Baba), ii) encourage firms peer-to-peer learning (e.g. organize quarterly peer groups with Uganda business groups), iii) target key firms in supplier 
FIGURE 11: Consumer welfare gains from trade when search externalities are shut down (CRS) compared to structurally estimated parameters (IRS)

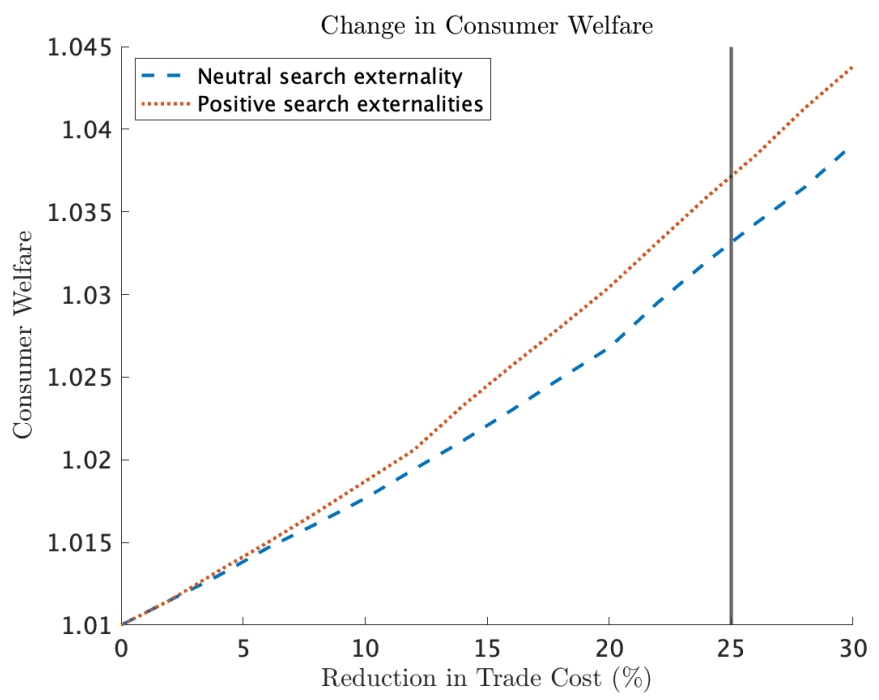

Notes: The y-axis shows the change in consumer welfare where the baseline is normalized to 1 . The $\mathrm{x}$-axis shows the reduction in trade costs from 0 to $30 \%$. The orange line (IRS) shows the change in the average number of suppliers when the model is estimated using the structurally estimated parameters which allows for increasing returns to scale in matching internationally and decreasing returns to scale in matching domestically. The blue line (CRS) shows the change in the average number of suppliers when the model is estimated shutting down differences in the returns to scale in matching between domestic and international markets.

development programmes (e.g. establish anchor firm support unit and annual publicsupplier meetings). Intervention (ii) mimics the work done by the Chinese government and documented by Cai and Szeidl (2017), where firms which meet regularly for business meetings have been shown to increase the number of clients by $12 \%$ and the number of suppliers by $9 \%$.

The idea behind this experiment is to consider whether the government's stated target would improve firm outcomes and where the search cost reduction would be best targeted. In order to consider this question, I run two separate counterfactual experiments - first lowering the domestic search costs and then the import search costs.

The outcomes from the experiment are given in Table 9 and Figure 12. When reducing domestic search costs, there is a sharp increase in buyers' domestic search and consequently the average number of domestic suppliers increases by $10 \%$. This is of a similar magnitude to the $9 \%$ increase in suppliers found in Cai and Szeidl (2017) follow- 
FiguRE 12: Search by marginal cost if reduce domestic search costs by $25 \%$

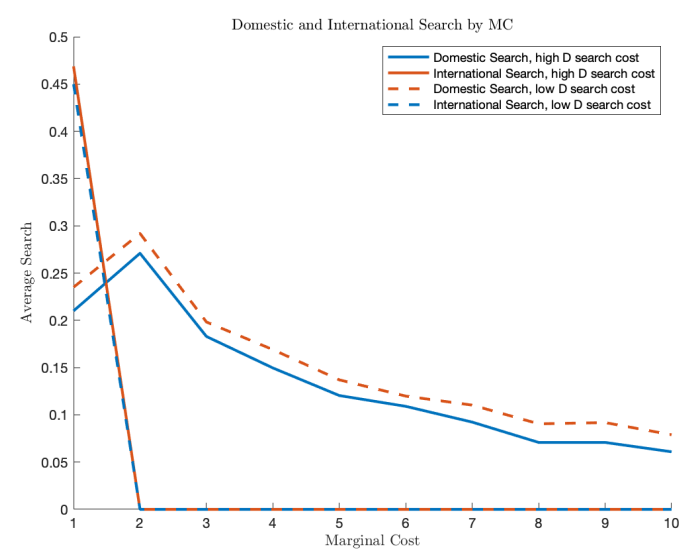

FiguRE 13: Search by marginal cost if reduce international search costs by $25 \%$

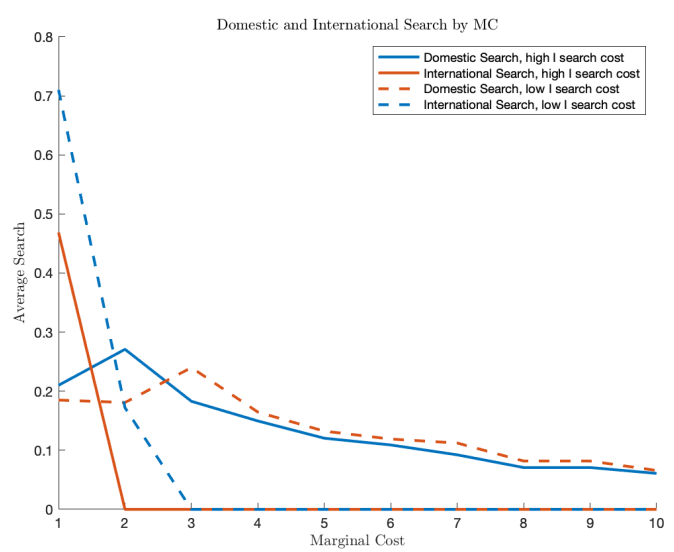

Notes: The x-axis breaks buyers into 10 different marginal cost bins, where 1 indicates the lowest marginal costs and 10 equals the highest marginal costs. The y-axis shows the average search undertaken by buyers in each of these groups. The solid blue and red lines show the amount of domestic and international search, respectively, before the reduction in search costs. The blue and red dashed lines show the amount of domestic and international search, respectively, after the search cost reduction. The left graph shows the impact for reducing domestic search costs. The right graph shows the impact from reducing international search costs.

ing the business-meeting intervention. As can be observed in Figure 12, this increase in domestic search is observed across all levels of buyer marginal cost. However, the increase in the number of domestic matches is relatively modest (10\%), as the increase in domestic search leads to an increase in domestic market congestion. There is also a small decline in international search $(-0.9 \%)$, as firms make a substitution decision away from international markets.

As shown in Table 9 and Figure 13, when reducing international search, there is a large increase in import search $(30.6 \%)$ leading to a $19 \%$ increase in foreign suppliers. As can be observed in Figure 13, this is concentrated among the low marginal cost firms, as for all other firms they still do not choose to pay the import fixed cost. These firms, reduce the amount they search domestically, given they are still subject to a convex cost of searching in both markets. This then frees up space in the domestic market, captured by higher marginal cost firms. Therefore, the second experiment acts in a similar way to the trade cost reduction in leading to welfare gains through both the lower marginal costs and the benefit of moving from the decreasing returns to scale market to the increasing 
returns to scale market. As a consequence, reducing international search costs increases consumer welfare by $3.7 \%$.

By contrast, when domestic search costs fall, firms increase domestic search, however, this leads to a large increase in domestic market tightness due to the domestic congestion. Therefore, the impact of the reform is muted.

These results provide support for the government of Uganda's policy of lowering search costs as the impact on welfare is of a similar magnitude to lowering international trade costs by $25 \%$. The results show that the impact of the reforms will be greater if the government focusses on lowering international search costs. Therefore, the government may focus on their planned interventions to train firms on using platforms such as Ali Baba and Amazon and by having firms meet with firms who have experience of importing in a similar vein to Cai and Szeidl (2017).

\section{Concluding Remarks}

Using novel data on both domestic and international firm-to-firm transactions from Uganda, I show that the presence of search frictions between buyers and suppliers, in a low-income country, can have a significant impact on how firms respond to a trade liberalization.

I show in a model of firm-to-firm search and matching in two markets that the relative size of search externalities determines the extent of sourcing reallocation, as well as changes to consumer welfare. Given the importance of the search externality parameters, I then show through both reduced-form evidence and structural model estimation that there are stronger positive externalities in international markets compared to domestic markets. I then demonstrate through model simulations that the impact of this channel on consumer welfare is quantitatively significant.

While, the estimates in this paper are specific to the Ugandan context, however, the mechanisms are general to any setting which has search frictions between buyers and suppliers. There is reason to believe that the relative size of the effects maybe larger in a low-income country setting where search frictions are substantial, although, this is 
speculative without obtaining similar data in a different setting. This does suggest a channel for future work.

The results in this paper provide support for policy intervention to address search frictions. As is the case with all search frictions, the first-best outcome would be to remove the search friction entirely. In the context of the model presented in this paper, this would mean all firms finding and matching with suppliers costlessly. In practice this is not feasible, instead, governments can focus on reducing search costs. The Ugandan government's goal of providing training on platforms such as Ali Baba and Amazon to Ugandan businesses will have a large impact as these channels directly target lowering international search costs. Similarly, encouraging firms to learn from each other has been shown in other contexts to improve firm-to-firm matching (Cai and Szeidl, 2017). Results from this paper suggest the Ugandan government should focus on interventions that target reducing the cost to international search as opposed to domestic search. This is because lowering the cost to domestic search may simply increase congestion leading to a small increase in matches. However, lowering international search costs will increase both international matches and reduce domestic congestion. 


\section{REFERENCES}

\section{Albornoz, Facundo, Héctor F Calvo Pardo, Gregory Corcos, and Emanuel}

Ornelas, "Sequential exporting," Journal of International Economics, 2012, 88 (1), $17-31$.

Allen, Treb, "Information frictions in trade," Econometrica, 2014, 82 (6), 2041-2083.

Antras, Pol and Arnaud Costinot, "Intermediated trade," The Quarterly Journal of Economics, 2011, 126 (3), 1319-1374.

_ , Teresa C Fort, and Felix Tintelnot, "The margins of global sourcing: Theory and evidence from us firms," American Economic Review, 2017, 107 (9), 2514-64.

Arkolakis, Costas, Arnaud Costinot, and Andres Rodriguez-Clare, "New trade models, same old gains?," American Economic Review, 2012, 102 (1), 94-130.

Arnosti, Nick, Ramesh Johari, and Yash Kanoria, "Managing congestion in matching markets," Available at SSRN 2427960, 2018.

Atkeson, Andrew and Ariel Burstein, "Pricing-to-market, trade costs, and international relative prices," American Economic Review, 2008, 98 (5), 1998-2031.

Atkin, David, Amit K Khandelwal, and Adam Osman, "Exporting and firm performance: Evidence from a randomized experiment," The Quarterly Journal of Economics, 2017, 132 (2), 551-615.

Bernard, Andrew B and Andreas Moxnes, "Networks and trade," Annual Review of Economics, 2018, 10, 65-85.

- and J Bradford Jensen, "Exceptional exporter performance: cause, effect, or both?," Journal of international economics, 1999, $4^{77}$ (1), 1-25.

_ and _, "Why some firms export," Review of Economics and Statistics, 2004, 86 (2), $561-569$. 
- and Swati Dhingra, "Contracting and the Division of the Gains from Trade," National Bureau of Economic Research Working Paper 21691, 2015.

_, Andreas Moxnes, and Karen Helene Ulltveit-Moe, "Two-sided heterogeneity and trade," Review of Economics and Statistics, 2018, 100 (3), 424-439.

_ , _ , and Yukiko U Saito, "Production networks, geography, and firm performance," Journal of Political Economy, 2019, 127 (2), 639-688.

Bisztray, Márta, Miklós Koren, and Adam Szeidl, "Learning to import from your peers," Journal of International Economics, 2018, 115, 242-258.

Bulzomi, Anna, Peter Danssaert, Sergio Finardi, and Ken Matthysen, "Supply Chains and Transport Corridors in East Africa," International Peace Information Service and TransArms-Research, 2014.

Bustos, Paula, "Trade liberalization, exports, and technology upgrading: Evidence on the impact of MERCOSUR on Argentinian firms," American economic review, 2011, $101(1), 304-40$.

Cai, Jing and Adam Szeidl, "Interfirm relationships and business performance," The Quarterly journal of economics, 2017, 133 (3), 1229-1282.

Carvalho, Vasco M, "From micro to macro via production networks," The Journal of Economic Perspectives, 2014, 28 (4), 23-47.

Chaney, Thomas, "The network structure of international trade," American Economic Review, 2014, 104 (11), 3600-3634.

Eaton, Jonathan, David Jinkins, James R Tybout, and Daniel Yi Xu, "Twosided Search in International Markets," Mimeo, 2016.

_ , Samuel Kortum, Francis Kramarz et al., "Firm-to-Firm Trade: Imports, exports, and the labor market," Brown University, unpublished manuscript, 2017. 
Fafchamps, Marcel and Simon Quinn, "Networks and manufacturing firms in africa: Results from a randomized field experiment," The World Bank Economic Review, 2016, $32(3), 656-675$.

Fieler, Ana Cecília, Marcela Eslava, and Daniel Yi Xu, "Trade, quality upgrading, and input linkages: Theory and evidence from colombia," American Economic Review, 2018, 108 (1), 109-46.

Government of Uganda, "Uganda Economic Growth Forum: Import Substitution and Export Promotion for Growth," 2019.

Hosios, Arthur J, "On the efficiency of matching and related models of search and unemployment," The Review of Economic Studies, 1990, 57 (2), 279-298.

Hottman, Colin J, Stephen J Redding, and David E Weinstein, "Quantifying the sources of firm heterogeneity," The Quarterly Journal of Economics, 2016, 131 (3), $1291-1364$.

International Monetary Fund, "Article IV Consultation," International Monetary Fund, 2019.

Kamal, Fariha and Asha Sundaram, "Buyer-seller relationships in international trade: Do your neighbors matter?," Journal of International Economics, 2016, 102, $128-140$.

Kathage, Angus Morgan, "Understanding the informal economy in African cities: Recent evidence from Greater Kampala," World Bank Blogs, 2018.

Krolikowski, Pawel Michal and Andrew H McCallum, "Goods-market frictions and international trade," 2017.

Lim, Kevin, "Firm-to-firm Trade in Sticky Production Networks," Technical Report, Society for Economic Dynamics 2017. 
Macchiavello, Rocco and Ameet Morjaria, "The value of relationships: evidence from a supply shock to Kenyan rose exports," American Economic Review, 2015, 105 (9), 2911-45.

_ and _ , "Competition and Relational Contracts in the Rwanda Coffee Chain," 2019.

Mangin, Sephorah and Benoît Julien, "Efficiency in search and matching models: A generalized hosios condition," Becker Friedman Institute for Research in Economics Working Paper, 2018, (2018-10).

Manova, Kalina, "Credit constraints, heterogeneous firms, and international trade," Review of Economic Studies, 2012, 80 (2), 711-744.

Melitz, Marc J, "The impact of trade on intra-industry reallocations and aggregate industry productivity," Econometrica, 2003, 71 (6), 1695-1725.

_ and Stephen J Redding, "New trade models, new welfare implications," American Economic Review, 2015, 105 (3), 1105-46.

Overseas Development Institute, "Productive employment and transformation in Uganda," Technical Report, ODI 2015.

Petrongolo, Barbara and Christopher A Pissarides, "Looking into the black box: A survey of the matching function," Journal of Economic literature, 2001, 39 (2), 390431.

Rauch, James E, "Business and social networks in international trade," Journal of economic literature, 2001, 39 (4), 1177-1203.

_ and Joel Watson, "Starting small in an unfamiliar environment," International Journal of industrial organization, 2003, 21 (7), 1021-1042.

_ and Vitor Trindade, "Ethnic Chinese networks in international trade," Review of Economics and Statistics, 2002, 84 (1), 116-130. 
Rogerson, Richard, Robert Shimer, and Randall Wright, "Search-theoretic models of the labor market: A survey," Journal of economic literature, 2005, 43 (4), 959-988.

Spray, John, "Reorganise, Replace or Expand? The Role of the Supply-Chain in FirstTime Exporting," Cambridge INET Working Paper 1741, 2017.

_ , "Reorganise, Replace or Expand? The role of the supply-chain in first-time exporting," Cambridge INET Working Paper 1741, 2017.

- and Sebastian Wolf, "Industries without smokestacks in Uganda and Rwanda," Mimeo, 2016.

Startz, Meredith, "The value of face-to-face: Search and contracting problems in Nigerian trade," Available at SSRN 3096685, 2016.

Steinwender, Claudia, "Real effects of information frictions: When the states and the kingdom became united," American Economic Review, 2018, 108 (3), 657-96.

Stole, Lars A and Jeffrey Zwiebel, "Intra-firm bargaining under non-binding contracts," The Review of Economic Studies, 1996, 63 (3), 375-410.

Tintelnot, Felix, Ayumu Ken Kikkawa, Magne Mogstad, and Emmanuel Dhyne, "Trade and domestic production networks," Technical Report, National Bureau of Economic Research 2018.

World Bank, "Doing Business 2011," World Bank Group, 2011.

_, "Doing Business 2016 : Trading Across borders," World Bank Group, 2016.

_, "Uganda Economic Update, 13th Edition, May 2019 : Economic Development and Human Capital in Uganda - A Case for Investing More in Education," World Bank Group, 2019. 


\section{A. Context Appendix}

\section{A.1. MAP OF TRADE CORRIDOR}

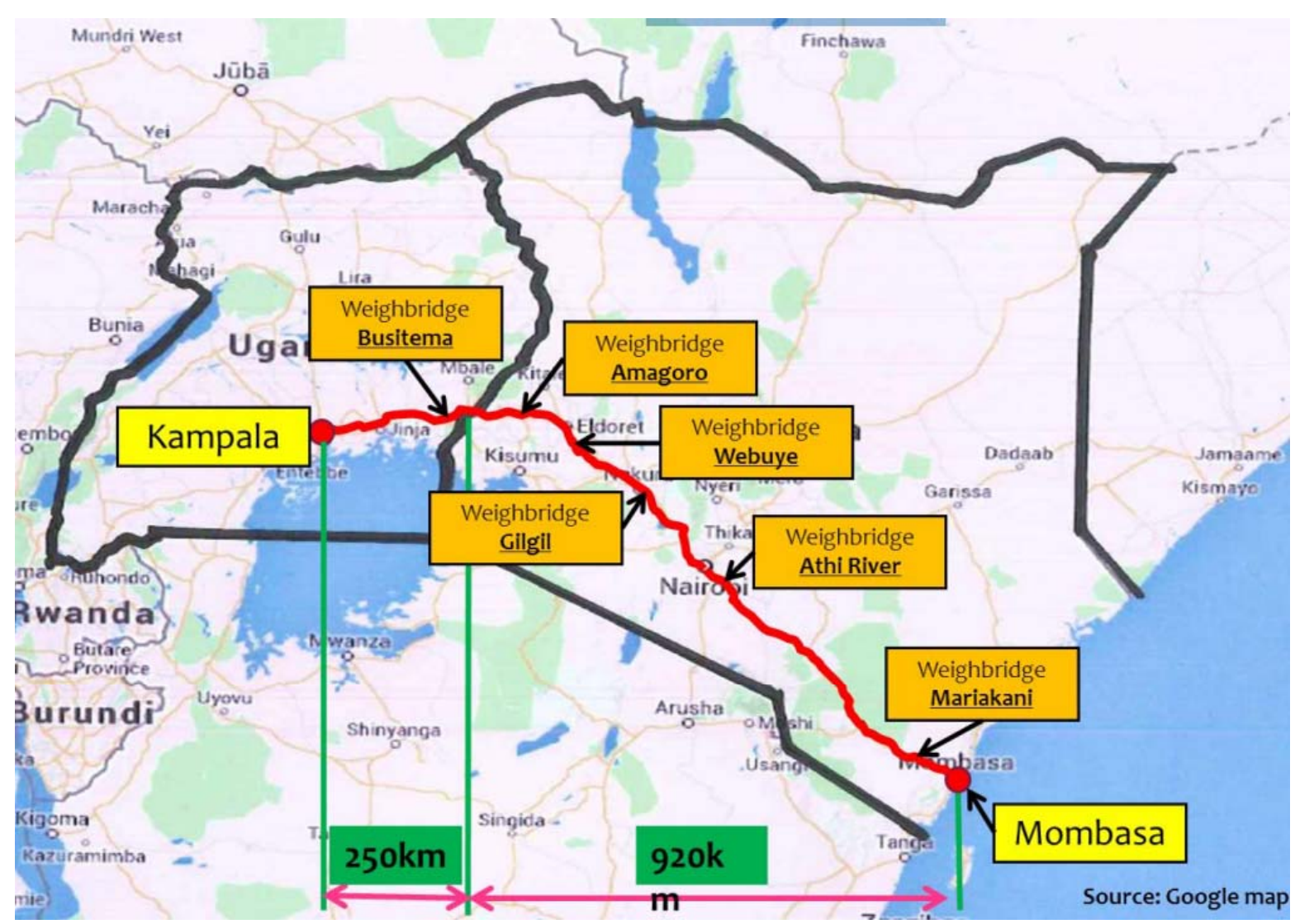

FiguRE 14: Map of trade corridor, Osawa, WCO

\section{A.2. DATA COMPARISON}

Given research using tax data remains rare, one potential concern might be that the data is of low quality. This section addresses this concern by comparing the tax data used in this study to other freely available data sources.

Figure 15 shows a comparison between the raw export trade data used in this study and trade data from the WTO. From the graph it appears as if the WTO data is understating the actual export volumes. However, for the purposes of this study, the important fact is how closely the two lines track one another showing that the data is strongly correlated 


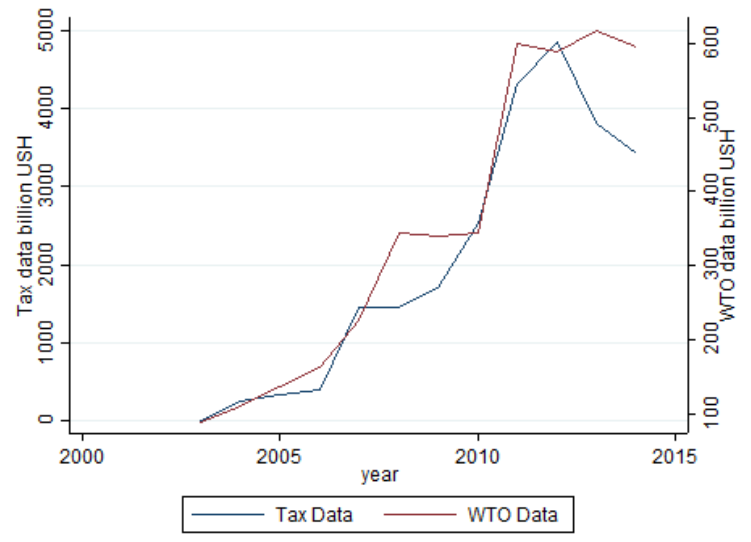

FiguRE 15: Exports data comparison

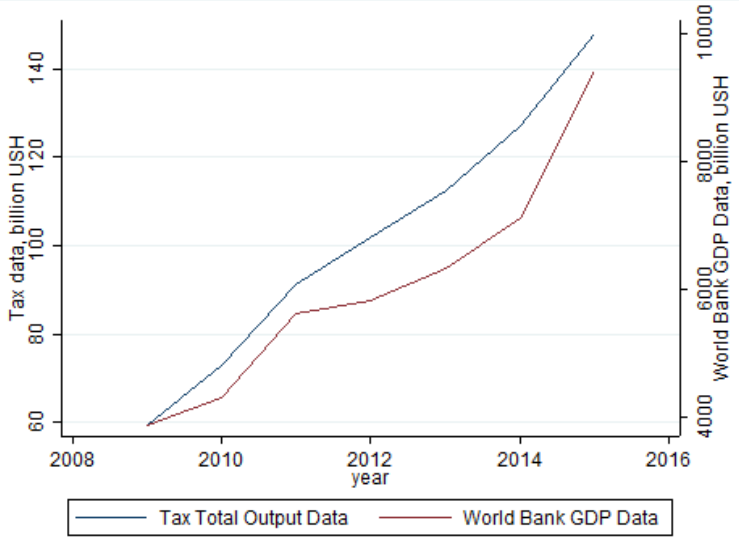

Figure 16: GDP and total output

Notes: The left-hand figure compares the Uganda Revenue Authority (URA) export data with data obtained from the World Trade Organization. The right-hand figure compares total output data from the URA's tax data with GDP data from the World Bank.

with the external source.

Figure 16 shows a comparison between the total output variable used in the tax data and GDP data from the World Bank. Unsurprisingly, the tax data is smaller than the GDP data given the tax data only observes formal sector firms. Importantly, like in 15, the correlation between the two lines is very strong again supporting the reliability of the tax data.

Finally, Spray and Wolf (2016) show the distribution of firms in each sector is consistent with those in the Uganda Business Census. 


\section{B. A Quantitative Model of Buyer-Supplier Search in Two MARKETS}

\section{B.1. Buyers AND Suppliers}

There is a measure $B$ continuum of buyers, measure $S_{D}$ continuum of domestic suppliers and measure $S_{I}$ continuum of international suppliers.

Suppliers produce differentiated products $(x)$ which they sell to buyers $(b)$ once they match. Let $B\left(s_{I}\right)$ denote the set of buyers who match with international suppliers. Similarly, let $B\left(s_{D}\right)$ denote the set of buyers who match with domestic suppliers. Suppliers choose search intensity $\sigma_{j}^{S}(n)$. There is an exogenously given probability $\delta$ of an existing match being severed.

There are $\Gamma$ buyer types indexed $i \in\{1,2, \ldots, \Gamma\}$ with marginal cost $c_{i}$ drawn from a known distribution, and match with $\mathbf{s}=\left\{s_{I}, s_{D}\right\}$ suppliers. This now warrants a change of subscripts from buyer $b$ to buyer type $i$. Buyers choose their search intensity $\sigma_{i}^{B}(\mathbf{s})$ and choose the proportion of search they exert domestically, $a$ such that $a \in[0,1]$, and internationally, $1-a$.

Buyers pay an iceberg trade $\operatorname{cost} \tau_{I}$ on each unit of international goods and iceberg trade cost $\tau_{D}$ on each unit of domestic goods, where I normalize $\tau_{D}=1$.

\section{B.2. Consumers}

Consumers have a nested CES utility function which shows their taste-for-variety over buyers $(b)$ and products $(x)$, such that

$$
\begin{gathered}
C=\left[\int_{b \in B} C_{b}^{\frac{\eta-1}{\eta}}\right]^{\frac{\eta}{\eta-1}} \\
C_{b}=\left[\sum_{x \in J\left(s_{I}\right)_{b}}\left(\psi_{I} C_{b}^{x}\right)^{\frac{\alpha-1}{\alpha}}+\sum_{x \in J\left(s_{D}\right)_{b}}\left(C_{b}^{x}\right)^{\frac{\alpha-1}{\alpha}}\right]^{\frac{\alpha}{\alpha-1}},
\end{gathered}
$$


where $J\left(s_{I}\right)_{b}$ is the set of international products $x$ offered by buyer $b$ and $J\left(s_{D}\right)_{b}$ is the set of domestic products $x$ offered by buyer $b, C_{b}^{x}$ is consumption of product $x$ from buyer $b$, and $C_{b}$ is consumption of the set of products offered by $b . \eta$ and $\alpha$ are the elasticities of substitution among products and buyers, respectively. I assume all international products have the same demand shifter, $I$, and all domestic products have the same demand shifter, $D$, which I normalize to 1 . If imports are higher quality products, we might expect $\quad I>1$ for imported goods, although I do not impose this.

\section{B.3. Pricing AND Division of Profits}

As buyers now match with multiple suppliers, they sell multiple goods. They, therefore, internalize the price set on one good on the demand of their other goods. This yields a first order condition on prices given by

$$
q_{x b}+\sum_{x^{\prime} \in J_{b}} \frac{\partial q_{x^{\prime} b}}{\partial p_{x b}}\left(p_{x^{\prime} b}-c_{x^{\prime} b}\right)=0 \quad \forall x \in J_{b}
$$

where $c_{x^{\prime} b}$ is the marginal cost of supplying product $x^{\prime}$ to consumers through buyer $b$. The intuition behind Equation B.3 is that buyers internalize that their pricing on one good alters demand on other goods.

The instantaneous profit flow created by buyer $b$ and its set of suppliers is now given by a summation over the profit provided by each product $x$ in buyer $b$ 's bundle $\left(J_{b}\right)$, such that

$$
\left.\pi_{b}(\mathbf{s})=\frac{E}{\eta P^{1-\eta}}\left[\sum_{x \in J_{b}} \frac{\eta}{\eta-1}\right)^{1-\alpha} \tau_{L} \tilde{c}_{b}^{1-\alpha}\right]^{\frac{1-\eta}{1-\alpha}},
$$

for $L \in\{D, I\}$ and where $\tilde{c}_{b}=c_{b} / \psi_{L}$ is the quality-adjusted marginal cost, $\mathbf{s}=\left\{s_{I}, s_{D}\right\}$ is a vector of the number of international and domestic suppliers, $P$ is the standard CES aggregate price index and $E$ is household expenditure. As long as $\alpha>\eta>1$, then the profit function is increasing in the aggregate price index and decreasing in marginal cost. This condition also ensures that there are diminishing returns to the number of suppliers, given that adding a new supplier appears in the summation $x \in J_{b}$ which leads to an 
increase in profit but at a decreasing rate, as long as the exponent $\frac{1-\eta}{1-\alpha}<1 .{ }^{37}$ If the buyer matches with a domestic supplier then $\tau_{D}={ }_{D}=1$. For higher international trade costs $\left(\tau_{I}\right)$ or smaller international demand shifter $\left(\psi_{I}\right)$ profits from matching with an international supplier are smaller.

As buyers now have multiple suppliers, division of profits becomes more complex. I assume Stole and Zwiebel (1996) bargaining which gives each seller a profit flow $z_{j i}$ equal to their bargaining share multiplied by their marginal contribution to profit which depends on whether the good is domestic or international $L \in\{D, L\} .{ }^{38}$

$$
\begin{aligned}
z_{j i}(\mathbf{s}) & =\Lambda \frac{\partial \pi_{i}^{T}(\mathbf{s})}{\partial s_{L}} \\
& \left.=\frac{\Lambda}{\alpha-1} \frac{\eta}{\eta-1}\right)^{-\eta} \frac{E}{P^{1-\eta}}\left[\sum_{j \in J_{b}} \tau_{L} \tilde{c}_{i}^{1-\alpha}\right]^{\frac{\alpha-\eta}{1-\alpha}} \tau_{L} \tilde{c}_{i}^{1-\alpha}
\end{aligned}
$$

Equation B.5 is very close to being a structural equation which would be estimatable in the data, therefore allowing the recovery of key parameters. However, the seller's profit $z_{j i}$ is not observable in the data. Instead, the data shows a firm-to-firm transaction which includes both profit and compensation for marginal costs in production of each good. If a constant fraction $\lambda$ of the variable costs is attributable to the seller, ${ }^{39}$ then the revenue transfer can be expressed between firms $r_{j i}$ in terms of fixed effects and observables

$$
\left.\left.r_{j i}(\mathbf{s})=\left(h_{j \mid i}\right)^{\frac{\alpha-\eta}{\alpha-1}} \frac{E}{P^{1-\eta}} \frac{\eta}{\eta-1}\right)^{-\eta} \tau_{L} \tilde{c}_{j i}\right)^{1-\eta}\left[\frac{B}{\alpha-1}+\lambda\right]
$$

where $r_{j i}$ is the revenue for seller $j$ from buyer $i, h_{j \mid i}=\frac{\tau_{L} \tilde{c}_{j}^{1-\alpha}}{\sum_{l=1}^{J} s_{l} \tau_{L} \tilde{c}_{i}^{1-\alpha}}$ is the within buyer- $i$ revenue share of a type- $j$ seller, $\lambda$ is the seller's fraction of marginal cost.

\footnotetext{
${ }^{37}$ In this way profit depends on the number of suppliers, however, this is not to be confused with diminishing returns to scale in the matching function discussed in Section B.4.

${ }^{38}$ Stole and Zwiebel (1996) is a generalization of Rubinstein bargaining to multiple firms based on Shapley value which gives firms a constant fraction of revenue

${ }^{39}$ This assumption only influences the estimation of the structural equation for the purpose of extracting the elasticity of substitution parameters. In all other aspects I consider the buyer and supplier to be jointly maximising profits.
} 


\section{B.4. SEARCh AND Matching}

Relative to the simple model, modelling search-and-matching is made more complex by the addition of a search intensity choice for buyers and suppliers $\left(\sigma^{B}, \sigma^{S}\right.$ respectively) and given that buyers have a choice on the proportion of search done domestically $(a) .{ }^{40}$

Following Eaton, Jinkins, Tybout and Xu (2016), I define a new variable, visibility $(H)$ of a type- $i$ buyer in domestic and international markets, respectively, as

$$
\begin{aligned}
& H_{i, D}^{B}(\mathbf{s})=a_{i}(\mathbf{s}) \sigma_{i}^{B}(\mathbf{s}) M_{i}^{B}(\mathbf{s}) \\
& H_{i, I}^{B}(\mathbf{s})=\left(1-a_{i}(\mathbf{s})\right) \sigma_{i}^{B}(\mathbf{s}) M_{i}^{B}(\mathbf{s}),
\end{aligned}
$$

where $M_{i}^{B}\left(s_{D}, s_{I}\right)$ is a measure of type- $i$ buyers with s sellers. Intuitively, buyers of type- $i$ are more visible if they are searching more $\left(a_{i} \sigma_{i},\left(1-a_{i}\right) \sigma_{i}\right)$ and if there is a larger mass of them $\left(M_{i}^{B}\right)$.

The overall visibility of buyers in the domestic and international market is a summation over all buyer types and for any number of existing matches.

$$
H_{L}^{B}=\sum_{i=1}^{I} \sum_{s_{L}=0}^{s_{L_{\max }}} H_{i, L}^{B}(\mathbf{s}) \text { for } L \in\{D, I\}
$$

Domestic and international sellers' visibility $\left(H_{D}^{S}, H_{I}^{S}\right)$ are defined symmetrically to buyers

$$
\begin{aligned}
& H_{D}^{S}(n)=\sigma_{D}^{S}(n) M_{D}^{S}(n) \\
& H_{I}^{S}(n)=\sigma_{I}^{S}(n) M_{I}^{S}(n) .
\end{aligned}
$$

The matching function is similar to the simple model, but is now increasing in buyer and seller visibility

$$
X_{D}\left(H_{D}^{S}, H_{D}^{B}\right)=\left(H_{D}^{B}\right)^{\gamma_{B}}\left(H_{D}^{S}\right)^{\gamma_{S}}
$$

\footnotetext{
${ }^{40}$ Where as in the simple model $a \in[0,1]$ and the amount of search internationally is $1-a$.
} 


$$
X_{I}\left(H_{I}^{S}, H_{I}^{B}\right)=\left(H_{I}^{B}\right)^{\beta_{B}}\left(H_{I}^{S}\right)^{\beta_{S}} .
$$

As in the simple model discussed in Section ??, the matching function exponents are key objects in the model. A positive externality to search would be indicated by high $\gamma_{S}, \gamma_{B}$ and $\beta_{S}, \beta_{B}$. This is because, at the margin, an increase in buyers or sellers visibility will lead to a large increase in the number of matches. There are increasing returns to scale in domestic matching if $\gamma_{S}+\gamma_{B}>1$. By contrast, a congestion externality to search would be indicated by low $\gamma_{S}, \gamma_{B}$ and $\beta_{S}, \beta_{B}$, as more firms entering leads to very few new matches. There are decreasing returns to scale in domestic matching if $\gamma_{S}+\gamma_{B}<1$. A low $\gamma_{S}$ would indicate that congestion is largely on the domestic supplier-side. Whereas, a low $\gamma_{B}$ would indicate that there is high congestion among domestic buyers. In Section 6, I structurally estimate the exponents using simulated method of moments.

The match flow per unit of buyer visibility $\theta$ is a measure of market tightness and is defined separately in the domestic and international markets, given by

$$
\theta_{D}=\frac{X_{D}\left(H_{D}^{S}, H_{D}^{B}\right)}{H_{D}^{B}} \quad \theta_{I}=\frac{X_{I}\left(H_{I}^{S}, H_{I}^{B}\right)}{H_{D}^{B}} .
$$

A higher value of $\theta$ simply indicates that the hazard-rate of finding a match is higher. ${ }^{41}$

\section{B.5. Search Cost}

In order to make sure that buyers do not enter a sorting equilibrium of only searching domestically or internationally, I assume positive and convex search $\operatorname{costs}^{42}$ with a fixed cost of search $F_{S}$ and an additional fixed cost of international search $F_{I}$ only paid if the firm chooses to search internationally.

$$
k^{B}=\left(\left(a \sigma^{B}\right)^{v}+\left((1-a) \sigma^{B}\right)^{v}\right)^{v}+F_{S}+F_{I}, \quad v>1
$$

\footnotetext{
${ }^{41} \theta_{S_{L}}$ is defined symmetrically for $L \in\{D, I\}$ type suppliers.

${ }^{42}$ See Section ?? for further justification of this assumption.
} 
Fixed costs are common in the trade literature following Melitz (2003) as they ensure that high marginal cost firms only sourcing domestically. They represent the up-front costs firms pay in entering international trade (see for instance Antras et al. (2017). I structurally estimate $F_{S}, F_{I}$ in Section 6 .

Sellers have a parallel set of search costs which are convex in the seller search intensity

$$
k_{L}^{S}=\left(\sigma^{S}\right)^{v}, \quad \text { for } L \in\{D, I\} \text { and } v>1 \text {, }
$$

which for simplicity are assumed to be the same for domestic and international suppliers.

\section{B.6. Optimal Search}

Buyers solve the following maximization problem by picking their optimal search intensity $\sigma$ and the proportion of that search intensity in the domestic market $a$

$$
\begin{aligned}
& V_{i}^{B}(\mathbf{s})= \\
& \max _{a, \sigma^{B}}\left\{\frac{\pi_{i}^{B}(\mathbf{s})-k^{B}\left(a_{i}, \sigma_{i}^{B}\right)+s_{D} \delta V_{i}^{B}\left(s_{D}-1\right)+a \sigma^{B} \theta_{D}^{B} V_{i}^{B}\left(s_{D}+1\right)+s_{I} \delta V_{i}^{B}\left(s_{I}-1\right)+(1-a) \sigma^{B} \theta_{I}^{B} V_{i}^{B}\left(s_{I}+1\right)}{\rho+s_{D} \delta+s_{I} \delta+a \sigma^{B} \theta_{D}^{B}+(1-a) \sigma^{B} \theta_{I}^{B}}\right\},
\end{aligned}
$$

where $V_{i}^{B}(\mathbf{s})$ is the present value of a type- $i$ buyer that is matches with vector $\mathbf{s} \in$ $\left\{s_{I}, s_{D}\right\}$ sellers, $\rho$ time preferences, $\delta$ is an exogenously given link death parameter.

Buyers receive profit equal to gross profit minus search costs, $\left(\pi_{i}^{B}(\mathbf{s})-k^{B}\left(a_{i}, \sigma_{i}^{B}\right)\right)$, until one of four events occurs with an endogenously given hazard: either (i) a buyer drops a domestic supplier $\left(V_{i}^{B}\left(s_{D}-1\right)\right)$, (ii) adds a domestic supplier $\left(V_{i}^{B}\left(s_{D}+1\right)\right)$, (iii) drops an international supplier $\left(V_{i}^{B}\left(s_{I}-1\right)\right)$, or (iv) adds an international supplier $\left(V_{i}^{B}\left(s_{D}+1\right)\right)$.

This yields policy functions for optimal search and the proportion of search in the domestic market where the change in cost of search is equal to the change in the value function from adding an additional domestic or international supplier multiplied by the 
hazard of these events occurring

$$
\begin{aligned}
& \frac{\partial k^{B}\left(\sigma^{B}, a\right)}{\partial \sigma^{B}} \leq a \theta_{D}^{B} \Delta_{s_{D}} V_{i}^{B}+(1-a) \theta_{I}^{B} \Delta_{s_{I}} V_{i}^{B} \\
& \frac{\partial k^{B}\left(\sigma^{B}, a\right)}{\partial a} \leq \sigma^{B} \theta_{D}^{B} \Delta_{s_{D}} V_{i}^{B}-\sigma^{B} \theta_{I}^{B} \Delta_{s_{I}} V_{i}^{B}
\end{aligned}
$$

where $\Delta_{s_{L}} V_{i}^{B}=V_{i}^{B}\left(s_{L}+1\right)-V_{i}^{B}\left(s_{L}\right)$ for $L \in\{D, I\}$. Equation B.16 and B.17 hold with equality when a firm searches both internationally and domestically $(a<1)$.

Suppliers solve a parallel problem, where the value $V$ to any seller matching with a type- $i$ buyer who has s suppliers depends on their type $L$ and is given by

$$
\begin{aligned}
V_{D, i, s}^{S} & =\frac{r_{i}(\mathbf{s})+\left(s_{D}-1\right) \delta V_{D, i, s_{D}-1}^{S}\left(s_{D}-1\right)+a_{i} \sigma_{i}^{B} \theta_{D}^{B} V_{D, i, s_{D}+1}^{S}}{\rho+s_{D} \delta+a_{i} \sigma_{i}^{B}(\mathbf{s}) \theta_{D}^{B}} \\
V_{I, i, s}^{S} & =\frac{r_{i}(\mathbf{s})+\left(s_{I}-1\right) \delta V_{I, i, s_{I}-1}^{S}\left(s_{I}-1\right)+\left(1-a_{i}\right) \sigma_{i}^{B} \theta_{I}^{B} V_{I, i, s_{I}+1}^{S}}{\rho+s_{I} \delta+\left(1-a_{i}\right) \sigma_{i}^{B}(\mathbf{s}) \theta_{I}^{B}}
\end{aligned}
$$

Intuitively, the supplier gets revenue $r_{i}(\mathbf{s})$ as defined in equation B.6, until they either lose a match with probability $\left(s_{L}-1\right) \delta$ or gain a match with probability depending on whether the supplier is domestic or international $a_{i} \sigma^{B} \theta_{D}^{B},\left(1-a_{i}\right) \sigma_{i}^{B} \theta_{I}^{B}$. Taking expected value of a match is a summation over buyer types:

$$
V_{L}^{S}=\sum_{i} \sum_{s=0}^{\infty} V_{L, i, s+1}^{S} P_{i}^{B}(\mathbf{s}), \quad \text { for } € \in\{D, I\}
$$

where $P_{i}^{B}(\mathbf{s})=H_{i}^{B}(\mathbf{s}) / H^{B}$ is the share of matches involving buyers of type $-i$ with $\mathbf{s}$ sellers.

Optimal seller search is then given by a parallel set of policy functions

$$
\begin{gathered}
\frac{\partial k_{D}^{S}\left(\sigma_{D}^{S}, s_{D}\right)}{\partial \sigma_{D}^{S}}=\theta_{D}^{S} V_{D}^{S} \\
\frac{\partial k_{I}^{S}\left(\sigma_{I}^{S}, s_{I}\right)}{\partial \sigma_{I}^{S}}=\theta_{I}^{S} V_{I}^{S} .
\end{gathered}
$$


The optimal level of seller search is, therefore, the expected value of a new relationship multiplied by the probability of a match.

\section{B.6.1. Equilibrium}

The model is completed via an equation of motion, where the change in the mass of buyers with $\mathbf{s}$ sellers is given by,

$$
\begin{aligned}
\dot{M}_{i}^{B}(s)= & {[\underbrace{a_{i} \sigma_{i}^{B} \theta_{D}^{B} M_{i}^{B}\left(s_{D}-1, s_{I}\right)}_{i}+\underbrace{\delta\left(s_{D}+1\right) M_{i}^{B}\left(s_{D}+1, s_{I}\right)}_{i i}+\underbrace{\left(1-a_{i}\right) \sigma_{i}^{B} \theta_{I}^{B} M_{i}^{B}\left(s_{D}, s_{I}-1\right)}_{i i i}} \\
& +\underbrace{\delta\left(s_{I}+1\right) M_{i}^{B}\left(s_{I}+1, s_{D}\right)}_{i v}]-[\underbrace{a_{i} \sigma_{i}^{B} \theta_{D}^{B}}_{v}+\underbrace{\delta s_{D}}_{v i}+\underbrace{\left(1-a_{i}\right) \sigma_{i}^{B} \theta_{I}^{B}}_{v i i}+\underbrace{\delta s_{I}}_{v i i i}] M_{i}^{B}\left(s_{D}, s_{I}\right) .
\end{aligned}
$$

Equation B.22 shows the change in mass of type- $i$ buyers with s sellers is equal to flows in $(i+i i+i i i+i v)$ minus flows out $(v+v i+v i i+v i i i)$. Flows in is made up of the mass of type $-i$ buyers who have: $(i) s_{D}-1$ suppliers multiplied by the probability of adding a domestic supplier; (ii) $s_{D}+1$ suppliers multiplied by the probability of losing a domestic supplier; (iii) $s_{I}-1$ suppliers multiplied by the probability of adding a international supplier; $(i v)$ $s_{I}+1$ suppliers multiplied by the probability of losing a international supplier. Flows out is made up of the mass of type $-i$ buyers who have s suppliers multiplied by the probability of: $(v)$ adding a domestic supplier; (vi) losing a domestic supplier; (vii) adding a international supplier; (viii) losing a international supplier. Finally, the measure of buyers of type $-i$ with $s_{L}=0$ is given by

$$
\begin{array}{r}
\dot{M}_{i}^{B}\left(0, s_{I}\right)=\left[\delta M_{i}^{B}\left(1, s_{I}\right)+\left(1-a_{i}\right) \sigma_{i}^{B} \theta_{I}^{B} M_{i}^{B}\left(0, s_{I}-1\right)+\delta\left(s_{I}+1\right) M_{i}^{B}\left(0, s_{I}\right)\right] \\
-\left[a_{i} \sigma_{i}^{B} \theta_{D}^{B}+\left(1-a_{i}\right) \sigma_{i}^{B} \theta_{I}^{B}+\delta s_{I}\right] M_{i}^{B}\left(0, s_{I}\right) .
\end{array}
$$




$$
\begin{array}{r}
\dot{M}_{i}^{B}\left(s_{D}, 0\right)=\delta M_{i}^{B}\left(s_{D}, 0\right)+ \\
\left.a_{i} \sigma_{i}^{B} \theta_{D}^{B} M_{i}^{B}\left(s_{D}-1,0\right)+\delta\left(s_{D}+1\right) M_{i}^{B}\left(s_{D}, 0\right)\right] \\
-\left[\left(1-a_{i}\right) \sigma_{i}^{B} \theta_{I}^{B}+a_{i} \sigma_{i}^{B} \theta_{D}^{B}+\delta s_{D}\right] M_{i}^{B}\left(s_{D}, 0\right) .
\end{array}
$$

A symmetric set of equations exists for suppliers.

As in Eaton, Jinkins, Tybout and Xu (2016), I look for a stationary equilibrium at the steady state, I set $\dot{M}_{i}^{B}(s)=\dot{M}_{j}^{S}(n)=0$ and solve the system of equations for all buyer types and suppliers given in equations B.22, B.23 and B.24. I treat each buyer type as exogenously given. 


\section{Mathematical Appendix}

\section{C.1. Comparative Statics in the two-Period Model}

The buyer picks their optimal $a$ in order to solve the following maximization problem

$$
\begin{gathered}
\text { C.1.1. REALlocation } \\
\pi_{b}=\frac{E}{\eta P^{1-\eta}}\left(\frac{\eta}{\eta-1}\right)^{1-\alpha} \tau_{I} \tilde{c}_{x b}^{1-\alpha} \\
\max _{a}\left\{a \sigma \theta_{D} \pi\left(s_{D}\right)+(1-a) \sigma \theta_{I} \pi\left(s_{I}\right)-k(a)\right\} .
\end{gathered}
$$

This yields a first order condition

$$
\sigma \theta_{D} \pi_{s_{D}}-\sigma \theta_{I} \pi_{s_{I}}-\frac{\partial k}{\partial a}=f\left(a, \tau_{I}\right)=0
$$

Totally differentiating C.3 and rearranging yields the comparative static of how $a$ changes as $\tau$ changes

$$
\frac{\partial f}{\partial a} \frac{\partial a}{\partial \tau_{I}}+\frac{\partial f}{\partial \tau_{I}} \Longrightarrow \frac{\partial a}{\partial \tau_{I}}=-\frac{\frac{\partial f}{\partial \tau_{I}}}{\frac{\partial f}{\partial a}} .
$$

Solving for each of these terms separately gives an explicit solution,

$$
\begin{gathered}
\frac{\partial a}{\partial \tau_{I}}=\frac{-\sigma \theta_{I} \frac{\partial \pi_{i}^{B}\left(s_{I}\right)}{\partial \tau_{I}}}{\frac{\partial^{2} k}{\partial a^{2}}-\sigma \frac{\partial \theta_{D}}{\partial a} \pi_{i}^{B}\left(s_{D}\right)+\sigma \frac{\partial \theta_{I}}{\partial a} \pi_{i}^{B}\left(s_{I}\right)} \\
\frac{\partial a}{\partial \tau_{I}}=\frac{-\sigma \theta_{I} \frac{\partial \pi_{i}^{B}\left(s_{I}\right)}{\partial \tau_{I}}}{\frac{\partial^{2} k}{\partial a^{2}}-\sigma^{2}\left(\gamma^{B}-1\right) \theta_{D} B_{D} \pi\left(s_{D}\right)-\sigma^{2}\left(\beta^{B}-1\right) \theta_{I} B_{I} \pi\left(s_{I}\right)}
\end{gathered}
$$




\section{C.1.2. Matching efficiency}

Consumer Welfare is broken into matching efficiency $A$ and consumption $C$.

$$
\begin{aligned}
W(a) & =\left[\int_{b \in B\left(s_{I}\right)} \psi_{I} C_{b}^{\frac{\eta-1}{\eta}}+\int_{b \in B\left(s_{D}\right)} C_{b}^{\frac{\eta-1}{\eta}}\right]^{\frac{\eta}{\eta-1}} \\
& =\underbrace{\left[a \sigma \theta_{D}+{ }_{I}(1-a) \sigma \theta_{I}\right]}_{A} \underbrace{\left[\int_{b \in B} C_{b}^{\frac{\eta-1}{\eta}}\right]^{\frac{\eta}{\eta-1}}}_{C} .
\end{aligned}
$$

Rewriting the matching efficiency $A$ by expanding the market tightness yields the following equation,

$$
A=a^{\gamma_{B}} S^{\gamma_{S}} B^{\gamma_{B}-1}+{ }_{I}(1-a)^{\beta_{B}} S^{\beta_{S}} B^{\beta_{B}-1} .
$$

taking a partial derivative of $A$

$$
\begin{aligned}
\frac{\partial A}{\partial \tau_{I}}= & \gamma_{B} a^{\gamma_{B}-1} S^{\gamma_{S}} B^{\gamma_{B}-1} \frac{\partial a}{\partial \tau_{I}}-\beta_{B} \psi_{I}(1-a)^{\beta_{B}-1} S^{\beta_{S}} B^{\beta_{B}-1} \frac{\partial a}{\partial \tau_{I}} \\
& \frac{\partial a}{\partial \tau_{I}}\left[\gamma_{B} a^{\gamma_{B}-1} S^{\gamma_{S}} B^{\gamma_{B}-1}-\beta_{B} \psi_{I}(1-a)^{\beta_{B}-1} S^{\beta_{S}} B^{\beta_{B}-1}\right]
\end{aligned}
$$

The first term $>0$ as shown in equation C.6, the second term determines the direction of the effect

$$
\begin{gathered}
\frac{\partial A}{\partial \tau_{I}}<0 \Longleftrightarrow \gamma_{B} a^{\gamma_{B}-1} S^{\gamma_{S}} B^{\gamma_{B}-1}<\beta_{B} \psi_{I}(1-a)^{\beta_{B}-1} S^{\beta_{S}} B^{\beta_{B}-1} \\
\gamma_{B} a^{\gamma_{B}-1}<\beta_{B} \psi_{I}(1-a)^{\beta_{B}-1} S^{\beta_{S}-\gamma_{S}} B^{\beta_{B}-\gamma_{B}}
\end{gathered}
$$

Therefore, the change in welfare due to matching efficiency following a fall in trade costs depends on $a, \psi_{I}$ and the matching exponents $\gamma_{B}, \gamma_{S}, \beta_{B}, \beta_{S}$. The main takeaway from equation C.10 is that for $a$ sufficiently large and $\psi \geq 1$, the change in welfare due to matching depends on the relative size of the matching exponents. If $\gamma_{B}<\beta_{B}$ and $\gamma_{S}<\beta_{S}$ i.e. returns to search are higher in the international market, then an increase in trade 
cost will lower welfare given firms move from matching in the increasing returns to scale international market to the decreasing returns to scale domestic market.

\section{C.2. Transfer Equation}

If cost per unit quality does not vary across products within buyers then the transfer equation collapses to the following

$$
\left.\left.r_{j i}(\mathbf{s})=\frac{E}{P^{1-\eta}} \frac{\eta}{\eta-1}\right)^{-\eta} s^{\frac{\alpha-\eta}{1-\alpha}} \tilde{c}^{1-\eta}\left[\frac{\Lambda}{\alpha-1}+\lambda \frac{\eta}{\eta-1}^{\eta-1}\right)\right] .
$$




\title{
D. EMPirical APPEndiX
}

\author{
D.1. Descriptive Statistics
}

Figure 17: Transport Costs and Imports
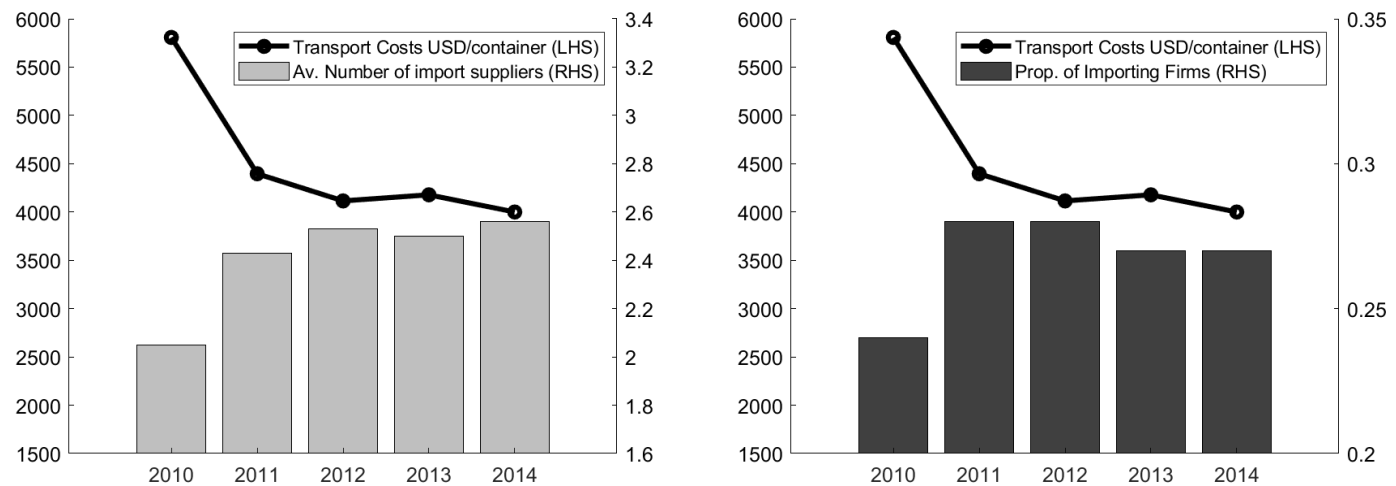

Notes: The black line shows transport cost in USD per 20-foot container from the World Bank's Trading Across Border Index, light grey bars on the left-hand graph show the average number of foreign suppliers for importers, and dark grey bars on the right-hand graph show the proportion of firms which import. The reason for the shorter time series is that I do not know the identity of foreign suppliers prior to 2010 .

\section{D.2. Robustness Tests}

\section{D.2.1. Alternative Specifications}

In this section, I rerun specification 1 utilising the full dataset and not just where the buyer is a retailer. I also include different geographical units of measurement from a neighborhood of $10 \mathrm{~km}, 1 \mathrm{~km}$, next door and the same building. Results are robust to all of these additions. 
TABle 10: Foreign Suppliers

\begin{tabular}{lcccc}
\hline \hline & $(1)$ & $(2)$ & $(3)$ & $(4)$ \\
& $Y_{i f t}$ & $Y_{i f t}$ & $Y_{i f t}$ & $Y_{i f t}$ \\
\hline$X_{i f, t-1}^{10 k m}$ & $0.0864^{* * *}$ & & & \\
& $(0.00693)$ & & & \\
$X_{i f, t-1}^{1 k m}$ & & & & \\
& & $0.0819^{* * *}$ & & \\
$X_{i f, t-1}^{\text {same }}$ & & $(0.00658)$ & & \\
& & & $0.0910^{* * *}$ & $0.0907^{* * *}$ \\
$X_{i f, t-1}^{\text {nextdoor }}$ & & & $(0.00624)$ & $(0.00651)$ \\
& & & & 0.00128 \\
$X_{i f, t-1}^{\text {other-city }}$ & & & & $(0.00994)$ \\
& & & & \\
\hline Observations & 4834635 & 4834635 & 4834635 & 4834635 \\
Year and Firm FE & YES & YES & YES & YES \\
\hline \hline
\end{tabular}

Notes: Unit of observation is buyer $i$, supplier $f$ and year $t$. Dependent variable $Y_{i f t}$ indicates a first match took place between buyer and supplier. $X_{i f t}^{k}$ is a count of buyers in region $k$ which added supplier $f$ in $t-1$. Coefficients are multiplied by 100 to read as percentage point marginal effects. Standard errors in parentheses are clustered at the buyer level. ${ }^{*} p<0.1,{ }^{* *} p<0.05,{ }^{* * *} p<0.01$ 
TABLE 11: Domestic Suppliers

\begin{tabular}{|c|c|c|c|c|}
\hline & $\begin{array}{l}(1) \\
Y_{i f t}\end{array}$ & $\begin{array}{l}(2) \\
Y_{i f t}\end{array}$ & $\begin{array}{l}(3) \\
Y_{i f t}\end{array}$ & $\begin{array}{l}(4) \\
Y_{i f t}\end{array}$ \\
\hline$X_{i f, t-1}^{10 k m}$ & $\begin{array}{c}0.00513 \\
(0.00606)\end{array}$ & & & \\
\hline$X_{i f, t-1}^{1 k m}$ & & $\begin{array}{c}0.00502 \\
(0.00612)\end{array}$ & & \\
\hline$X_{i f, t-1}^{\text {same }}$ & & & $\begin{array}{c}0.00509 \\
(0.00613)\end{array}$ & $\begin{array}{c}0.00465 \\
(0.00631)\end{array}$ \\
\hline$X_{i f, t-1}^{n e x t d o o r}$ & & & & $\begin{array}{c}0.000616 \\
(0.000322)\end{array}$ \\
\hline$X_{i f, t-1}^{o t h e r-c i t y}$ & $\begin{array}{c}-0.00515^{* * *} \\
(0.000962) \\
\end{array}$ & $\begin{array}{r}-0.00515^{* * *} \\
(0.000967) \\
\end{array}$ & $\begin{array}{r}-0.00515^{* * *} \\
(0.000972) \\
\end{array}$ & $\begin{array}{r}-0.00516^{* * *} \\
(0.000938) \\
\end{array}$ \\
\hline $\begin{array}{l}\text { Observations } \\
\text { Year and Firm FE }\end{array}$ & $\begin{array}{c}27975967 \\
\text { YES }\end{array}$ & $\begin{array}{c}27975967 \\
\text { YES }\end{array}$ & $\begin{array}{c}27975967 \\
\text { YES }\end{array}$ & $\begin{array}{c}27975967 \\
\text { YES }\end{array}$ \\
\hline
\end{tabular}

Notes: Unit of observation is buyer $i$, supplier $f$ and year $t$. $Y_{i f t}$ indicates a first match took place between buyer and supplier. $X_{i f t}^{k}$ is a count of buyers in region $k$ which added supplier $f$ in $t-1$. Coefficients are multiplied by 100 to read as percentage point marginal effects. Standard errors in parentheses are clustered at the buyer level. $p<0.1,{ }^{* *} p<0.05,{ }^{* * *} p<0.01$ 
TABLE 12: Same and next-door balance table

\begin{tabular}{lcc}
\hline \hline Distance & Proportion of firms in same sector & Difference with same building \\
\hline Same building & 0.097 & \\
& $(0.296)$ & -0.009 \\
Next-door building & 0.088 & $(0.014)$ \\
& $(0.284)$ & $-0.037^{* * *}$ \\
Next-door building $<$ distance $<0.1 \mathrm{~km}$ & 0.060 & $(0.012)$ \\
& $(0.237)$ & $-0.046^{* * *}$ \\
$0.1 \mathrm{~km}<$ distance $<0.15 \mathrm{~km}$ & 0.051 & $(0.017)$ \\
& $(0.219)$ & $-0.053^{* *}$ \\
$0.15 \mathrm{~km}<$ distance $<0.2 \mathrm{~km}$ & 0.044 & $(0.021)$ \\
& $(0.204)$ & $-0.057^{* *}$ \\
$0.2 \mathrm{~km}<$ distance $<0.25 \mathrm{~km}$ & 0.040 & $(0.026)$ \\
\end{tabular}

\section{D.2.2. VERY LOCAL SHOCKS DRIVE RESUlTS}

To address the concern that shocks drive reduced form results, I look at the proportion of firms in the same building which are in the same ISIC 4-digit sector and compare that to the proportion of firms in the next-door building. Results are shown in Table 12. While there is a small difference, it is not statistically significant. However, when I look at firms further away, I do see this difference increasing. I therefore conclude that there is some firm agglomeration, but that it is happening at a block level and not at a building level.

\section{D.2.3. SPILlOVER EXISTS BUt IS NOT SEARCH RELATED}

A second alternative explanation is that a spillover is taking place, but that it is not search related. For instance, we might expect that transport costs could be driving the results. To allay these concerns, I test if the marginal effect is smaller among firms where one would expect search frictions to be less prevalent. To test for this, I interact the independent variables with whether the foreign supplier exported from the East African Community (EAC). This is because one would expect search frictions to be smaller in local neighbors like Kenya or Tanzania when compared to more distant locations. We would therefore expect when estimating equation D.1 that the positive search externality 
TABLE 13: Imports Suppliers from East African Community

\begin{tabular}{|c|c|}
\hline & $\begin{array}{c}(1) \\
Y_{\text {ift }}\end{array}$ \\
\hline$X_{t-1}^{\text {same }}$ & $\begin{array}{c}0.0931^{* * *} \\
(0.00665)\end{array}$ \\
\hline$X_{t-1}^{s a m e} \times E A C_{f}$ & $\begin{array}{c}-0.0346^{* *} \\
(0.0151)\end{array}$ \\
\hline$X_{t-1}^{\text {other-city }}$ & $\begin{array}{l}-0.00223 \\
(0.00176)\end{array}$ \\
\hline$X_{t-1}^{\text {other-city }} \times E A C_{f}$ & $\begin{array}{l}-0.00486 \\
(0.00552)\end{array}$ \\
\hline Observations & 4834635 \\
\hline \multicolumn{2}{|c|}{$\begin{array}{l}\text { Notes: Unit of observation is buyer } i \text {, supplier } f \text { and year } t . Y_{i f t} \text { in- } \\
\text { dicates a first match took place between buyer and supplier. } X_{i f t}^{k} \text { is } \\
\text { a count of buyers in region } k \text { which added supplier } f \text { in } t-1 . E A C C_{f} \\
\text { indicates the supplier operates in the East African Community. Coef- } \\
\text { ficients are multiplied by } 100 \text { to read as percentage point marginal ef- } \\
\text { fects. Standard errors in parentheses clustered at the buyer level. } \\
p<0.1,{ }^{* *} p<0.05,{ }^{* * *} p<0.01\end{array}$} \\
\hline
\end{tabular}

for EAC suppliers is weaker $\left(\mu_{2}<0\right)$.

$Y_{i f t}=\mu_{1} X_{i f, t-1}^{\text {same }}+\mu_{2} X_{i f, t-1}^{\text {same }} \times E A C_{f}+\gamma_{1} X_{i f, t-1}^{\text {other-city }}+\gamma_{2} X_{i f, t-1}^{\text {other-city }} \times E A C_{f}+\alpha_{f}+\alpha_{i}+\alpha_{t}+u_{i}$

Results shown in Table 13 confirm that suppliers in the EAC have a smaller positive spillover. This is again consistent with a narrative in which search is driving results.

Another prediction consistent with search frictions, is that suppliers which are not supply-constrained will be able to match with multiple buyers, and so we should not observe a negative congestion effect. This is why we did not expect to find a strong congestion externality on foreign imports, given international suppliers are characterized by being large firms with cheap access to credit and multiple customers. By contrast, domestic Ugandan firms are characterized by being small with limited access to credit. You might therefore expect that Ugandan firms cannot make multiple matches in a given period, thus making the domestic market more congested.

If this is indeed the case, I would expect domestic Ugandan suppliers which are also 
TABle 14: Domestic Export Suppliers

\begin{tabular}{lc}
\hline \hline & $(1)$ \\
& $Y_{i f t}$ \\
\hline$X_{t-1}^{\text {same }}$ & 0.00236 \\
& $(0.00358)$ \\
$X_{t-1}^{\text {same }} \times$ exporter $_{f}$ & 0.00358 \\
& $(0.00802)$ \\
$X_{t-1}^{\text {other-city }}$ & $-0.00574^{* * *}$ \\
& $(0.000680)$ \\
$X_{t-1}^{\text {other-city }} \times$ exporter $_{f}$ & $0.00268^{* *}$ \\
& $(0.000609)$ \\
\hline Observations & 27975967 \\
\hline \hline
\end{tabular}

Notes: Unit of observation is buyer $i$, supplier $f$ and year $t . Y_{i f t}$ indicates a first match took place between buyer and supplier. $X_{i f t}^{k}$ is a count of buyers in region $k$ which added supplier $f$ in $t-1$. exporter $f$ indicates supplier $f$ is an exporter. Coefficients are multiplied by 100 to read as percentage point marginal effects. Standard errors in parentheses clustered at the buyer level. ${ }^{*} p<0.1,{ }^{* *} p<0.05,{ }^{* * *} p<0.01$

exporters to act in a similar way to foreign exporters, as they are less likely to be supply constrained. This is tested in equation D.2.

$Y_{i f t}=\mu_{1} X_{i f, t-1}^{\text {same }}+\mu_{2} X_{i f, t-1}^{\text {same }} \times$ Exporter $_{f}+\gamma_{1} X_{i f, t-1}^{\text {other-city }}+\gamma_{2} X_{i f, t-1}^{\text {other-city }} \times$ Exporter $_{f}+\alpha_{i}+\alpha_{t}+u_{i f t}$

Results in Table 14 show that domestic suppliers which are exporters, and hence less supply constrained, have a smaller negative effect from making a match elsewhere in the country. This is again consistent with the search narrative. 